\title{
ASPECTOS DA TRANSMISSÃO DA LEISHMANIOSE VISCERAL NO MUNICÍPIO DE MIRANDÓPOLIS, REGIÃO NOROESTE DO ESTADO DE SÃO PAULO
}

\section{CARLOS NORIYUKI KANETO}

Tese apresentada ao Departamento de Epidemiologia da Faculdade de Saúde Pública da Universidade de São Paulo para a obtenção do título de "Doutor em Saúde Pública".

Área de Concentração: Epidemiologia

Orientadora: Prof ${ }^{\mathbf{a}}$. Drª . Eunice Aparecida Bianchi Galati

São Paulo 
Autorizo, exclusivamente para fins acadêmicos e cientificos, a reprodução total ou parcial desta tese, por processos fotocopiadores.

Assinatura

Data: 
À memória de meus pais À Vera, companheira também nesta jornada À Carla e ao Luciano, dádivas divinas recebidas nesta vida 


\section{AGRADECIMENTOS}

À Prof . Dr ${ }^{3}$. Eunice Aparecida Bianchi Galati, do Departamento de Epidemiologia da FSP/USP, pelo apoio, incentivo e pela coragem e confiança em aceitar a orientação com prazo exíguo para a execução da pesquisa.

Ao Dr. Alexandre Gonçalves Pimentel, diretor do Departamento de Saúde do município de Mirandópolis, pela compreensão e viabilização do projeto.

Ao Dr. Nilton Moraes Gonçalves, diretor do Centro de Controle de Zoonoses de Mirandópolis pelo apoio e colaboração em todas as atividades do projeto desenvolvidas no municipio.

Ao Prof. Dr. Delsio Natal, do Departamento de Epidemiologia da FSP/ USP, pelo incentivo, e sugestões durante a execução do projeto.

Ao Dr. Reginaldo Peçanha Brazil, diretor do Laboratório de Leishmanioses do Centro de Pesquisas René Rachou, da Fundação Oswaldo Cruz de Minas Gerais pelas sugestões apresentadas para a condução do projeto.

Aos senhores José Dias dos Santos, Valdemir Elias Fernandes e Waldemís Teixeira Santos, funcionários do Centro de Controle de Zoonoses de Mirandópolis, pela colaboração nas atividades de campo e pelo auxílio na manipulação dos animais.

Aos senhores André Luís Placo, Bruno José Polles Lisboa, João Carlos Pacheco, Lauro Bueno Costa e Rodrigo José Santana, funcionários da Prefeitura Municipal de Mirandópolis, pela colaboração nos trabalhos de campo.

À $\mathrm{Dr}^{\mathrm{a}}$. Lílian Aparecida Colebrusco Rodas, Assistente Técnica de Pesquisa Científica e Tecnológica, à $\mathrm{Dr}^{\mathrm{a}}$. Daniela Witacker Poletto, bióloga e, extensivamente, ao Dr. Clóvis Pauliquevis, diretor regional da Superintendência de Controle de Endemias em Araçatuba, pela colaboração na identificação dos flebotomíneos.

Ao Dr. Serafim Justo Filho, Assistente de Recursos Naturais e ao Dr. Antonio Pistori Buzachero, diretor do Escritório de Desenvolvimento Rural de Andradina, pelas informações gerais sobre o município de Mirandópolis e pelo fornecimento dos dados climatológicos.

À Prof ${ }^{a}$. Dr ${ }^{a}$. Neusa Saltiél Stobbe e à Prof . Dr ${ }^{a}$. Katia Denise Saraiva Brescian, do Departamento de Apoio, Produção e Saúde Animal do Curso de 
Medicina Veterinária de Araçatuba - UNESP, pela colaboração nas colheitas de amostras de sangue e na coordenação da campanha de vacinação anti-rábica.

Aos senhores Adélio Gurgel do Amaral, Ana Paula da Silva Almeida, Ana Paula Ferreira Corrêa, André Maciel Crespilho, Anna Claudia Marques Serrano, Bianca Calil Daher, Camila Santos Manoel, Celina Kazue Morinishi, Daniela Gomes Cagnoto, Diogo José Cardilli, Fabiana Oda, Fábio Luis Bonello, Giovani Fernando Araújo, Gleise Kelly Silva Ferreira, Juliana Falcato Vecina, Lígia Garcia Mesquita Marcos Ituo Okada, Priscilla Andrea dos Santos, Rodrigo Stéfano Ceretta, Rúbia Bueno da Silva, Taiana Pereira da Costa, Tatiana de Oliveira Gerzoschskowitz, Thaís Eliane Binotto, Thaís Mioto Martineli e Thiago André Carreo Costa, acadêmicos de Medicina Veterinária, pela ajuda na execução da campanha de vacinação anti-rábica e colheita de amostras de sangue dos animais.

À Dr ${ }^{a}$. Maria Cecília Gibrail de Oliveira Camargo, encarregada do Setor de Sorologia e Imunologia, à $\operatorname{Dr}^{\mathrm{a}}$. Elisa San Martin Mouriz Savani, à $\operatorname{Dr}^{\mathrm{a}}$. Sandra Nicoletti Dáuria e, extensivamente, ao Dr. Hildebrando Montenegro Netto, diretor da Divisão de Laboratório de Zoonoses do Centro de Controle de Zoonoses do município de São Paulo, pela realização dos testes sorológicos de imunofluorescência indireta.

À Prof ${ }^{\star}$. Dr. ${ }^{a}$ Valéria Marçal Félix de Lima, do Departamento de Clínica, Cirurgia e Reprodução Animal do Curso de Medicina Veterinária de Araçatuba UNESP, pela realização dos testes de Elisa.

Ao Prof. Dr. Luiz Eduardo Fonseca, do Departamento de Apoio, Produção e Saúde Animal do Curso de Medicina Veterinária de Araçatuba - UNESP, pelas facilidades oferecidas para o transporte pessoal, de material, equipamentos e, principalmente, dos animais de laboratório.

À Prof ${ }^{a}$ Dr ${ }^{a}$ Luciane Biazzono, do Departamento de Clínica, Cirurgia e Reprodução Animal do Curso de Medicina Veterinária de Araçatuba - UNESP, pela colaboração nas necropsias dos animais soropositivos.

Ao Prof. Dr. Mario Jefferson Quirino Lousada, do Departamento de Apoio, Produção e Saúde Animal do Curso de Medicina Veterinária de Araçatuba - UNESP, por permitir a utilização de instalações sob sua responsabilidade para a manutenção dos animais de laboratório. 
Ao Dr. Luiz Gustavo Ferraz Lima e Sra. Gilmara Castilho Whitaker Arispe, do Departamento de Apoio, Produção e Saúde Animal do Curso de Medicina Veterinária de Araçatuba - UNESP, pelo apoio técnico-laboratorial.

À Prof́. Dr ${ }^{a}$. Silvia Helena Venturolli Perri, do Departamento de Apoio, Produção e Saúde Animal do Curso de Medicina Veterinária de Araçatuba - UNESP, pelas sugestões e pela análise estatística dos dados.

À Prof ${ }^{a}$. Dr ${ }^{a}$. Lucille Winter e Sr. Ricardo Andrade Zampieri, do Laboratório de Biologia Molecular de Tripanosomatídeos do Instituto de Ciências Biológicas da Universidade de São Paulo pela identificação molecular das estirpes de Leishmania isoladas.

Ao Prof. Dr. Almério de Castro Gomes pelas recomendações e sugestões na redação deste trabalho.

Ao Prof. Dr. Antonio Carlos da Silva, do Departamento de Análises Clínicas da Escola de Farmácia e Odontologia de Alfenas, Minas Gerais pelas recomendações e sugestões na redação deste trabalho.

Ao Prof. Dr. Marcos Franke Pinto, do Departamento de Apoio, Produção e Saúde Animal do Curso de Medicina Veterinária de Araçatuba - UNESP, pela colaboração na editoração eletrônica das imagens.

Ao $\mathrm{Sr}$. Orlando Olivério Filho e $\mathrm{Sr}^{\mathrm{a}}$. Jacira Satiko Olivério, pela solidariedade, incentivo e apoio material e moral nos momentos dificeis.

Ao Conselho Nacional de Desenvolvimento Científico e Tecnológico pelo apoio financeiro concedido.

A todos que, de alguma maneira, contribuíram com a realização deste trabalho. 


\section{RESUMO}

Kaneto $\mathrm{CN}$. Aspectos da transmissão da leishmaniose visceral no município de Mirandópolis, região noroeste do Estado de São Paulo. São Paulo, 2000. [Tese Doutorado - Faculdade de Saúde Pública da USP].

Objetivo: Devido a localização do município de Mirandópolis em região com recente identificação da ocorrência de leishmaniose visceral, o presente estudo teve por objetivo a realização de estudo epidemiológico para verificar as possibilidades de transmissão dessa parasitose em suas áreas urbana e rural, em 2000. Método. As pesquisas sobre a ocorrência do vetor foram realizadas com o emprego de armadilhas automáticas luminosas em miniatura, instaladas semanalmente, durante o ano 2000, em 6 pontos fixos urbanos e 5 rurais. Os pontos urbanos compreenderam o peridomicílio e intradomicílio de três residências e os rurais, chiqueiro, galinheiro, curral, abrigo do cão e intradomicílio, todos localizados em uma única propriedade. Foram consideradas as interferências da temperatura e da precipitação pluviométrica na densidade de flebotomíneos. Para investigar a infecção natural por flagelados, os flebotomíneos foram capturados com armadilhas de Shannon e aspiradores manuais. Realizou-se um inquérito sorológico com o emprego da técnica de imunofluorescência indireta em amostras de sangue venoso de 603 cães recolhidas em papel de filtro. Utilizou-se 62 amostras de soros caninos para comparar os testes de imunofluorescência e Elisa, quanto à sensibilidade e especificidade. Inoculação intraperitoneal de macerados de pool de órgãos combinados com semeadura em meio NNN foram realizados a partir de 13 cães sorologicamente positivos. Resultados. $L$. longipalpis foi capturada durante todo o ano de modo positivamente correlacionado com a temperatura do ar. A atratividade exercida por bovinos, suínos, aves, cães e homem foram semelhantes. A prevalência de soros reagentes estimada no inquérito canino foi de $1,7 \%(n=603)$. O desempenho do teste de Elisa foi superior ao teste de imunofluorescência. Não foram encontradas formas flageladas de protozoários em 19 fềmeas de L. longipalpis dissecadas, porém, foram isoladas duas cepas de Leishmania chagasi a partir de dois cães infectados. Conclusão. Com enfoque nos principais elos da cadeia de transmissão da leishmaniose visceral existem possibilidades de transmissão para os habitantes do município proporcionadas pela presença constante e disseminada do vetor, pelo encontro de reservatório 
sorologicamente positivo tanto no meio urbano como na zona rural e pela presença do próprio agente etiológico constatada.

Descritores: Leishmaniose visceral. Transmissão. Lutzomyia longipalpis. Inquérito canino. Teste de imunofluorescência indireta. Teste de Elisa. Município de Mirandópolis. 


\section{SUMMARY}

Kaneto CN. Aspects of the transmission of visceral leishmaniasis in Mirandópolis County, in the northeast of São Paulo state. São Paulo, 2000 [Ph.D. Thesis- Faculdade de Saúde Pública- USP]

Objective: Because it is located in a region of a recent occurrence of visceral leishmaniasis an epidemiological study for the purpose of evaluating the potential risk of the disease in Mirandópolis was undertaken during 2000. Methods. Weekly captures of phlebotomine sandflies with miniature automatic light traps were made at 6 urban fixed (three intradomiciles and peridomicilies) points and at 5 rural sites of a single small farm (hen house, pigpen, corral, dog-house and intradomicilie). The influence of temperature and rainfall on the population density of phlebotomines was considered. Shannon traps and aspirators were also used to capture females probably infected by flagellates, for research. A serological survey using the indirect immunofluorescence test (IFI) on venous blood taken from 603 dogs and collected on absorbent paper was undertaken. The sensitivity and specificity of an enzyme-linked immunosorbent assay (Elisa) and immuno-fluorescence test were compared using 62 canine sera. Intraperitoneal inoculation of hamsters using a pool of macerated organs from 13 serological positive dogs and inoculation in NNN medium were carried out. Results. L. longipalpis was found throughout the year and the population was found to be positively correlated with air temperature. The attraction exercised by cattle, pigs, chicken, dogs and men was similar. The prevalence of serum positive dog from the canine inquiry was $1.7 \%$ by IFI, which was less sensitive than Elisa. No flagellated forms were found in 19 dissected females of $L$. longipalpis but two strains of Leishmania chagasi were isolated from two of the infected dogs. Conclusion. Considering the main links in the transmission chain of visceral leishmaniasis there exist conditions favourable to the transmission of the disease to the inhabitants of the area studied due to the constant presence and dissemination of the vector and by virtue of the existence of a serological positive reservoir in the urban as well as the rural areas. 
Key words: Visceral Leishmaniasis. Transmission. Lutzomyia longipalpis. Canine survey. Indirect immuno-fluorescence test. Elisa test. Mirandopolis County. 


\section{ÍNDICE}

1 INTRODUÇÃO 1

2 OBJETIVOS 11

2.1 OBJETIVO GERAL 11

$\begin{array}{ll}2.2 \text { OBJETIVOS ESPECÍFICOS } & 11\end{array}$

3 MÉTODO 12

3.1 ÁREA DE ESTUDO 12

3.2 DAdOS CLIMATOLÓGICOS 12

3.3 ESTUDOS ENTOMOLÓGICOS 13

3.3.1 Captura de flebotomíneos com armadilhas automáticas luminosas em miniatura 13

3.3.2 Captura de flebotomineos com armadilha de Shannon e $\begin{array}{ll}\text { aspiradores elétricos } & 14\end{array}$

3.3.3 Investigação da infeç̧ão natural de flebotomíneos por flagelados $\quad 16$

$\begin{array}{ll}3.4 \text { SOROLOGIA } & 17\end{array}$

$\begin{array}{lll}3.4 .1 & \text { Inquérito sorológico canino } & 17\end{array}$

3.4.2 Comparação do teste de imunofluorescência indireta e o ensaio imunoenzimático - Enzimed-linked immunosorbent assay (Elisa) $\quad 18$

3.5 ISOLAMENTO DE Leishmania 19

3.6 CAPTURA DE MARSUPIAIS 22

3.7 ANÁLISE ESTATÍSTICA 23

4 RESULTADOS 24

4.1 DADOS ENTOMOLÓGICOS 24

4.1.1 Capturas de flebotomíneos com armadilhas automáticas luminosas $\begin{array}{ll}\text { em miniatura } & 24\end{array}$

4.1.2 Capturas de flebotomíneos com armadilhas de Shannon e apiradores elétricos 
4.1.3 Investigação do indice de infecção natural de flebotomíneos por $\begin{array}{ll}\text { flagelados } & 32\end{array}$

4.2 DADOS DOS RESERVATÓRIOS 32

4.3 COMPARAÇÃO DO TESTE DE IMUNOFLUORESCÊNCIA INDIRETA $\begin{array}{ll}\text { E ELISA } & 34\end{array}$

4.4 COLHEITA DE MATERIAL DE GAMBÁS 35

4.5 DADOS DO AGENTE 35

5 DISCUSSÃO

6 CONCLUSÕES

7 REFERÊNCIAS $\quad 50$

\begin{abstract}
ANEXO
Anexo 1 - Localização do município de Mirandópolis em relação ao Estado de São Paulo e planta da cidade
\end{abstract}

Anexo 2 - Localização dos pontos fixos de captura de flebotomíneos na área urbana do município de Mirandópolis

Anexo 3 - Localização dos postos de vacinação anti-rábica e de colheita de amostras de sangue de cães, na área urbana, no município de Mirandópolis, em 2000

Anexo 4 - Etiquetas de identificação das amostras de sangue dos cães

Anexo 5 - Esquema representativo de sistema de marcação utilizado nas orelhas de gambás capturados, com a finalidade de individualização 
Anexo 6 - Nematódeo observado no interior de uma fềmea de

Anexo 7 - Número de cães com dono, da área urbana, examinados pelo teste de imunofluorescência indireta para o diagnóstico da leishmaniose visceral segundo sexo e residência na cidade de Mirandópolis. Agosto de 2000

Anexo 8 - Número de cães, com dono, da zona rural, examinados pelo teste de imunofluorescência indireta para o diagnóstico da leishmaniose visceral segundo sexo, no município de Mirandópolis. Agosto de 2000

Anexo 9 - Numero de cães errantes examinados pelo teste de imunofluorescência indireta para o diagnóstico da leishmaniose visceral, segundo sexo e local de captura, no município de Mirandópolis.

Agosto de 2000

Anexo 10 - Temperatura $\left({ }^{\circ} \mathrm{C}\right)$ máxima $(\max$ ) e mínima $(\min$.$) do ar no$ Município de Mirandópolis (SP). Dados diários. Janeiro a junho de 2000

Anexo 11 - Temperatura $\left({ }^{\circ} \mathrm{C}\right)$ máxima (max.) e mínima (min.) do ar no Município de Mirandópolis (SP). Dados diários. Julho dezembro de 2000

Anexo 12 - Pluviosidade (mm) no município de Mirandópolis em 2000. Dados diários 


\section{INTRODUÇÃO}

Leishmanioses são agravos à saúde provocados por diversas espécies de protozoários tripanosomatídeos do gênero Leishmania Ross, 1903. Constituem-se em importantes zoonoses parasitárias largamente difundidas por todos os continentes, exceto a Austrália e Malásia, com presença assinalada em vinte e um paises do continente americano (DEDET 1993).

Segundo estimativas da Organização Mundial de Saúde (WHO 1990), 350 milhões de pessoas vivem em áreas de risco, com cerca de 12 milhões de pessoas infectadas.

Entre os hospedeiros vertebrados de Leishmania, além do homem, inclui-se uma variada gama de mamíferos silvestres e domésticos como roedores, canídeos, edentados, marsupiais, procionídeos, ungulados e primatas que desempenham o papel de reservatórios (DEDET 1993).

Dípteros de várias espécies de diferentes gêneros da subfamília Phlebotominae estão envolvidos na transmissão das leishmanioses (GALATI 1995).

$\mathrm{Na}$ América, cerca de 460 espécies de flebotomíneos são conhecidas, das quais aproximadamente $10,0 \%$ estão envolvidas na transmissão de leishmanioses (CIPA GROUP 1999).

Os flebotomíneos são pequenos dípteros muito pilosos, que se caracterizam pela presença de dez veias atingindo a borda alar e com a veia transversa $r-m$ situada entre o terço basal e o meio da asa. Suas formas imaturas desenvolvem-se em solo úmido rico em matéria orgânica, entre pedras, raizes expostas, folhas caídas no chão, em tocas e abrigos de animais. As formas adultas não apresentam a tendência de se afastarem de seus criadouros ou abrigos, dificilmente se afastando além de 250 metros (MORRISON et al. 1993). Estudos laboratoriais têm demonstrado que de ovo a adulto decorre um período de cerca de 30 dias e a longevidade das fêmeas varia de 15 a 20 dias (RANGEL et al. 1986).

De acordo com diferentes critérios relacionados aos agentes etiológicos dessas enfermidades, como suas características morfológicas, genéticas, bioquímicas e imunológicas, assim como a distribuição geográfica e, de acordo ainda, om as 
manifestações clínicas que provocam nos indivíduos acometidos por elas, essas antropozoonoses podem ser classificadas sob duas formas principais: a tegumentar e a visceral.

A leishmaniose tegumentar se reveste de grande importância em saúde pública devido a sua prevalência e gravidade dos casos. Provoca lesões deformantes e estigmatizantes nas pessoas acometidas, em decorrência da destruição de mucosas que ocasiona. Essas formas dermatotrópicas da leishmaniose podem ser causadas por diferentes espécies do gênero Leishmania, distribuídas em dois subgêneros Leishmania e Viannia.

No Brasil, foram identificadas seis espécies de Leishmania relacionadas com a etiologia da leishmaniose tegumentar, uma pertencente ao subgênero Leishmania e cinco ao subgênero Viannia: Leishmania (Leishmania) amazonensis Lainson \& Shaw, 1972, Leishmania (Viannia) braziliensis Vianna, 1911, L. (V.) guyanensis Floch, 1954, L. ( $V$.$) lainsoni Silveira, Shaw, Braga \& Ishikawa, 1987, L. (V.) naiffi$ Lainson \& Shaw, 1989, L. ( $V$.) shawi Lainson, Braga, Souza, Povoa \& Ishikawa, 1989 (DEDET 1993; GOMES 1992).

Segundo DEDET (1993), os principais vetores da leishmaniose tegumentar no Brasil, pertencem aos subgêneros Nyssomyia Barretto, 1962 e Psychodopygus Mangabeira, 1941 do gênero Lutzomyia França, 1924, mas de acordo com GALATI (1995) essas espécies integram três gêneros, Bichromomyia Artemiev, 1991, Nyssomyia e Psychodopygus. A estes, pode-se ainda acrescer dois outros gêneros, segundo esse último autor, Pintomyia Costa Lima, 1932 e Migonemyia Galati, 1995 (CIPA GROUP, 1999).

Os reservatórios naturais dos agentes da leishmaniose tegumentar são pouco conhecidos (DEDET 1993; LAINSON e SHAW 1987). Roedores dos gêneros Proechimus e Oryzomys constituem-se nos principais reservatórios de $L$ (L.) amazonensis na Amazônia. Nesta região, marsupiais Didelphis, Philander, Marmosa, Caluromys e Metachirus além do canídeo Cerdocyon thous desempenham o papel de hospedeiros secundários (LAINSON 1985; LAINSON e SHAW 1987). 
No Estado de São Paulo essa espécie de Leishmania foi isolada do roedor Akodon no Vale do Ribeira (TOLEZANO 1994).

A preguiça de dois dedos Choloepus didactylus e o tamanduá Tamandua tetradactyla são considerados os principais reservatórios silvestres de $L$. $(V$.) guyanensis. Também o gambá Didelphis marsupialis, em certas zonas urbanas, assume o papel de reservatório dessa espécie de protozoário (ARIAS el al. 1981; CHRISTENSEN et al. 1982; LAINSON e SHAW 1987).

Roedores Agouti paca (Rodentia: Dasyproctida) têm sido encontrados infectados por L.(V.) lainsoni no Pará. Nesse Estado e também no Acre, L.(V.) shawi tem sido detectada em macacos Cebus apella e Chiropotes satanus, em preguiças Choloepus didactylus e Bradypus tridactylus e em procionideos Nasua nasua.

L. V.) naiffi tem sido detectada no tatu Dasypus novemcinctus (LAINSON e SHAW 1989).

No que diz respeito ao reservatório silvestre da $L$.(L.) braziliensis, foram isolados parasitos que se supõem pertencerem a essa espécie, de roedores, tais como Akodon arviculoides, Oryzomys capito, Oryzomys nigripes, Rattus rattus, Rhipidomys leucodactylus, do marsupial Didelphis marsupialis e da preguiça Choloepus didactilus (GRIMALDI et al. 1989; LAINSON e SHAW 1987; LAINSON et al. 1994; DEDET 1993)

Entretanto, existem relatos de infecções de cães e equídeos por $L$. $(V$.) braziliensis, havendo uma correlação entre a prevalência e distribuição da infecção desses animais e as infecções humanas (AGUILAR et al. 1987; BARRETTO et al. 1986; FALQUETO et al. 1987; FALQUETO et al. 1991; PIRMEZ et al. 1988; ROSA et al. 1988; YOSHIDA et al.1990).

A forma visceral da leishmaniose tem como agente etiológico na América Leishmania (L.) chagasi Cunha \& Chagas, 1937 (GRIMALDI e TESH 1993; LAINSON e SHAW 1987).

A leishmaniose visceral já foi assinalada em 19 dos 27 estados brasileiros, impondo-se como importante problema de saúde pública devido à incidência em caráter esporádico ou endemo-epidêmico e a gravidade dos casos. 
Com um período de incubação de quatro a seis meses (MANSON-BAHR et al.1963), a leishmaniose visceral, clinicamente, se caracteriza por provocar perda de peso, tosse, febre, diarréia, hepatoesplenomegalia e letargia, embora deva se ressalvar que esses sintomas podem não ocorrer simultaneamente e, também, que outras condições patológicas podem manifestar os mesmos sintomas (ARIAS et al. 1996).

A leishmaniose visceral é uma doença de evolução crônica e relativamente freqüente entre pessoas que vivem em áreas endêmicas. Pessoas de todas as idades e de ambos os sexos são susceptíveis à enfermidade, porém, as manifestações clínicas clássicas ocorrem principalmente em crianças desnutridas (BADARÓ et al. 1986; CERF et al. 1987) ou em adultos imunossuprimidos (BADARÓ et al. 1986). A enfermidade atinge principalmente crianças com idade inferior a dez anos com $60,0 \%$ das ocorrências assinaladas em menores de quatro anos de idade (GOMES 1996)

A taxa de mortalidade nos casos tratados é pequena, quando a terapia com antimoniais pentavalentes é rapidamente conduzida, segundo a Organização Mundial da Saúde (WHO 1995). Entretanto, na maioria dos casos não tratados adequadamente, a doença é fatal e o índice de mortalidade varia de $75,0 \%$ a $95,0 \%$ (MARZOCHI et al. 1985; BADARÓ et al. 1986).

Mais de 1000 casos humanos ocorrem anualmente no Brasil (SILVA et al. 2001) e a maior ocorrência de óbitos em grupos etários mais jovens faz com que seja bastante elevado o custo social em termos de anos potenciais de vida perdidos (VIEIRA e COELHO 1998).

O agente etiológico da leishmaniose visceral nas Américas, L. chagasi, pode se apresentar, naturalmente, sob duas formas evolutivas: a forma flagelada ou promastigota é fusiforme e móvel e se desenvolve no tubo digestivo do inseto vetor. A outra, aflagelada, é ovóide e encontrada no interior de células do sistema fagocítico mononuclear dos tecidos do hospedeiro vertebrado (GOMES 1996).

O homem e outros animais vertebrados infectam-se quando o seu organismo é invadido pelas formas promastigotas de Leishmania veiculadas pelos insetos vetores 
que sugam uma ampla variedade de animais vertebrados e exercem a hematofagia, predominantemente, no período noturno (YOUNG e DUNCAN 1994).

A transmissão da parasitose se dá pela picada de fềmeas hematófagas que necessitam do repasto sangüíneo para o desenvolvimento dos seus ovários. Durante o exercício desse repasto, o inseto se infecta através da ingestão de formas amastigotas de Leishmania presentes no citoplasma de macrófagos da derme do hospedeirc vertebrado infectado.

No intestino médio do flebotomíneo, as formas amastigotas se transformam em promastigotas as quais passam por um intenso processo de multiplicação. Em seguida, as formas promastigotas se diferenciam em formas infectantes e se dirigem para a faringe do inseto.

As fêmeas se tornam infectantes 3 a 4 dias após o repasto sangüíneo contaminante. Durante um novo repasto sangüíneo, ocorre a deposição de formas promastigotas infectantes na intimidade da derme de outro hospedeiro. Conseqüentemente, ocorre a invasão de macrófagos, no interior dos quais, a Leishmania se multiplica até provocar o rompimento dos mesmos, com novas invasões de outros macrófagos. Em seguida, ocorre a disseminação hematogênica para outros tecidos, principalmente os de órgãos ricos em células do sistema fagocítico mononuclear, como o figado, o baço, os linfonodos e medula óssea (GOMES et al. 1996).

Em praticamente todas as áreas de ocorrência da leishmaniose visceral nas Américas, Lutzomyia longipalpis (Lutz \& Neiva, 1912) tem sido identificada como a espécie vetora da parasitose (LAINSON e SHAW 1987).

L. longipalpis, aparentemente, adapta-se facilmente ao peridomicílio, residências e abrigos de animais e sua densidade populacional parece aumentar logo após a estação chuvosa (FORATTINI 1973). É considerada uma espécie com características antropozoofilicas e a prática de tornar o peridomicílio local de criação de animais domésticos (cães, aves, etc.) parece ter influenciado, favoravelmente, a manutenção de sua relação biológica com esses animais. 
O conhecimento de alguns de seus aspectos biológicos, de sua dinâmica populacional e a verificação de sua infecção natural por Leishmania é de importância relevante pois o vetor é o elo essencial entre as fontes de infecção e os susceptíveis

No Brasil, L. longipalpis tem sido incriminada como espécie vetora da leishmaniose visceral desde 1938, época em que também foram descobertos os primeiro casos da infecção em cães no país (CHAGAS 1938).

Embora a transmissão da leishmaniose visceral no Brasil e nas Américas seja atribuida quase que exclusivamente à L. longipalpis, em algumas localidades essa constatação não pôde ser confirmada. Dessa maneira, em um foco na Colômbia, Pintomyia (Pifanomyia) evansi (Nuñes-Tovar, 1924) foi a espécie incriminada como vetor (TRAVI et al. 1996). No Brasil, na região urbana de Corumbá e Ladário, a transmissão parece estar a cargo de L. cruzi (Mangabeira, 1938), espécie predominante na área onde, adicionalmente, se constatou a ausência de $L$. longipalpis (GALATI et al. 1997; SANTOS et al. 1998)

No âmbito do Estado de São Paulo, ao descreverem o flebotomíneo $L$. longipalpis, LUTZ e NEIVA (1912) citam a sua presença no município de São Paulo. Todavia, COSTA LIMA (1932) denunciou o erro por parte desses autores, na identificação dos espécimens paulistas, os quais pertenciam a Pintomyia fischeri (Pinto, 1926).

Entretanto, em áreas rurais situadas em terrenos montanhosos com afloramento de rochas do Estado de São Paulo, a presença de L. longipalpis vem sendo assinalada desde os anos 70 (FORATTINI et al. 1970, 1976).

Em 1997, a presença desse flebotomíneo foi constatada em área urbana do município de Araçatuba (COSTA et al. 1997), localizada numa região com características topográficas e paisagísticas bem diferentes das anteriormente observadas.

Investigações entomológicas posteriores detectaram a presença de $L$. longipalpis em outros municípios da região noroeste do Estado de São Paulo como Andradina, Valparaíso, Guararapes, Santo Antonio do Aracanguá, Auriflama e Mirandópolis.

No município de Araçatuba, 10,2\% de 568 domicílios pesquisados foram positivos para L. longipalpis (GALIMBERTTI et al. 1999). 
Os principais reservatórios da leishmaniose visceral são os cães domésticos (DEANE e DEANE 1962; LAINSON e SHAW 1987; SILVA et al. 1997) e a sua presença como companhia constante do homem e o seu trânsito através de áreas endêmicas têm contribuído para a dispersão da doença (ARIAS et al. 1996). Nesse aspecto, a maioria dos autores concorda que a participação do cão como reservatório doméstico de L. chagasi, tenha sido a principal causa da mudança ecológica da leishmaniose visceral, inicialmente estabelecida nas áreas rurais e que, recentemente, tem avançado para as áreas urbanas (GOMES et al. 1996; LAINSON e SHAW 1987).

Entre os reservatórios silvestres, duas espécies de raposas têm sido assinaladas: Dusicyon vetulus (DEANE e DEANE 1954; DEANE e DEANE 1955; DEANE 1956; ALENCAR 1961), encontrada infectada no Ceará e Cerdocyon thous nos estados do Pará (LAINSON et al. 1969; LAINSON e SHAW 1971; SILVEIRA et al. 1982) e Mato Grosso do Sul (MELLO et al. 1988).

Mais recentemente, a infecção natural de Cerdocyon thous com L. chagasi foi constatada em Minas Gerais, tendo sido comprovada com o emprego de técnicas moleculares de reação em cadeia de polimerase e hibridação (SILVA et al. 2000).

Os gambás, aparentemente, também têm importância na epidemiologia da leishmaniose visceral. Didelphis albiventris foi encontrado infectado na Bahia (SHERLOCK et al. 1984) e Didelphis marsupialis na Colômbia (CORREDOR et al. 1989; TRAVI et al. 1994).

O homem não parece ter grande importância epidemiológica no papel de fonte de infecção para o vetor, sendo a transmissão considerada largamente dependente da presença de cães infectados (LAINSON e SHAW 1987), os quais podem sofrer um intenso parasitismo cutâneo que facilita a infecção dos flebotomíneos (DEANE e DEANE 1954).

Desse ponto de vista, portanto, a doença nos cães assume maior relevância epidemiológica que a infeção humana. Acrescente-se ainda que a enzootia é mais prevalente e, geralmente, apresenta um contingente de animais assintomáticos com alto grau de parasitismo na pele sã e vísceras. Em todo o país, a leishmaniose visceral canina coexiste com a leishmaniose humana em todos os focos conhecidos e, regra 
geral, ela precede a ocorrência de casos humanos (ALENCAR 1978; DEANE 1956; MARZOCHI et al. 1985).

Recentemente essa condição pôde ser observada em área de ocorrência recente da parasitose como em Araçatuba, noroeste do Estado de São Paulo (GALIMBERTTI et al. 1999; TOLEZANO et al. 1999).

As manifestações clínicas da leishmaniose visceral nos cães podem ser bastante variáveis. De um modo geral, o quadro clínico da doença nos cães se assemelha à doença humana, com febre irregular, palidez de mucosas, emagrecimento progressivo até um estado de caquexia intensa na fase terminal (MARZOCHI et al.1985). A hipertrofia do Sistema Fagocitário Mononuclear leva a hepato-esplenomegalia e adenopatia generalizada, sendo os linfonodos poplíteos, os mais comumente afetados (FEITOSA 2000), porém, os sinais mais evidentes são as alterações dermatológicas. São freqüentes a queda de pêlos acompanhada de descamações ou dermatites furfuráceas, lesões ulcerativas, principalmente no focinho e orelhas, onicogrifose ou alongamento das unhas, prurido, pelame opaco, lesões oculares com opacidade da córnea após conjuntivite purulenta, apatia, diarréia, paresia dos membros, edema e vômitos (MARZOCHI et al., 1985; FEITOSA et al. 2000)

O diagnóstico da leishmaniose canina pode ser feito através dos sintomas clínicos e da demonstração do parasita em punções aspirativas de órgãos linfóides, provas sorológicas e por métodos moleculares.

Nos estudos soro-epidemiológicos, o teste de imunofluorescência indireta (IFI), também conhecido como reação de imunofluorescência indireta (RIFI), realizado com eluato de sangue dessecado em papel de filtro tem sido amplamente utilizado em inquéritos caninos (MARZOCHI et al. 1985; NUNES et al. 1988, 2001; GALLIMBERTI et al. 1999; SILVA et al. 2001)

Com relação ao tratamento com antimoniais, contrariamente ao que ocorre na doença humana, o mesmo não tem sido eficaz. Tentativas realizadas com a aplicação intramuscular de $100 \mathrm{mg} / \mathrm{kg} / \mathrm{dia}$ de antimonial, paradoxalmente, levaram ao agravamento do estado geral (MARZOCHI et al. 1985). O emprego de sulfato de aminosidina intramuscular foi testado com três esquemas de tratamento: 20 $\mathrm{mg} / \mathrm{Kg} / \mathrm{dia}$, por $15 \mathrm{dias} ; 80 \mathrm{mg} / \mathrm{Kg} / \mathrm{dia}$, por $20 \mathrm{dias}$ e $40 \mathrm{mg} / \mathrm{Kg} / \mathrm{dia}$ por $30 \mathrm{dias}$, 
apresentando resultados que variaram da morte dos animais, melhoras temporárias dos mesmos, mas mantendo a condição de portador da infecção por Leishmania e completa cura parasitológica e clínica. Todavia, os autores não recomendam o tratamento como alternativa para a eliminação dos cães para controle da leishmaniose, tendo-se em vista que um tratamento não efetivo pode prolongar a condição de portadores da infecção dos animais e também, induzir resistência ̀̀ droga (VEXENAT et al. 1998). Assim, considera-se que não existe tratamento eficaz para cães infectados com L. chagasi (MONTEIRO 1994).

Anteriormente considerada uma doença eminentemente rural e quase restrita a algumas regiões nordestinas, a reemergência da leishmaniose visceral foi verificada principalmente em Terezina e São Luís. Dados epidemiológicos recentes revelam uma crescente urbanização da leishmaniose visceral, com o avanço da enfermidade para outras regiões atingindo inclusive grandes centros como Belo Horizonte e Rio de Janeiro (ARIAS et al. 1996).

A distribuição geográfica da leishmaniose visceral e do seu vetor vem se ampliando no Brasil, possivelmente como conseqüência das modificações do ecossistema provocadas pelo homem, principalmente pela devastação florestal, que leva à dispersão dos reservatórios naturais do parasita, assim como, à criação de ecótopos adequados à proliferação do seu vetor (MARZOCHI et al. 1994; SHERLOCK 1994).

No período de 1983 a 1997, 30.466 casos de leishmaniose visceral foram notificados no Brasil, distribuídos pelas Regiões Norte $(3,3 \%)$, Nordeste $(91,2 \%)$, Sudeste $(4,3 \%)$ e Centro-Oeste $(1,1 \%)$ (VIEIRA e COELHO 1998).

Torna-se oportuno constatar que até 1997, o Estado de São Paulo não figurava entre as unidades federativas brasileiras com ocorrência da leishmaniose visceral oficialmente assinalada, embora, na década de 70 e início da de 80 , houvesse registros da ocorrência de casos autóctones de leishmaniose visceral na Grande São Paulo, nos município de Diadema e São Paulo (IVERSSON et al. 1979, 1982). Todavia, em ambas as ocorrências, não foi possível identificar elos da cadeia de transmissão no que tange a reservatório e vetores 
A partir do final de 1998, cães com suspeita clínica de leishmaniose foram observados na cidade de Araçatuba e um inquérito sorológico revelou uma positividade de $15,5 \%$, em 457 cães examinados, através da reação de imunofluorescência indireta (GALLIMBERTI et al. 1999).

A presença de $L$. chagasi também pôde ser constatada em cães do municipio comprovando a expansão territorial da leishmaniose visceral, principalmente na região noroeste do Estado de São Paulo (TOLEZANO et al. 1999).

A doença, em Araçatuba, inicialmente diagnosticada em cães, posteriormente foi assinalada também no homem. Subseqüentemente, em outros municípios vizinhos, foi detectada a presença do vetor e também da infecção canina.

Diante da importância crescente que a leishmaniose visceral adquire no Estado de São Paulo, especialmente no âmbito da região noroeste, onde mais recentemente, a enfermidade atingiu vários seres humanos, fazem-se necessários estudos e pesquisas sobre o comportamento do vetor, sua relação com o protozoário, com o homem e com animais, além da realização de estudos soro-epidemiológicos e protozoológicos acerca da ocorrência da leishmaniose em cães e outros prováveis reservatórios para melhor dimensionar situações de possibilidade de transmissão da parasitose nessa região.

Tendo em vista as observações da enzootia precedendo a ocorrência da leishmaniose visceral na população humana em Araçatuba, o presente estudo visa contribuir com o sistema de saúde local, fornecendo informações sobre a ocorrência da parasitose na população canina e melhorar a estratégia de aproximação de uma real prevalência da infecção nessa espécie animal. Pretende fornecer, ainda, informações sobre aspectos relacionados à ecologia do vetor, para a implementação de medidas de controle baseadas nesses elos da cadeia de transmissão. 


\section{OBJETIVOS}

\section{1 Objetivo Geral}

Estudar a possibilidade de transmissão de leishmaniose visceral no municipio de Mirandópolis, localizado em região de ocorrência recente da doença com enfoque na população de reservatórios e no vetor.

\section{2 Objetivos Específicos}

2.2.1 Investigar a presença de L. longipalpis em domicílios e peridomicílios de área urbana e rural e a sua distribuição sazonal.

2.2.2 Identificar a atração do vetor por animais domésticos mantidos em áreas peridomiciliares.

2.2.3 Investigar o índice de infecção natural de flebotomíneos por flagelados.

2.2.4 Identificar a prevalência de anticorpos anti-Leishmania em cães.

2.2.5 Isolar e identificar espécies de Leishmania encontrada em cães soropositivos.

2.2.6 Investigar a presença da infecção em marsupiais.

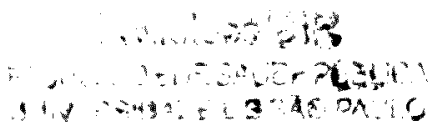




\section{MÉTODO}

\section{1 Área de estudo}

Os trabalhos foram conduzidos no município de Mirandópolis, localizado na região noroeste do Estado de São Paulo distante $608 \mathrm{~km}$ da capital e $80 \mathrm{~km}$ de Araçatuba, município representativo da região (Anexo 1). Sua sede municipal situase a $21^{\circ} 7^{\prime} 25^{\prime \prime} \mathrm{LS}$ e $51^{\circ} 5^{\prime} \mathrm{LW}$, com altitude de $423 \mathrm{~m}$ acima do nível do mar.

Ocupando uma área de $1.008 \mathrm{~km}^{2}$, cujo relevo varia de suave ondulado a ondulado, com solo do tipo polidzolizado Lins-Marília, faz divisa ao norte com os municípios de Irapuru, Pacaembu, Flórida Paulista e Junqueirópolis, ao sul, com Lavínia, a leste, com Guaraçaí e, a oeste, com Pereira Barreto.

O clima é tropical do tipo $\mathrm{Cw}$ segundo a classificação de Köeppen, com duas estações distintas: a chuvosa e a seca. Geralmente, a estação chuvosa inicia-se em outubro e vai até abril. $O$ período seco inicia-se em maio, tornando-se mais acentuado nos meses de junho a agosto. Estas estações podem também ser definidas pelas variações de temperatura. Na estação seca se concentram os meses mais frios, principalmente junho e julho e, na estação chuvosa, os meses mais quentes do ano.

A população atual do município é de 25.928 habitantes, 22.279 dos quais vive na zona urbana, onde se localizam pequenas indústrias de móveis, comércio e prestação de serviços. Na zona rural, onde habitam 3.649 pessoas, as principais explorações agropecuárias são cana-de-açúcar, pecuária de corte e de leite, avicultura de postura e fruticultura, especialmente, goiaba, manga e abacaxi.

\section{2 Dados climatológicos}

Os dados da precipitação pluviométrica $(\mathrm{mm})$ e da temperatura do $\operatorname{ar}\left({ }^{\circ} \mathrm{C}\right)$ foram fornecidos pelo Escritório de Desenvolvimento Rural de Andradina, órgão da Secretaria da Agricultura e Abastecimento do Estado de São Paulo e pela Prefeitura Municipal de Mirandópolis, respectivamente. 


\section{3 Estudos entomológicos}

\section{3. 1 Captura de flebotomíneos com armadilhas automáticas luminosas em miniatura}

Em três pontos urbanos, representados por moradias aleatoriamente selecionadas, foram utilizadas armadilhas automáticas luminosas em miniatura (NATAL et al. 1991).

Essas moradias são representativas de um tipo de residência muito comum e predominante na cidade. São casas térreas, de alvenaria, com aproximadamente 80 $\mathrm{m}^{2}$ de área construída em terrenos de $250 \mathrm{~m}^{2}$.

Duas delas se localizam na área central da cidade e uma na periferia (Anexo 2) e, em todas elas, existem anexos domiciliares destinados à criação de galinhas. Além disso, os amplos quintais, não pavimentados e com plantas diversas, permitem o acúmulo de objetos e materiais de natureza variada tais como vasilhames, pedaços de madeiras, telhas, além do acúmulo de folhas e frutos caídos das árvores.

Em cada residência, duas armadilhas luminosas em miniatura foram instaladas a cerca de 1,0 metro e meio do chão, uma na área domiciliar e outra no ambiente peridomiciliar, perfazendo um total de 6 pontos fixos urbanos de captura de flebotomíneos (Figura 1).

As capturas na zona rural foram realizadas no Sítio Nossa Senhora de Fátima, estabelecimento rural que mantém animais domésticos de diferentes espécies, entre elas, bovinos, suínos, aves e cães.

$\mathrm{Na}$ zona rural, as capturas foram realizadas de maneira concomitante com as feitas na zona urbana. Simultaneamente, instalou-se uma armadilha em cada abrigo de cada espécie animal (pocilga, canil, curral e galinheiro). Uma quinta armadilha foi instalada no interior da residência do proprietário para avaliação indireta da atração exercida pelo homem sobre os flebotomíneos.

Todas essas capturas foram semanais e realizadas das 18:00 às 6:00 horas, não obedecendo ao horário de verão, durante o período de janeiro a dezembro de 2000 


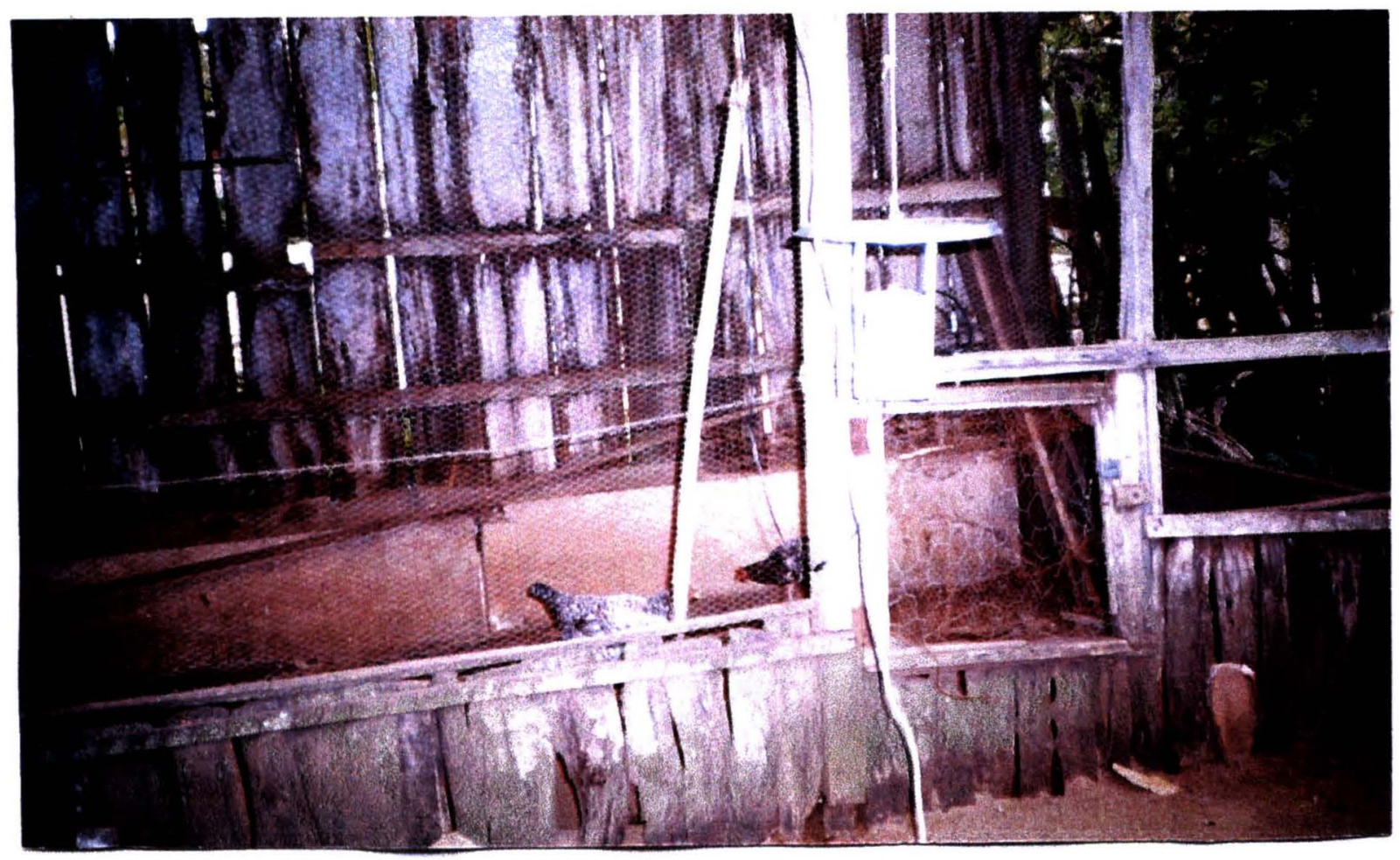

Figura 1 - Armadilha automática luminosa em miniatura.

Os flebotomíneos obtidos através das capturas com as armadilhas luminosas, após serem mortos em atmosfera com éter ou clorofórmio, foram acondicionados em caixas entomológicas devidamente identificadas. Em seguida, foram encaminhados para o laboratório da Superintendência de Controle de Endemias (SUCEN), em Araçatuba ou para o Laboratório de Phlebotominae da Faculdade de Saúde Pública da USP. Após serem submetidos ao processo de clarificação, foram identificados adotando-se a nomenclatura para as espécies de acordo com a classificação de GALATI (1995).

\section{3. 2 Captura de flebotomíneos com armadilha de Shannon e aspiradores elétricos}

Armadilhas de Shannon modificadas, nas cores preta ou branca (GALATI, 2001) com dois indivíduos capturando, durante quatro horas, das 18:00 às 22:00 
horas, foram instaladas no peridomicilio, preferencialmente em quintais de residências onde a infecção canina havia sido constatada ou nas suas proximidades (Figura 2). Nesses locais e em outras residências onde a presença de $L$. longipalpis já havia sido previamente confirmada com a utilização de armadilhas automáticas luminosas, foram também realizadas capturas com aspiradores elétricos, alimentados por baterias de 6 Volts, com os operadores realizando as aspirações nas paredes internas e externas das casas, nos anexos domiciliares, nos abrigos de animais e, mesmo diretamente sobre eles (Figura 3).

Essas modalidades de captura de flebotomíneos foram destinadas, prioritariamente, a obtenção de exemplares fêmeas para a investigação de infecção natural de $L$. longipalpis por flagelados.

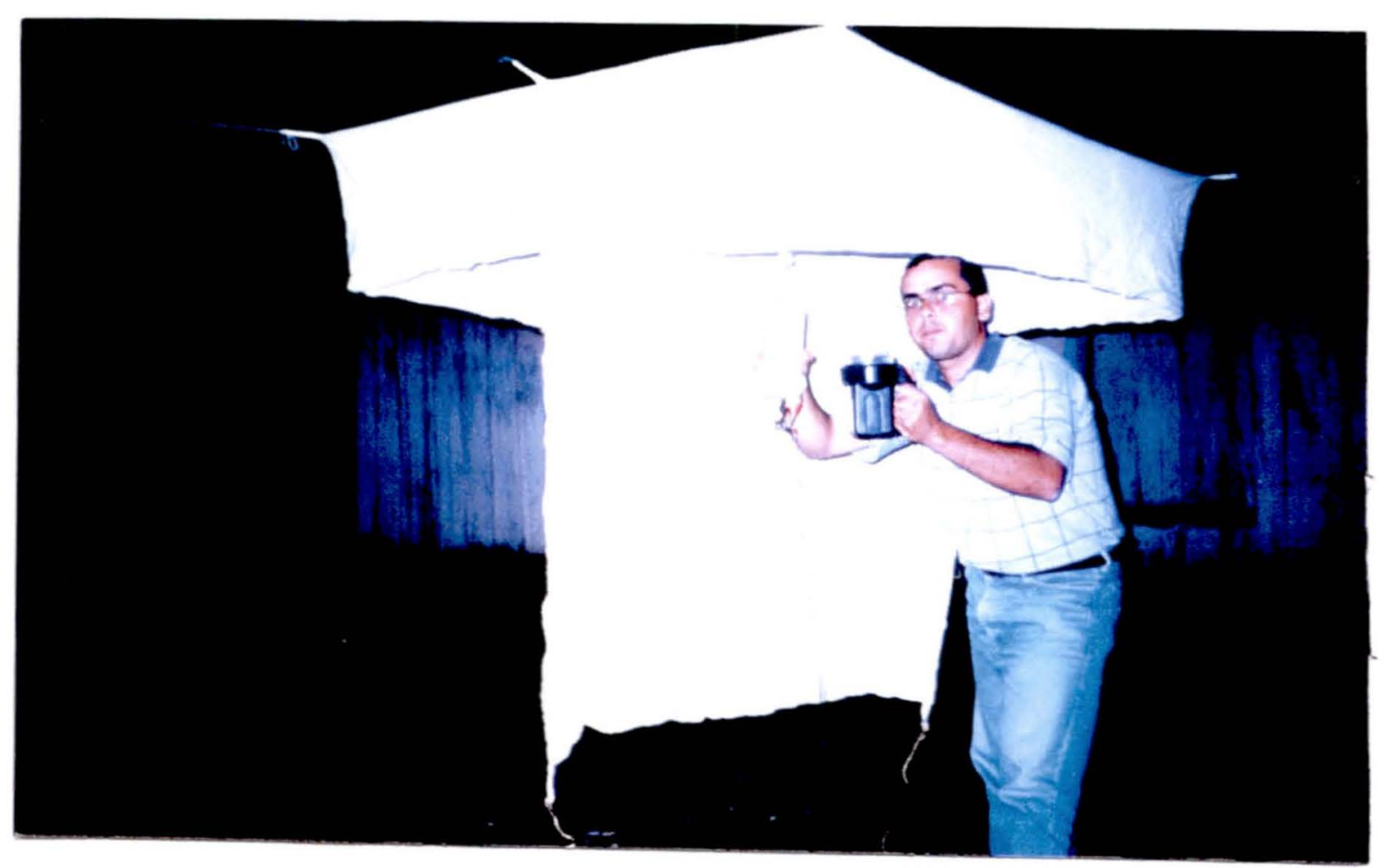

Figura 2 - Captura de flebotomíneos com armadilha de Shannon. 


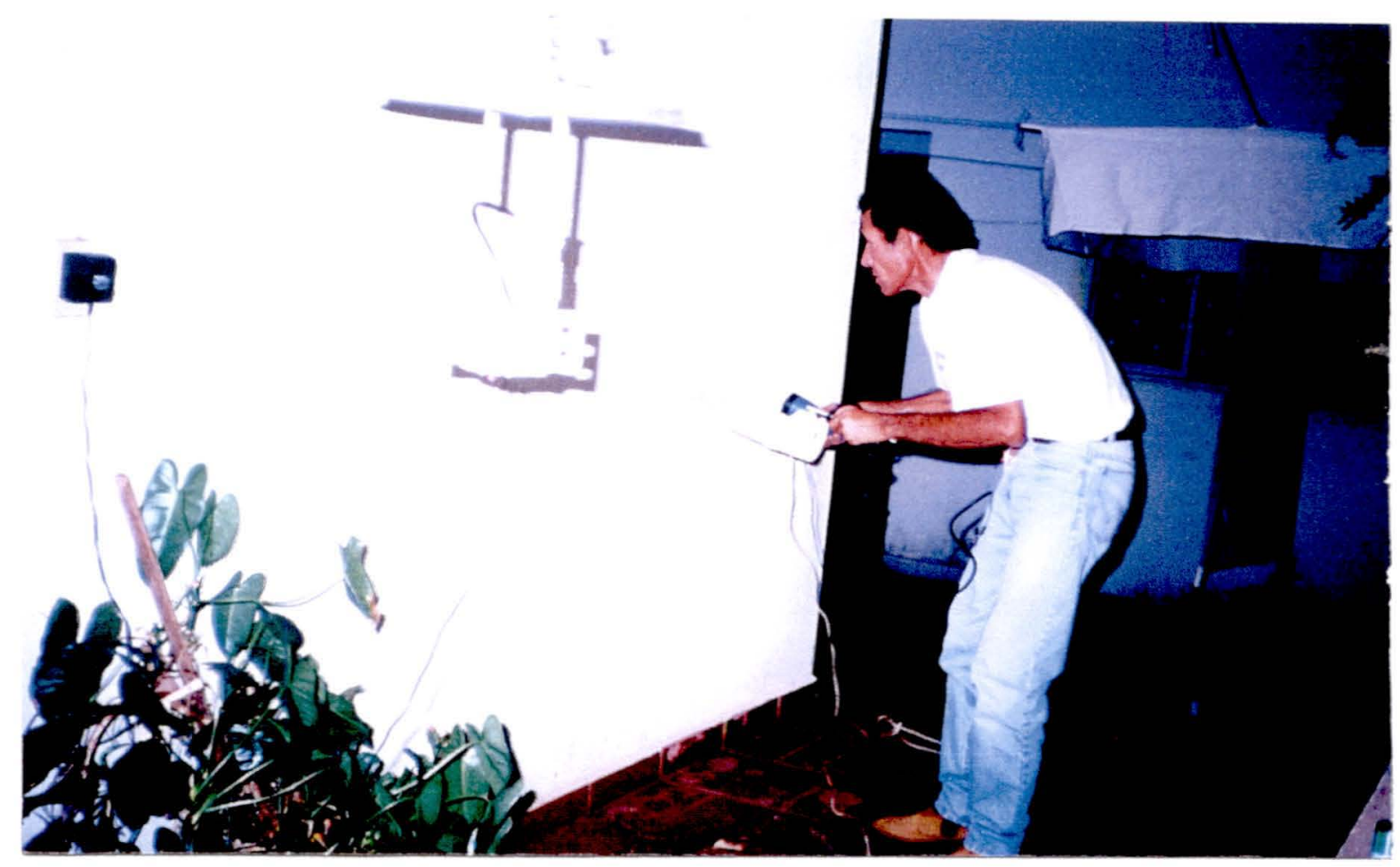

Figura 3 - Captura de flebotomíneos com aspirador elétrico.

\section{3. 3 Investigação da infecção natural de flebotomíneos por flagelados}

Os copos coletores dos aspiradores elétricos foram então transportados para o Centro de Controle de Zoonoses do município. No laboratório improvisado e instalado nas suas dependências, os flebotomíneos capturados foram soltos em gaiolas entomológicas e contidos individualmente em tubos de ensaio.

As fêmeas foram anestesiadas com éter e colocadas em uma lâmina de microscopia. Com o auxílio de um estereoscópio e estiletes, foram retiradas as patas e asas do inseto que, em seguida foi transferido para uma gota de solução físiológica esterilizada, depositada na mesma lâmina.

A dissecção do flebotomíneo, expondo o tubo digestivo e as espermatecas foi possibilitada com o emprego de estiletes entomológicos.

Em seguida, após a sobreposição de uma lamínula, observou-se, microscopicamente, com aumento de 400 vezes, fazendo-se a pesquisa de flagelados e a identificação do flebotomíneo através da morfologia das espermatecas. 
Os machos foram mortos e encaminhados para o laboratório da SUCEN, em Araçatuba, para clarificação e identificação, procedendo-se de maneira idêntica à mencionada nas capturas com armadilhas luminosas.

\section{4 Sorologia}

\section{4. 1 Inquérito sorológico canino}

As colheitas de sangue foram realizadas nos animais, acima de três meses de idade da área urbana e rural, cujos proprietários consentiram, sendo efetuadas durante a campanha de vacinação anti-rábica canina, que ocorreu em agosto de 2000 .

Nove postos de vacinação/ colheita de sangue foram estabelecidos, oito deles localizados nos principais bairros da cidade e um instalado na zona rural do município (Anexo 3).

Cães errantes capturados no município durante esse período também foram incluídos no inquérito.

As amostras de sangue foram obtidas através da punção da veia cefálica $\mathrm{e}$ recolhidas em fragmentos padronizados de papel de filtro, devidamente acompanhados de etiquetas de identificação (Anexo 4).

Os papéis de filtro impregnados com as amostras de sangue total dos cães, após secos, foram remetidos para o Centro de Controle de Zoonoses de São Paulo.

Os exames sorológicos foram realizados através do teste de imunofluorescência indireta, segundo metodologia adotada por SAN MARTINSAVANI (1998) e utilizada pelo Laboratório de Imunologia daquela instituição.

As amostras foram consideradas positivas quando apresentaram títulos iguais ou superiores a 40 . 
3. 4. 2 Comparação do teste de imunofluorescência indireta e ensaio imunoenzimático - Enzyme-linked immunosorbent assay (Elisa)

Amostras de soro sangüíneo foram obtidas de cães errantes recolhidos pelos funcionários do serviço de captura de cães do município e, também, de cães doados pelos seus proprietários. Cerca de metade desses últimos eram portadores de patologias como demodiciose, tumores venéreos, úlceras e dermatites. Alguns deles apresentavam alterações clínicas como linfoadenomegalia, alterações dermatológicas das mais variadas, onicogrifose e emaciação, sintomas esses compatíveis com a leishmaniose visceral tornando, portanto, a amostra intencionalmente tendenciosa, diante do objetivo almejado, de se ampliar a identificação de mais animais infectados por Leishmania, com a utilização de duas técnicas sorológicas distintas.

As colheitas de sangue foram realizadas através de punção da veia cefálica (Figura 4) ou da jugular. Cerca de $5,0 \mathrm{ml}$ foram colhidos de cada animal e acondicionados em tubos de ensaio.

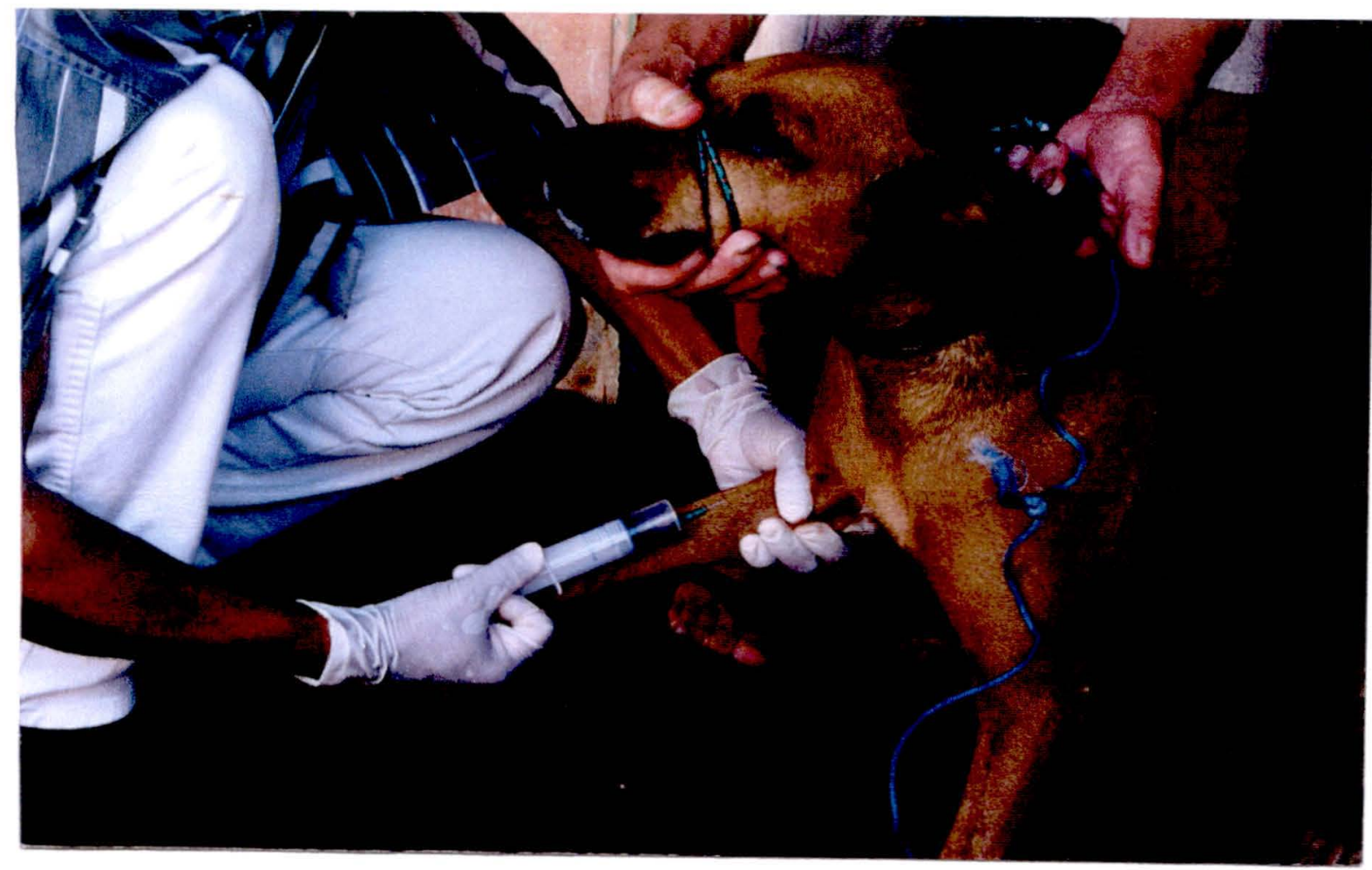

Figura 4 - Colheita de sangue venoso. 
As amostras de sangue foram submetidas à centrifugação (2500 rpm durante 10 minutos) para uma melhor separação do soro sangüíneo. A seguir, separou-se duas aliquotas de 1,0 $\mathrm{ml}$ de cada soro, as quais foram acondicionadas em tubos de polipropileno rotulados e congelados a $-17^{\circ} \mathrm{C}$, assim permanecendo armazenados até o envio aos laboratórios.

Os soros sangüineos foram então remetidos em caixas isotérmicas com gelo, para o Laboratório de Imunologia do Centro de Controle de Zoonoses de São Paulo e para o Laboratório de Imunologia do Curso de Medicina Veterinária de Araçatuba, da Universidade Estadual Paulista (UNESP), para serem examinadas com o emprego do teste de imunofluorescência e do Elisa, respectivamente.

\section{5 Isolamento de Leishmania}

Cães reagentes a uma ou a ambas provas sorológicas empregadas foram humanitariamente sacrificados e, em seguida, submetidos à necropsia nas dependências do ambulatório do Centro de Controle de Zoonoses de Mirandópolis.

De maneira individualizada, ou seja, de cada animal submetido à eutanásia, foram colhidos pequenos fragmentos com aproximadamente $1,0 \mathrm{~g}$ de baço, figado, medula óssea do fêmur e linfonodo (pré-escapular ou poplíteo), os quais foram macerados em conjunto, em gral esterilizado, e suspensos em solução salina esterilizada.

O pool de órgãos resultante teve dois destinos: a semeadura em meio artificial e a inoculação em animal sensível.

Uma pequena alíquota de $0,2 \mathrm{ml}$ foi semeada, assepticamente, em tubos de ensaio (15,0 X 5,0 mm) contendo cerca de 10,0 ml de meio NNN (Nicolle, Novy, MacNeal).

Imediatamente após o inóculo, adicionou-se aos tubos de ensaio, 1,0 $\mathrm{ml}$ do meio líquido RPMI-1640 acrescido de antibióticos (100.000 UI/ ml de penicilina e $100.000 \mu \mathrm{g} / \mathrm{ml}$ de gentamicina) e $20,0 \%$ de soro bovino fetal, conforme preconizado por RIERA et al. (2000). 
Aproximadamente $1,0 \mathrm{ml}$ da suspensão dos órgãos de cada cão foi inoculado pela via intra-peritoneal, em um hamster (Mesocricetus auratus) com 5 meses de idade, de acordo com SHERLOCK (1996).

Os tubos contendo o meio de cultura inoculados com o pool de órgãos dos cães, foram mantidos em estufa regulada para a temperatura de $23,0{ }^{\circ} \mathrm{C}$ durante 7 dias. Após esse periodo, uma pequena gota da fase líquida do meio de cultura foi observada entre lâmina e lamínula sob microscópio óptico com aumento de 400 vezes.

Após um período de 4 a 5 meses, os hamsters foram sacrificados. Assepticamente colheu-se um lavado, por meio da injeção de $2,0 \mathrm{ml}$ de solução salina esterilizada na cavidade peritoneal do animal, com posterior recuperação parcial do líquido injetado (Figura 5). Procedimento este, análogo à técnica utilizada para a obtenção de taquizoítos de Toxoplasma gondii a partir de camundongos infectados por este protozoário (JACOBS e MELTON 1957).

Cerca de $0,2 \mathrm{ml}$ desse lavado foi então semeado em tubos contendo meio NNN, ao qual também se adicionou o meio líquido, de maneira idêntica à utilizada para a semeadura de órgãos dos cães, já descrita.

Os tubos semeados foram mantidos em estufa regulada para $23^{\circ} \mathrm{C}$, durante sete dias, após os quais, uma pequena gota do meio líquido foi microscopicamente examinada entre lâmina e laminula com aumento de 400 vezes.

Em seguida, procedeu-se a abertura da cavidade abdominal dos hamsters através de incisão mento-pubiana. Decalques de figado e baço foram confeccionados através da aposição de fragmentos desses órgãos em lâminas de microscopia (Figura 6). Após secas ao ar, essas preparações foram submetidas à coloração por um conjunto de corantes para coloração diferencial rápida ${ }^{a}$ e observadas em microscópio óptico com aumento de 1000 vezes.

\footnotetext{
${ }^{a}$ Instant Prov. Newsprov Produtos para Laboratório Ltda. Pinhais - Paraná
} 


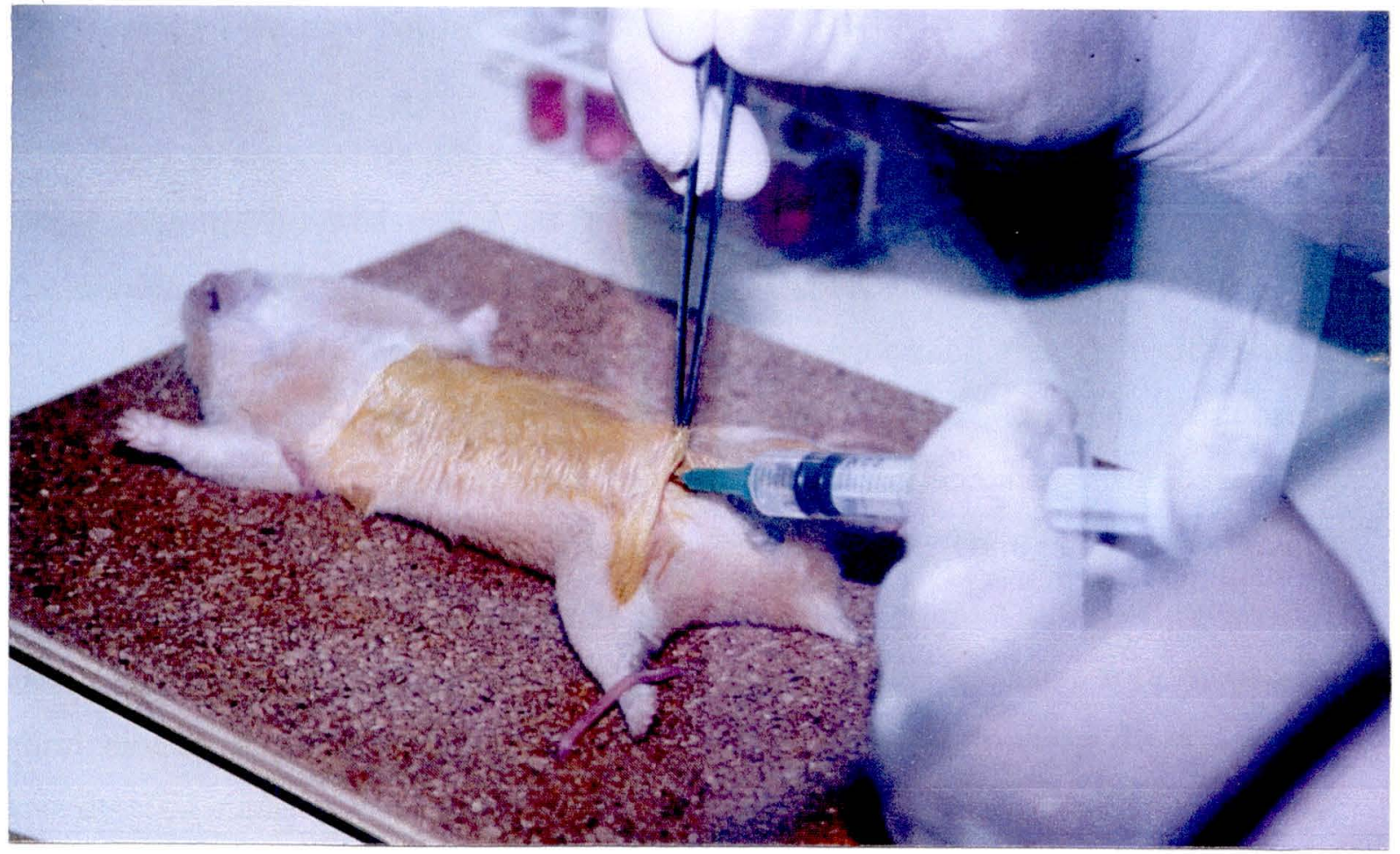

Figura 5 - Obtenção de lavado peritoneal de hamster.

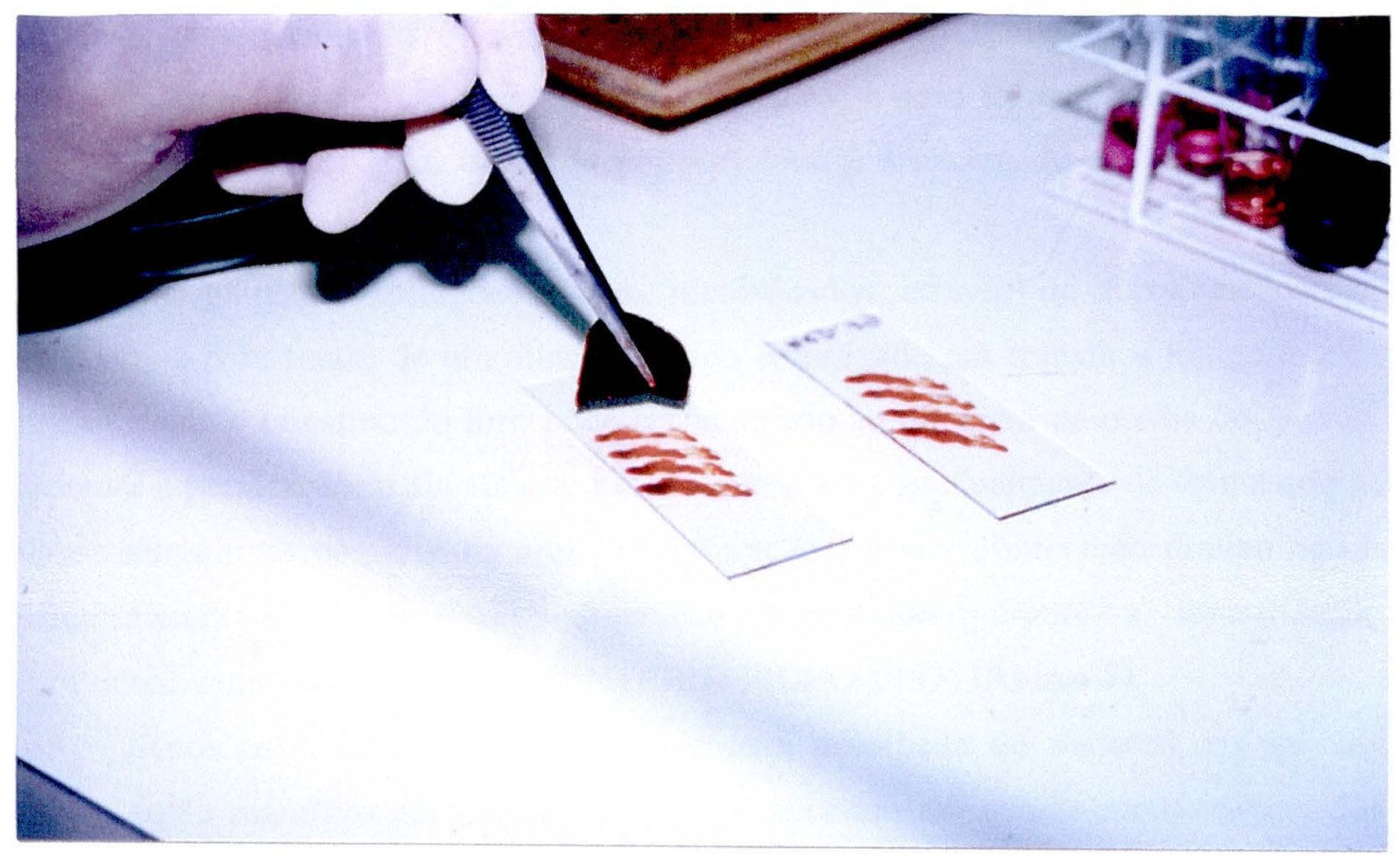

Figura 6 - Confecção de preparações (decalques) de baço de hamster em lâminas de microscopia. 


\section{6 Captura de marsupiais}

Para as capturas de gambás, foram utilizadas como armadilhas, gaiolas de aço de tamanho médio (40 $\mathrm{cm} \times 18 \mathrm{~cm} \times 17 \mathrm{~cm}$ ) e como isca, banana madura, considerada como a mais atrativa (MONTEIRO FILHO 1987).

As armadilhas foram instaladas em áreas peridomiciliares de residências de moradores da cidade que comunicaram ao Centro de Controle de Zoonoses a provável presença de gambás em seus quintais. Em cada oportunidade, duas armadilhas foram instaladas por três dias consecutivos, com observações diárias realizadas no período da manhã para se verificar o sucesso ou não das capturas.

Para a colheita de amostras de sangue, os animais foram contidos quimicamente através da aplicação subcutânea de uma combinação de ketamina na dose de $10,0 \mathrm{mg} / \mathrm{kg}$ p.v. com xilazina na dose de $2,0 \mathrm{mg} / \mathrm{kg} \mathrm{p.v}$.

Aproximadamente $5,0 \mathrm{ml}$ de sangue foram colhidos por meio de punção da veia jugular. Cerca de 1,0 a 2,0 $\mathrm{ml}$ foram acondicionados em tubos de hemólise contendo anticoagulante, sendo armazenados para estudos com o emprego de técnicas moleculares, e o restante foi depositado em tubos de hemólise sem anticoagulante. Desses últimos, após a coagulação, o soro foi recolhido com pipeta Pasteur e transferido para tubos de polipropileno e armazenado a $-20,0^{\circ} \mathrm{C}$ até a realização dos testes.

Os gambás capturados foram identificados através de furos na orelha, valendo-se para tanto, de um alicate do tipo empregado em trabalhos em couro, de maneira que o tamanho do furo pode ser adaptado ao tamanho da orelha do animal. Durante a perfuração, o alicate era pressionado lenta e gradualmente de forma que os vasos sangüíneos contidos na área da perfuração sofriam obliteração diminuindo o sangramento. O sistema de numeração empregado permite a identificação individualizada de 99 animais (MONTEIRO FILHO 1987) (Anexo 5).

Após os procedimentos realizados para a colheita do material, os animais foram então mantidos em gaiola, onde permaneceram até que se recuperassem dos efeitos da anestesia

Tendo em vista a circunstancial indisponibilidade de métodos de diagnóstico da leishmaniose visceral aplicáveis a essa espécie animal que permitisse uma tomada 
de decisão caso se confirmasse a doença, houve-se por bem, devolver os gambás às suas condições naturais.

Após a constatação inequívoca da completa recuperação do animal que fora submetido à marcação e à colheita de sangue, o mesmo foi devolvido às condições naturais em uma mata localizada nas proximidades da cidade, respeitando-se, portanto, a tendência global de preservar a biodiversidade.

\section{7 Análise estatística}

A análise estatística constituiu-se de:

Coeficiente de correlação de Pearson para verificar correlação entre o número de L. longipalpis e a temperatura do ar e precipitação pluviométrica.

Teste Qui-quadrado ou teste exato de Fischer para verificar associação entre variáveis.

Teste de McNemar para comparar duas proporções com amostras dependentes (resultados dos dois exames de um mesmo animal).

Teste de Kruskal-Wallis para comparar os locais de captura na avaliação indireta do hábito alimentar.

Teste de Mann-Whitney para comparar os locais de captura domiciliar e peridomiciliar no ambiente urbano.

As estatísticas foram consideradas significativas quando $\mathrm{p}<0,05$.

As análises estatísticas foram efetuadas empregando-se o programa SAS (Statistical Analysis System). 


\section{RESULTADOS}

\section{1 Dados entomológicos}

\section{1. 1 Capturas de flebotomíneos com armadilhas automáticas luminosas em miniatura}

Os rendimentos mensais das capturas de flebotomíneos, realizadas semanalmente, com armadilhas luminosas automáticas em seis pontos fixos de captura na área urbana, estão dispostos na Tabela 1 e os dados da análise estatística na Tabela 2 .

Tabela 1 - Número mensal de espécimens de L. longipalpis capturados, semanalmente com armadilhas automáticas luminosas, segundo local e sexo, no município de Mirandópolis (área urbana). Janeiro a dezembro de 2000

\begin{tabular}{|c|c|c|c|c|c|c|c|c|c|c|c|c|c|c|c|}
\hline \multirow[b]{3}{*}{ Mês/ sexo } & \multicolumn{4}{|c|}{ Residência 1} & \multicolumn{4}{|c|}{ Residência 2} & \multicolumn{4}{|c|}{ Residência 3} & \multicolumn{3}{|c|}{ Total } \\
\hline & \multicolumn{2}{|c|}{ domicílio } & \multicolumn{2}{|c|}{$\begin{array}{l}\text { peri- } \\
\text { domicílio }\end{array}$} & \multicolumn{2}{|c|}{ domicílio } & \multicolumn{2}{|c|}{$\begin{array}{l}\text { peri- } \\
\text { domicílio }\end{array}$} & \multicolumn{2}{|c|}{ domicílio } & \multicolumn{2}{|c|}{$\begin{array}{l}\text { peri- } \\
\text { domicílio }\end{array}$} & \multirow[b]{2}{*}{$\mathbf{m}$} & \multirow[b]{2}{*}{$\mathbf{f}$} & \multirow[b]{2}{*}{$m+f$} \\
\hline & $\mathbf{m}$ & $\mathrm{f}$ & $\mathbf{m}$ & $E$ & $\mathbf{m}$ & $\mathrm{f}$ & $\mathbf{m}$ & $\mathrm{f}$ & $\mathbf{m}$ & $\mathrm{f}$ & $\mathbf{m}$ & $f$ & & & \\
\hline Janeiro & 11 & 0 & 6 & 0 & 8 & 0 & 1 & 3 & 1 & 0 & 0 & 1 & 27 & 4 & 31 \\
\hline Fevereiro & $9 *$ & 5 & 7 & 4 & 7 & 1 & 1 & 0 & 3 & 0 & 1 & 1 & 28 & 11 & 39 \\
\hline Março & 24 & 3 & 17 & 1 & 4 & 2 & 1 & ) & 7 & 2 & 2 & 0 & 55 & 8 & 63 \\
\hline Abril & 4 & 2 & 55 & 4 & 6 & 0 & 21 & 0 & 2 & 0 & 9 & 1 & 97 & 7 & 104 \\
\hline Maio & 2 & 1 & 6 & 0 & 0 & $1 * *$ & 7 & 0 & 1 & 0 & 13 & 2 & 29 & 4 & 33 \\
\hline Junho & 8 & 0 & 2 & 0 & 1 & 0 & 4 & 4 & 1 & 0 & 45 & 2 & 61 & 6 & 67 \\
\hline Julho & 0 & () & 1 & 0 & 0 & 1 & 3 & 1 & 0 & 0 & 1 & 2 & 5 & 4 & 9 \\
\hline Agosto & 10 & 1 & 0 & 0 & 3 & 0 & 1 & 0 & 0 & 0 & 0 & 0 & 14 & 1 & 15 \\
\hline Setembro & 0 & 0 & 5 & 0 & 0 & 2 & 0 & 0 & 5 & 1 & 0 & 0 & 10 & 3 & 13 \\
\hline Outubro & 6 & 3 & 12 & 1 & 0 & 1 & 4 & 0 & 1 & 0 & 0 & 0 & 23 & 5 & 28 \\
\hline Novembro & 0 & 1 & 1 & 0 & 0 & 1 & 0 & 0 & 0 & 0 & 0 & 0 & 1 & 2 & 3 \\
\hline Dezembro & 2 & 2 & 1 & 0 & 0 & 1 & 1 & 1 & 1 & 0 & 0 & 0 & 5 & 4 & 9 \\
\hline Total & 76 & 18 & 113 & 10 & 29 & 10 & 44 & 9 & 22 & 3 & 71 & 9 & 355 & 59 & 414 \\
\hline
\end{tabular}

$\mathrm{m}=$ macho; $\mathrm{f}=$ fềmea.

* mais dois espécimes de Nyssomyia whitmani (Antunes \& Coutinho, 1939).

**mais um espécime de Evandromyia termitophila (Martins Falcão \& Silva, 1964).

A distribuição do número mensal de flebotomíneos capturados com periodicidade semanal, em cinco pontos fixos localizados na zona rural, está discriminada na Tabela 3 e com os números médios (Média de Williams) 
representados na Figura 7. Os dados da análise estatística estão dispostos na Tabela 4.

Tabela 2 - Média, desvio padrão, mediana e média de Williams do número de $L$. longipalpis capturado na área urbana. Mirandópolis (SP), 2000

\begin{tabular}{ccc}
\hline & & Local \\
Medidas e Testes estatísticos & Domicílio & Peridomicílio \\
Média & 13,2 & 21,3 \\
Desvio padrão & 11,5 & 26,7 \\
Mediana & 10,5 & 12,5 \\
Média de Williams & 9,4 & 11,1 \\
\hline Teste de Mann-Whitney & & $\mathrm{z}=0,34722^{\mathrm{ns}}$ \\
\hline
\end{tabular}

${ }^{\mathrm{ns}}$ não significativo ao nivel de $5 \%(\mathrm{p}>0,05)$ 
Tabela 3 - Número mensal de L. longipalpis capturado semanalmente com armadilhas automáticas luminosas, segundo local e sexo, no município de Mirandópolis (área rural). Janeiro a dezembro de 2000

\begin{tabular}{lccccccccccccc}
\hline \multicolumn{1}{c}{ Local } & \multicolumn{3}{c}{ Domicílio } & \multicolumn{2}{c}{ Galinheiro } & \multicolumn{2}{c}{ Curral } & \multicolumn{2}{c}{ Canil } & \multicolumn{2}{c}{ Pocilga } & \multicolumn{3}{c}{ Total } \\
Mês/ Sexo & m & f & m & f & m & f & m & f & m & f & m & f & m+f \\
\hline Janeiro & 0 & 1 & 0 & 0 & 3 & 4 & 0 & 0 & 4 & 0 & 7 & 5 & 12 \\
Fevereiro & 0 & 0 & 2 & 1 & 11 & 1 & 0 & 1 & 2 & 0 & 15 & 3 & 18 \\
Março & 0 & 1 & 0 & 1 & 10 & 4 & 9 & 3 & 0 & 0 & 19 & 9 & 28 \\
Abril & 1 & 0 & 4 & 3 & 0 & 0 & 1 & 0 & 0 & 0 & 6 & 3 & 9 \\
Maio & 1 & 1 & 1 & 1 & 0 & 1 & 0 & 1 & 0 & 0 & 2 & 4 & 6 \\
Junho & 3 & 1 & 0 & 0 & 0 & 0 & 0 & 0 & 0 & 0 & 3 & 1 & 4 \\
Julho & 0 & 0 & 0 & 0 & 1 & 0 & 0 & 0 & 0 & 0 & 1 & 0 & 1 \\
Agosto & 1 & 0 & 2 & 1 & 1 & 2 & 3 & 1 & 0 & 1 & 7 & 5 & 12 \\
Setembro & 0 & 2 & 0 & 0 & 1 & 1 & 0 & 1 & 1 & 0 & 2 & 4 & 6 \\
Outubro & 1 & 3 & 0 & 0 & 1 & 1 & 8 & 4 & 1 & 0 & 11 & 8 & 19 \\
Novembro & 1 & 2 & 0 & 2 & 0 & 1 & 1 & 0 & 0 & 0 & 2 & 5 & 7 \\
Dezembro & 3 & 1 & 0 & 0 & 1 & 0 & 5 & 1 & 2 & 0 & 11 & 2 & 13 \\
\hline \multicolumn{1}{c}{ Total } & 11 & 12 & 9 & 9 & 29 & 15 & 27 & 12 & 10 & 1 & 86 & 49 & 135 \\
\hline m $=$ macho; f $=$ fêmea. & & & & & & & & & &
\end{tabular}

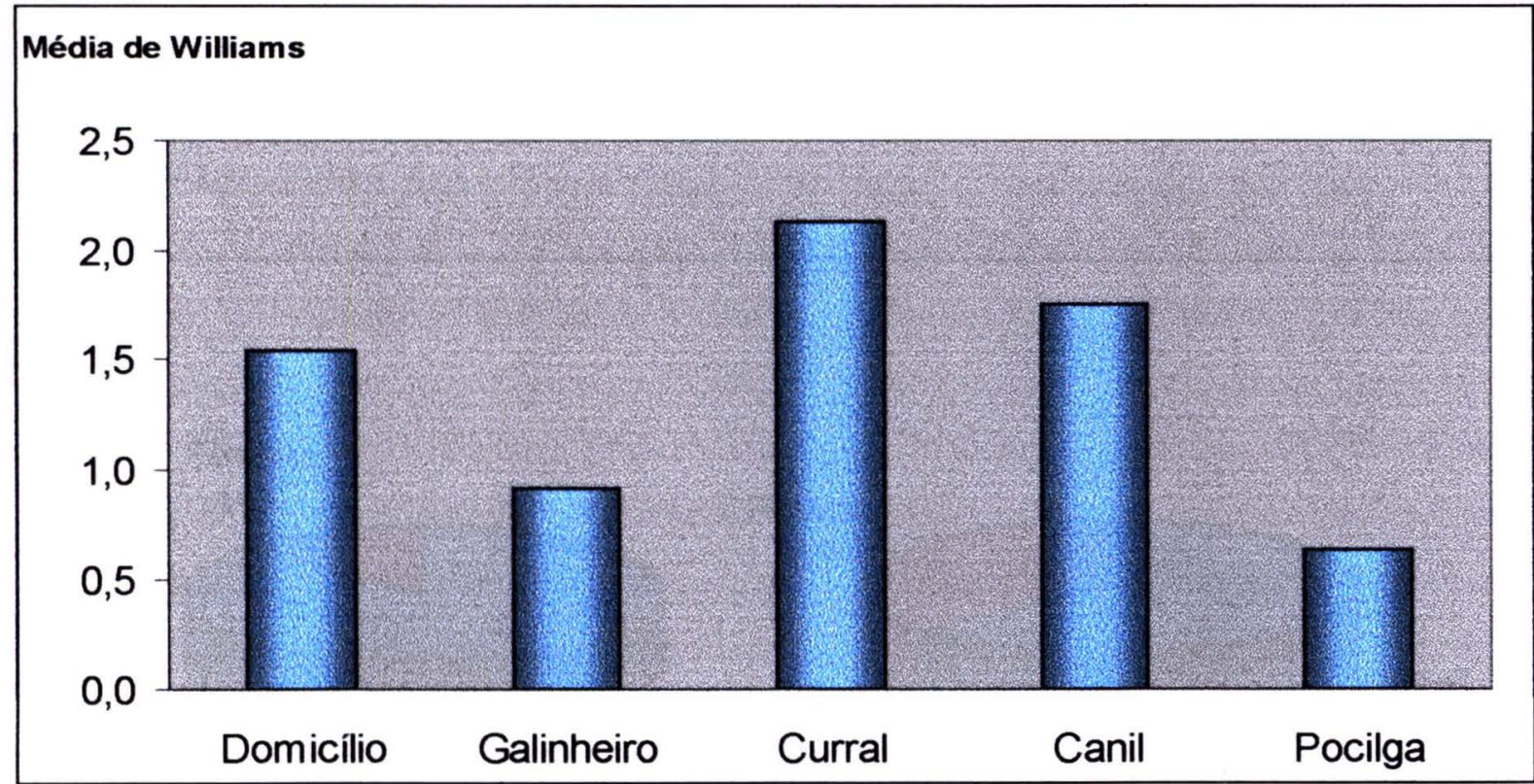

Figura 7 - Número médio de L. longipalpis (Média de Williams), semanalmente capturado, de acordo com local de captura, em área rural, no município de Mirandópolis, em 2000. 
Tabela 4 - Média, desvio padrão, mediana e média de Williams do número de $L$. longipalpis capturado, semanalmente, em domicílio e em abrigos de animais, em área rural, no município de Mirandópolis, em 2000

\begin{tabular}{cccccc}
\hline $\begin{array}{c}\text { Medidas e Teste } \\
\text { estatístico }\end{array}$ & Domicílio & Galinheiro & Curral & Canil & Pocilga \\
\hline Média & 1,92 & 1,50 & 3,67 & 3,25 & 0,92 \\
Desvio padrão & 1,51 & 2,11 & 4,76 & 4,45 & 1,24 \\
$\begin{array}{c}\text { Mediana } \\
\text { Média de Williams }\end{array}$ & 1,5 & 0,5 & 1,5 & 1,0 & 0,5 \\
\hline $\begin{array}{c}\text { Teste de Kruskal- } \\
\text { Wallis }\end{array}$ & 0,91 & 2,13 & 1,75 & 0,63 \\
\hline ns não significativo ao nível de $5 \%(\mathrm{p}>0,05)$ & & & \\
\hline
\end{tabular}

Os machos foram mais freqüentes proporcionando uma razão macho/ fềmea de 4,1:1. Essa predominância dos machos pôde ser constatada tanto nas capturas promovidas na zona urbana $(6,0: 1,0)$, como realizadas na área rural $(1,75: 1,0)$ (Figura 8).

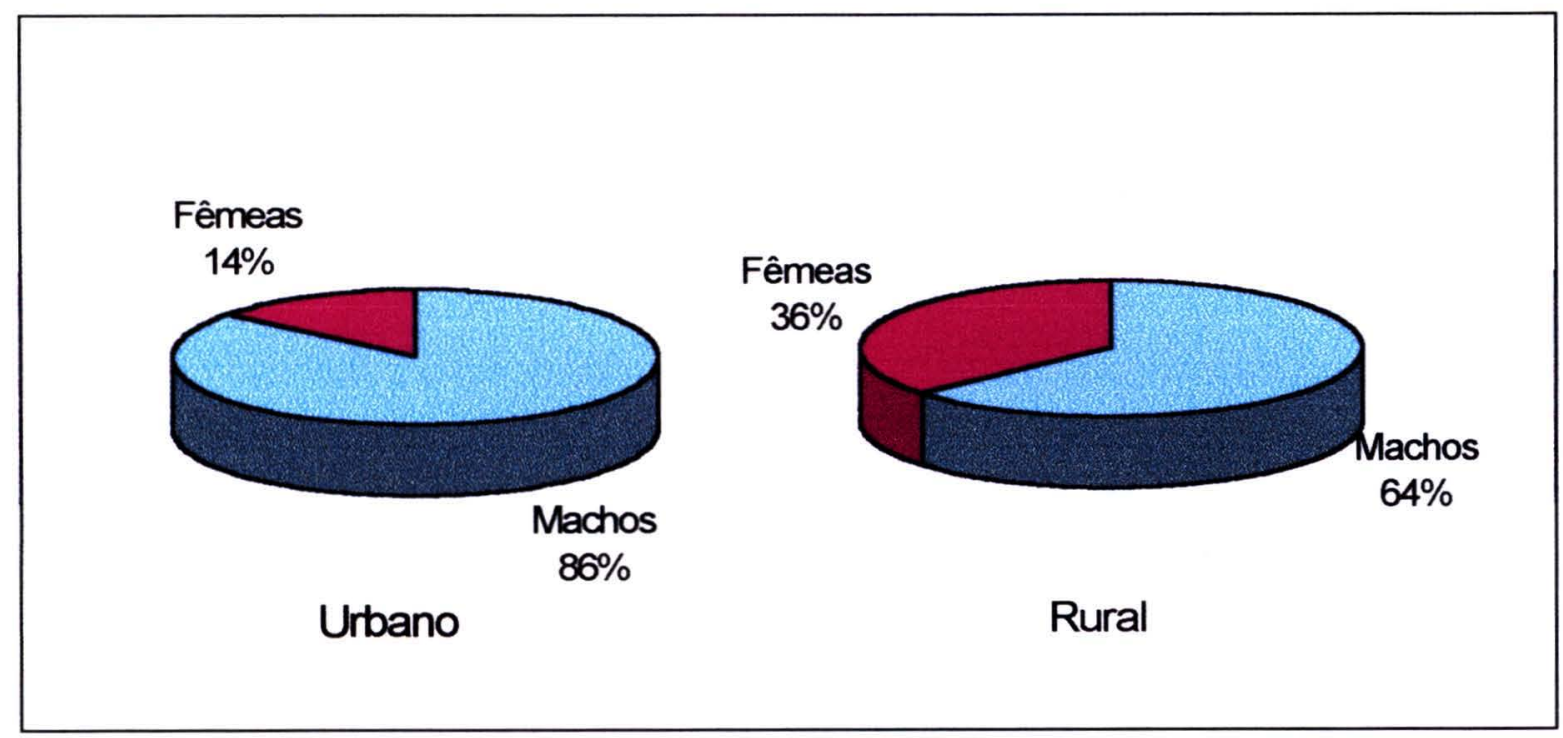

Figura 8 - Percentuais de exemplares machos e fềmeas de L. longipalpis, capturados com armadilhas automáticas luminosas, semanalmente, em pontos fixos urbanos e rurais no município de Mirandópolis, em 2000. 
Levando-se em consideração o conjunto de dados obtidos através da utilização sistemática de armadilhas luminosas em miniatura, no meio urbano e na zona rural do município, os rendimentos mais expressivos foram obtidos nos meses de março, abril e junho, especificamente nas $12^{\mathrm{a}}, 14^{\mathrm{a}}$ e $24^{\mathrm{a}}$ semanas de captura e os mais baixos na segunda quinzena de julho, ocasião em que o rendimento das capturas foi nulo ( $27^{\mathrm{a}}$ e $28^{\mathrm{a}}$ semanas de captura).

Os resultados da análise estatística dos dados, estão dispostos na Tabela 5 , enquanto as Figuras 9 e 10 ilustram essas ocorrências e permitem, ainda, observar a flutuação da densidade de L. longipalpis ao longo do período de estudo.

Tabela 5 - Coeficiente de correlação de Pearson entre as variáveis

$$
\text { Variável }^{(1)}
$$

$\mathrm{N}^{\circ}$ de insetos e temperatura do ar

$N^{\circ}$ de insetos e precipitação pluviométrica

(1) $\mathrm{n}^{\circ}$ de insetos transformados em $\log (\mathrm{x}+1)$

* significativo ao nível de $5 \%(p<0,05)$

${ }^{n s}$ não significativo ao nível de $5 \%(p>0,05)$
Coeficiente de correlação

$$
\begin{gathered}
0,4019^{*} \\
-0,08494^{n s}
\end{gathered}
$$




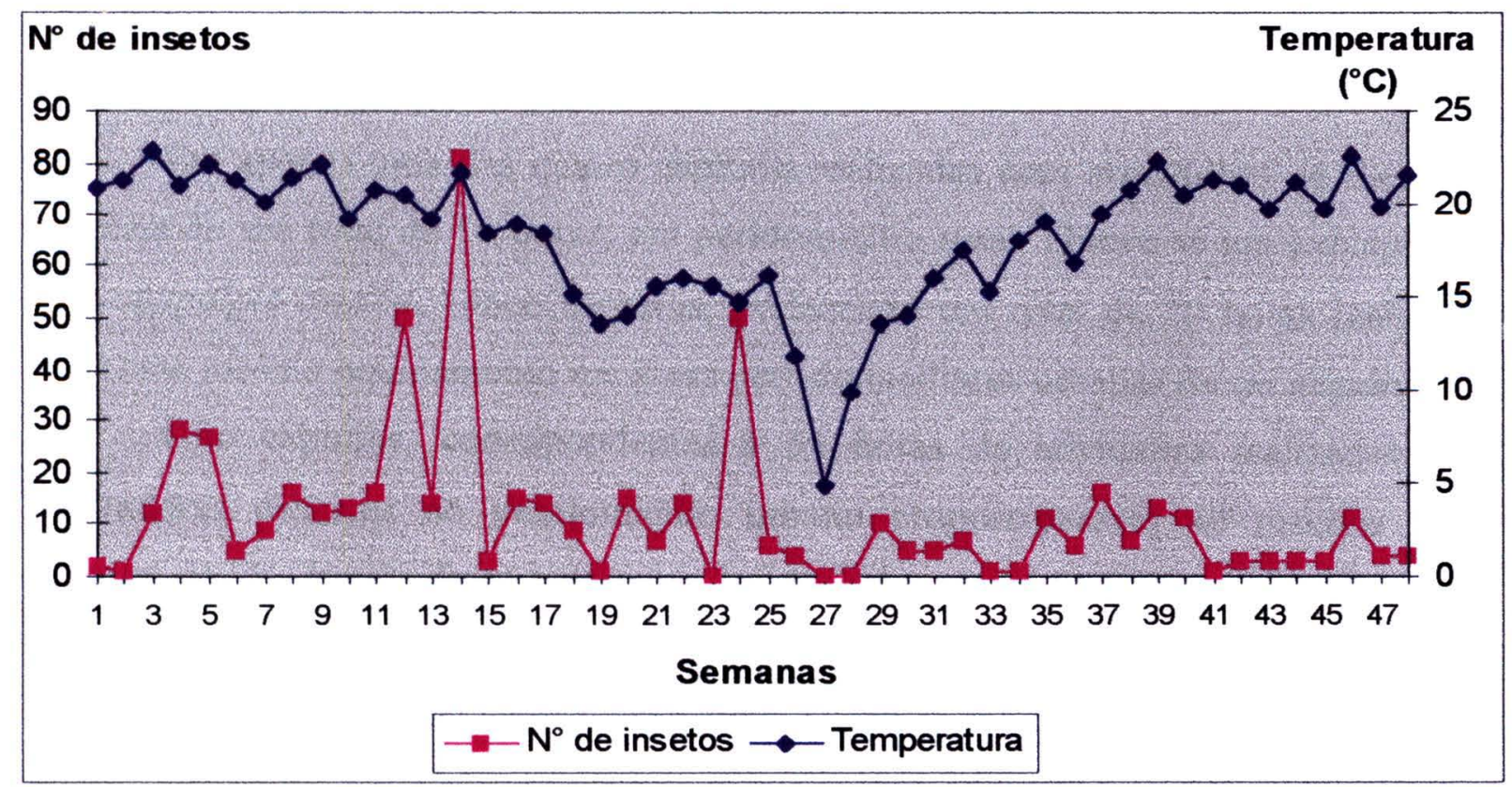

Figura 9 - Distribuição semanal de $L$. longipalpis capturados e temperatura $\left({ }^{\circ} \mathrm{C}\right)$. Mirandópolis (SP), 2000.

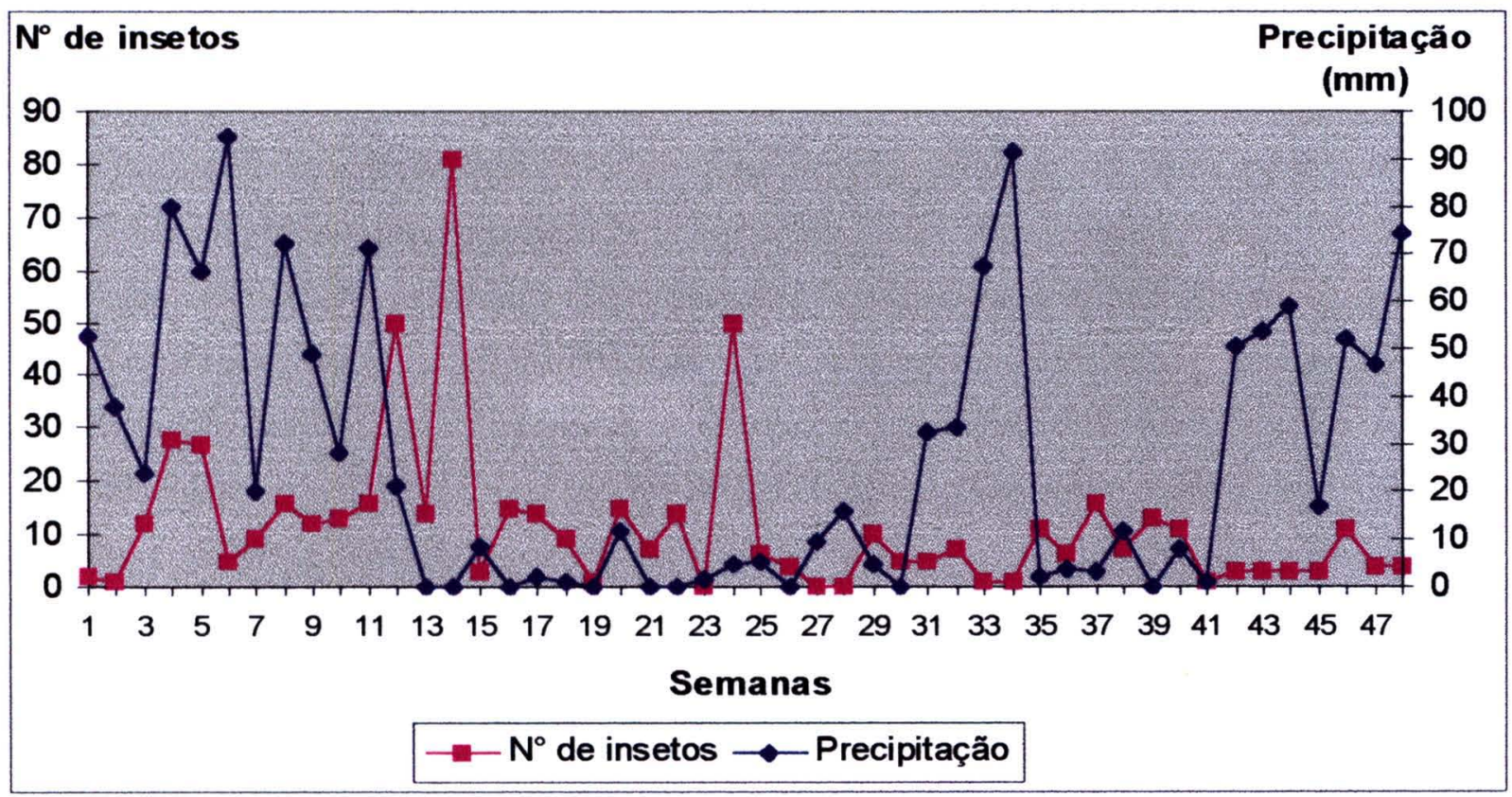

Figura 10 - Distribuição semanal de L. longipalpis capturados e precipitação pluviométrica $(\mathrm{mm})$. Mirandópolis (SP), 2000. 


\section{1. 2 Captura de flebotomíneos com armadilhas de Shannon e aspiradores automáticos}

Em apenas uma das quatro capturas realizadas com armadilhas de Shannon, perfazendo um total de 16 horas, em peridomicílio rural, obteve-se um exemplar de L. longipalpis macho. Cinco capturas, perfazendo um total de 20 horas realizadas com esse mesmo equipamento em áreas peri-domiciliares urbanas foram negativas.

Oito capturas, correspondentes a 64 horas de atividades realizadas com aspiradores elétricos no peridomicílio urbano proporcionaram 40 machos e 19 fêmeas de $L$. longipalpis, entretanto, a despeito do esforço despendido com a realização de 6 capturas executadas simultaneamente, com operadores utilizando aspiradores em bovinos, suínos, aves (Figuras 11 a 13) e cães, que totalizaram 96 horas de trabalho nenhum exemplar de flebotomíneo foi obtido na zona rural.

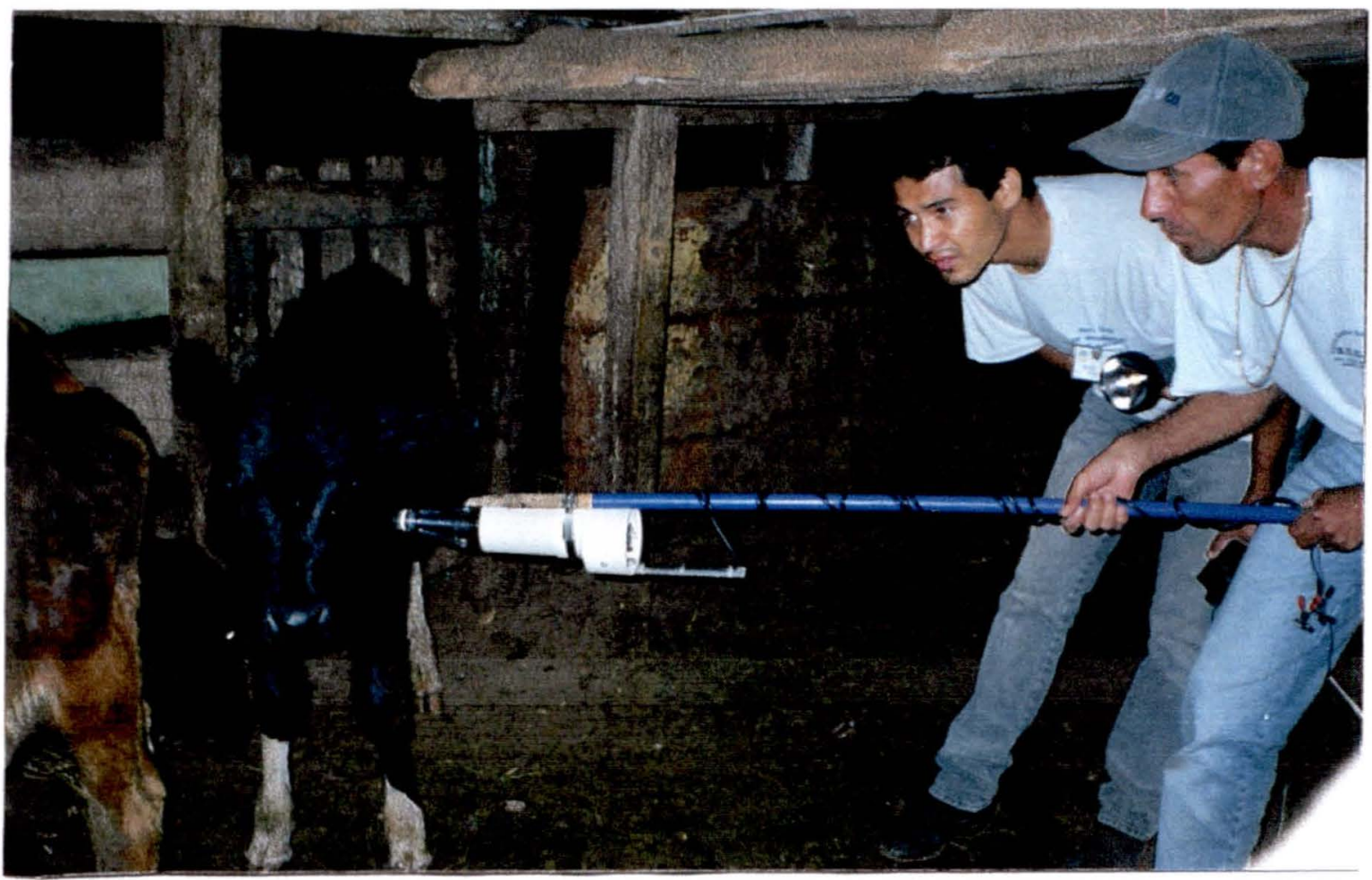

Figura 11 - Captura de flebotomíneos com aspiradores diretamente sobre bovinos. 


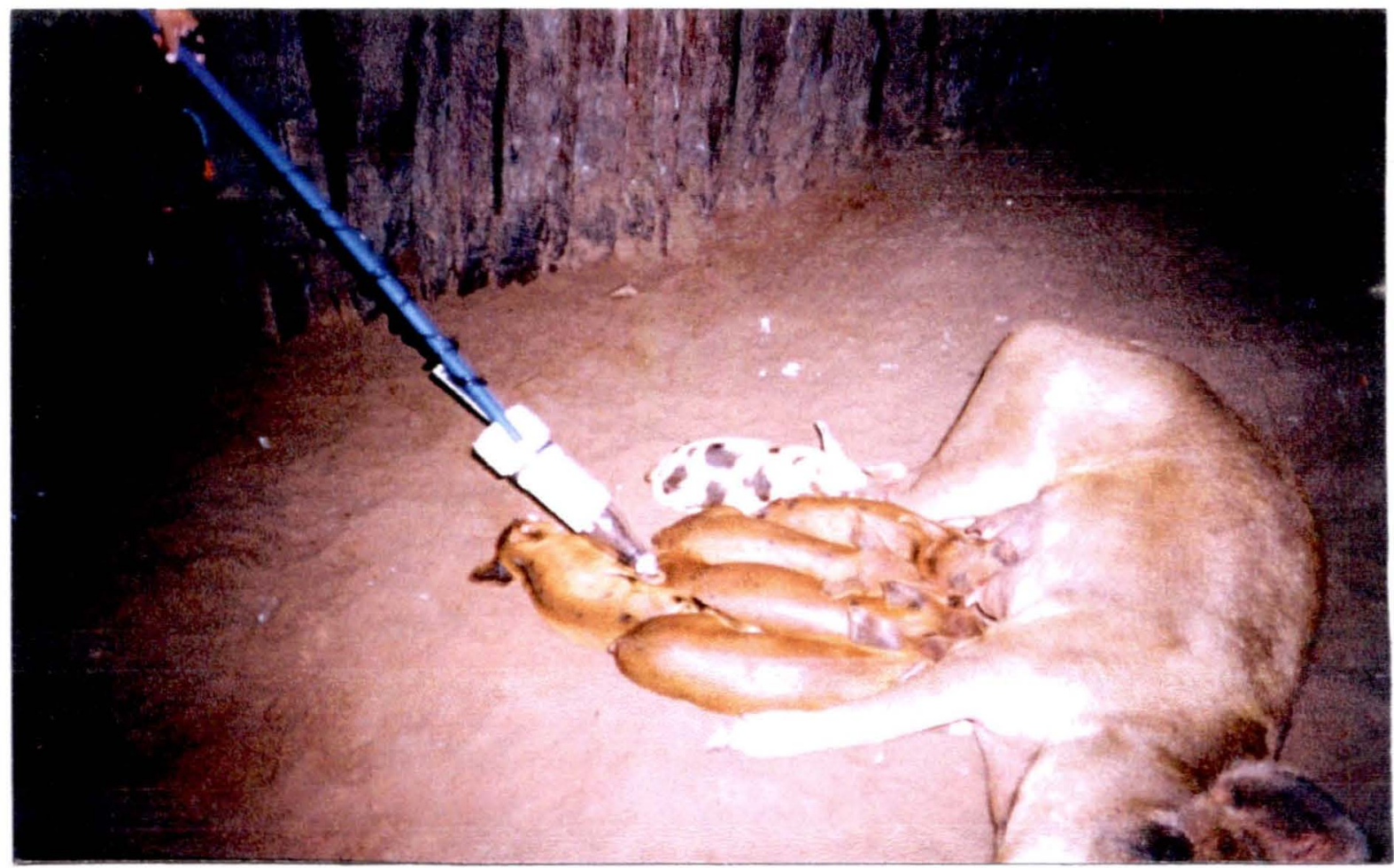

Figura 12 - Captura de flebotomíneos por aspiração direta sobre suínos.

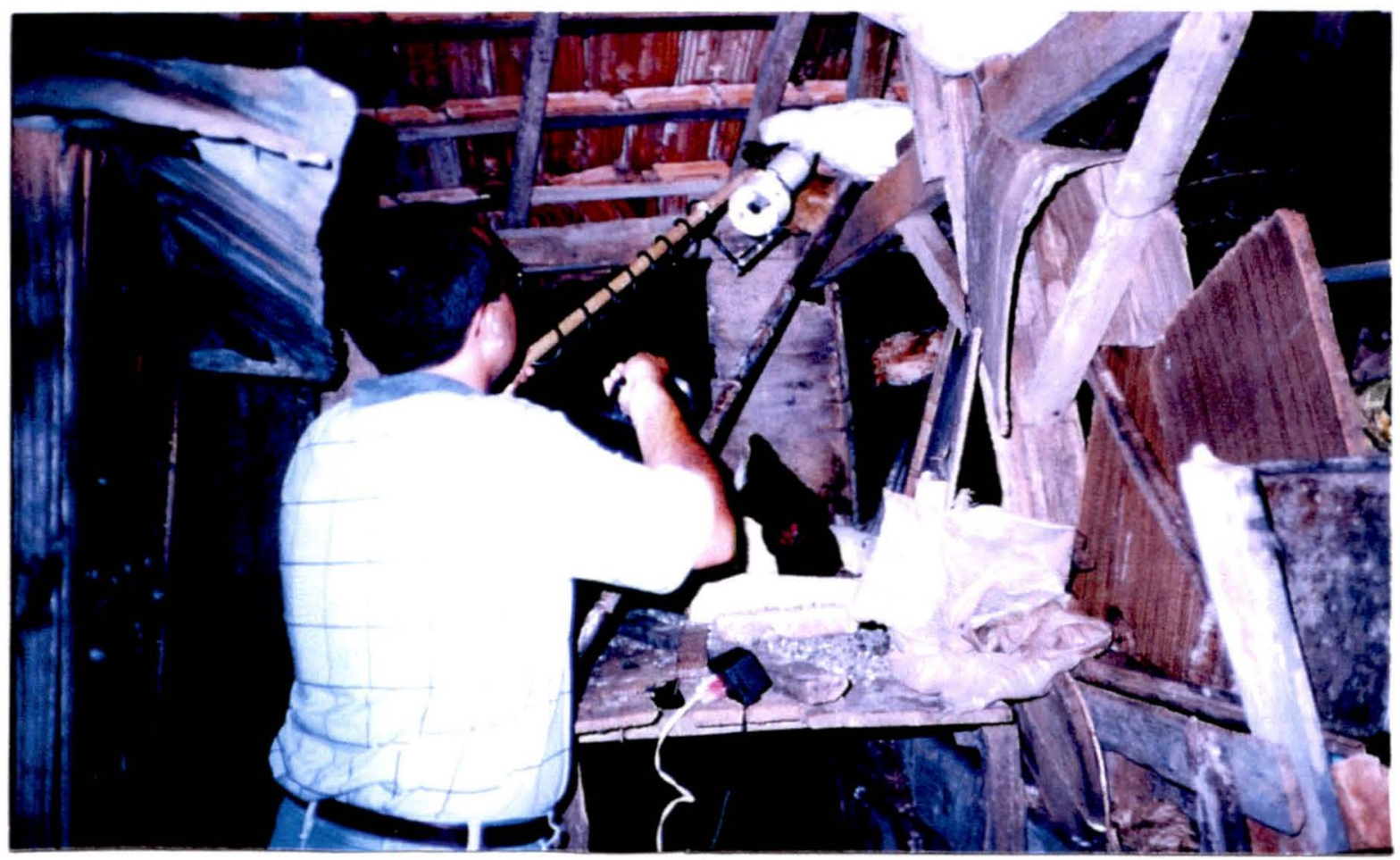

Figura 13 - Captura de flebotomíneos com aspiradores em aves. 


\section{1. 3 Investigação do índice de infecção natural de flebotomíneos por flagelados.}

Todas as 19 fêmeas de L. longipalpis capturadas com aspiradores elétricos foram dissecadas e nenhuma apresentou formas flagelares no tubo digestivo. Uma delas apresentou um nematódeo, provavelmente de filarídeo (Anexo 6).

\section{2 Dados dos reservatórios}

A prevalência da leishmaniose visceral canina para o município de Mirandópolis pôde ser estimada em 1,7\% (10 positivos em 603 cães examinados) através do inquérito realizado. Esse dado, juntamente com outros resultados obtidos estão mais detalhadamente distribuídos nas Tabelas 6 a 8 .

Após cerca de trinta dias dos exames laboratoriais, dos 10 animais sorologicamente positivos identificados pelo teste de imunofluorescência indireta, 5 $(50,0 \%)$ (Pernipá, Tita, Ju, Dara e Lupe) se encontravam em aparente estado de perfeita saúde, não apresentando nenhuma alteração ao exame físico que pudesse suspeitar de leishmaniose visceral. Nem mesmo a linfadenomegalia e alterações dermatológicas, consideradas como dois dos principais sintomas da leishmaniose visceral (FEITOSA et al. 2000) pôde ser constada, nessa oportunidade, nesses animais.

Para confirmação dos resultados, os animais reagentes, foram reexaminados pelo IFI. Desta feita, porém, as amostras de soro sanguíneo foram obtidas após a centrifugação de sangue venoso colhido da veia cefálica ou jugular para a titulação do nível de anticorpos anti-Leishmania. Todos as amostras foram reagentes na diluição 1:40 ou superior, cujos valores dos títulos foram de 40 (Pernipá), 160 (Lupe e Dara) e 320 (Tita e Ju).

Examinadas pelo teste Elisa, essas amostras tiveram a positividade para leishmaniose visceral também confirmada.

Quanto aos outros cinco animais positivos detectados pelo inquérito sorológico, dois não puderam ser localizados, dois haviam sido encaminhados para 
Tabela 6 - Número e percentual de cães examinados pelo teste de imunofluorescência indireta segundo sexo e resultado do teste de associação

\begin{tabular}{cccccccc}
\hline & \multicolumn{3}{c}{ Teste de imunofluorescência indireta } & \multicolumn{3}{c}{ Total } \\
Sexo & \multicolumn{2}{c}{ Positivo } & \multicolumn{2}{c}{ Negativo } & & \\
& $\mathrm{N}$ & $\%$ & $\mathrm{~N}$ & $\%$ & $\mathrm{~N}$ & $\%$ & \\
\hline Macho & 5 & 1,5 & 340 & 98,5 & 345 & 100,0 & ns \\
Fêmea & 5 & 1,9 & 253 & 98,1 & 258 & 100,0 & \\
Total & 10 & 1,7 & 593 & 98,3 & 603 & 100,0 & \\
\hline
\end{tabular}

${ }^{\mathrm{ns}}$ não significativo ao nível de $5 \%$ pelo teste exato de Fisher $(\mathrm{p}>0,05)$

Tabela 7 - Número e percentual de cães examinados pelo teste de imunofluorescência indireta segundo procedência e resultado da significância do teste de associação

\begin{tabular}{cccccccc}
\hline & \multicolumn{3}{c}{ Teste de imunofluorescência indireta } & \multicolumn{3}{c}{ Total } \\
Procedência & \multicolumn{2}{c}{ Positivo } & \multicolumn{2}{c}{ Negativo } & & \\
& $\mathrm{N}$ & $\%$ & $\mathrm{~N}$ & $\%$ & $\mathrm{~N}$ & $\%$ & \\
\hline Urbano & 9 & 1,8 & 488 & 98,2 & 497 & 100,0 & ns \\
Rural & 1 & 0,9 & 105 & 99,1 & 106 & 100,0 & \\
Total & 10 & 1,7 & 593 & 98,3 & 603 & 100,0 & \\
\hline
\end{tabular}

${ }^{\text {ns }}$ não significativo ao nível de $5 \%$ pelo teste exato de Fisher $(p>0,05)$

Tabela 8 - Número e percentual de cães com dono e errantes examinados pelo teste de imunofluorescência indireta, e resultado da significância do teste de associação

\begin{tabular}{ccccccccc}
\hline & \multicolumn{3}{c}{ Teste de imunofluorescência indireta } & \multicolumn{3}{c}{ Total } \\
Cão & \multicolumn{2}{c}{ Positivo } & \multicolumn{2}{c}{ Negativo } & & & \\
& $\mathrm{N}$ & $\%$ & $\mathrm{~N}$ & $\%$ & $\mathrm{~N}$ & $\%$ & \\
\hline Com dono & 9 & 1,53 & 578 & 98,47 & 587 & 100,00 & ns \\
Errante & 1 & 6,25 & 15 & 93,75 & 16 & 100,00 & \\
Total & 10 & 1,66 & 593 & 98,34 & 603 & 100,00 & \\
\hline
\end{tabular}

${ }^{n s}$ não significativo ao nível de $5 \%$ pelo teste exato de Fisher $(p>0,05)$ 
eutanásia por seus proprietários por estarem caquéticos, depressivos e com alterações dermatológicas sugestivas de leishmaniose visceral e, o último deles, veio a óbito por causa desconhecida e, aparentemente, segundo o seu proprietário, sem ter apresentado qualquer sinal indicativo de leishmaniose visceral.

\section{3 Comparação do teste de imunofliuorescência indireta e Elisa}

Amostras de soro sangüíneo de 28 cães errantes e de 34 cães doados pelos seus proprietários foram examinadas pelo teste de imunofluorescência indireta e pelo Elisa.

Dos 20 animais soropositivos por pelo menos uma das provas empregadas, quatro $(20,0 \%)$ apresentavam sinais indicativos de leishmaniose visceral. Dois animais encontravam-se em péssimo estado geral, apresentando-se extremamente caquéticos, e com úlceras no abdome e membros. Os outros dois apresentavam um quadro avançado e generalizado de demodiciose e edema de patas. Todos os demais animais soropositivos (16/20) identificados nessa amostra, apresentavam um estado geral de regular para bom, sem apresentar nenhum sinal sugestivo de doença.

Os resultados dos exames sorológicos realizados com o emprego de ambas as técnicas, além de permitir a identificação de novos animais doentes para as tentativas de isolamento de Leishmania possibilitaram a comparação de seus resultados os quais encontram-se discriminados na Tabela 9.

Tabela 9 - Número e percentual de cães examinados pelo Elisa e pelo teste de imunofluorescência indireta e resultado da significância do teste de McNemar. Mirandópolis (SP), 2000

\begin{tabular}{cccccccc}
\hline Teste de & \multicolumn{3}{c}{ Teste de Elisa } & \multicolumn{3}{c}{ Total } \\
$\begin{array}{c}\text { Imunofluorescência } \\
\text { Indireta }\end{array}$ & \multicolumn{2}{c}{ Positivo } & \multicolumn{2}{c}{ Negativo } & \multicolumn{2}{c}{} \\
\hline Positivo & 7 & 11,29 & 0 & 0,00 & 7 & 11,29 & $*$ \\
Negativo & 13 & 20,97 & 42 & 67,74 & 55 & 88,71 & \\
Total & 20 & 32,26 & 42 & 67,74 & 62 & 100,00 & \\
\hline
\end{tabular}

* significativo ao nível de $5 \%$ pelo teste McNemar $(p<0,05)$ 
Comparando-se o IFI e Elisa observa-se para o primeiro teste:

Sensibilidade $(\mathrm{S})=7 / 20=35,0 \%$
Especificidade $(\mathrm{E})=42 / 42=100,0 \%$
Valor Preditivo Positivo $\left(\mathrm{VP}^{+}\right)=7 / 7=100,0 \%$
Valor Preditivo Negativo $\left(\mathrm{VP}^{-}\right)=42 / 55=76,4 \%$

\section{4 Colheita de material de gambás}

Ao longo do período de estudo, colheitas de sangue de cinco didelfideos capturados em quintais de residências localizadas na cidade foram efetuadas. Os animais apresentavam um bom estado geral e aparentemente estavam saudáveis, não apresentando nenhum sintoma de doença.

As amostras dos soros sanguíneos obtidos dos gambás encontram-se armazenadas a $-20{ }^{\circ} \mathrm{C}$ no Laboratório de Imunologia do Centro de Controle de Zoonoses de São Paulo e deverão ser examinadas através do IFI, de maneira análoga à utilizada com as amostras dos cães, utilizando-se, porém, conjugado anti-didelfideo preparado pelo mesmo laboratório o qual dispõe de tecnologia própria para tanto.

As amostras de sangue total encontram-se armazenadas a $-20{ }^{\circ} \mathrm{C}$ no Laboratório de Bioquímica do Curso de Medicina Veterinária da Faculdade de Odontologia de Araçatuba para serem processadas pela técnica da reação em cadeia de polimerase ou Polymerase Chain Reaction (PCR), assim que as mesmas estejam ajustadas e disponiveis.

\section{5 Dados do agente}

Treze dos 30 cães sorologicamente positivos identificados pelo teste de imunofluorescência indireta e/ ou pelo teste de Elisa foram necropsiados. Regra geral, as lesões macroscópicas mais evidentemente observadas foram a hepato- 
esplenomegalia e linfoadenomegalia, porém não foram realizadas observações necroscópicas mais acuradas, por fugirem do escopo desse trabalho.

As tentativas de isolamento de Leishmania a partir da inoculação de órgãos dos cães soropositivos diretamente em meio artificial foram infrutiferas. Em alguns tubos a contaminação fúngica se fez presente e as pesquisas realizadas no sétimo dia pós-semeadura não evidenciaram a presença do protozoário.

Nos hamsters inoculados com o pool de órgãos dos cães soropositivos não foi observada nenhuma alteração, como caquexia ou ascite, que fosse indicativa de infecção por Leishmania.

Após aproximadamente 6 meses, duas estirpes de Leishmania puderam ser isoladas, em conseqüência da semeadura de exsudato peritoneal dos hamsters inoculados com pool de órgão dos cães soropositivos.

Uma estirpe era originária de um cão não reagente ao IFI e outra de um animal reagente a ambos os testes utilizados.

As formas amastigotas do parasito estavam contidas no interior de macrófagos (Figura 14) ou disseminadas pelo interstício das células hepáticas ou esplênicas (Figura 15) de hamsters do modelo biológico empregado.

As formas promastigotas flagelares, observadas no meio artificial (Figura 16) e em cultura pura, foram encaminhadas para o Laboratório de Biologia Molecular de Tripanosomatideos do Instituto de Ciências Biomédicas da USP, tendo sido identificadas, molecularmente, como Leishmania (L.) chagasi. 


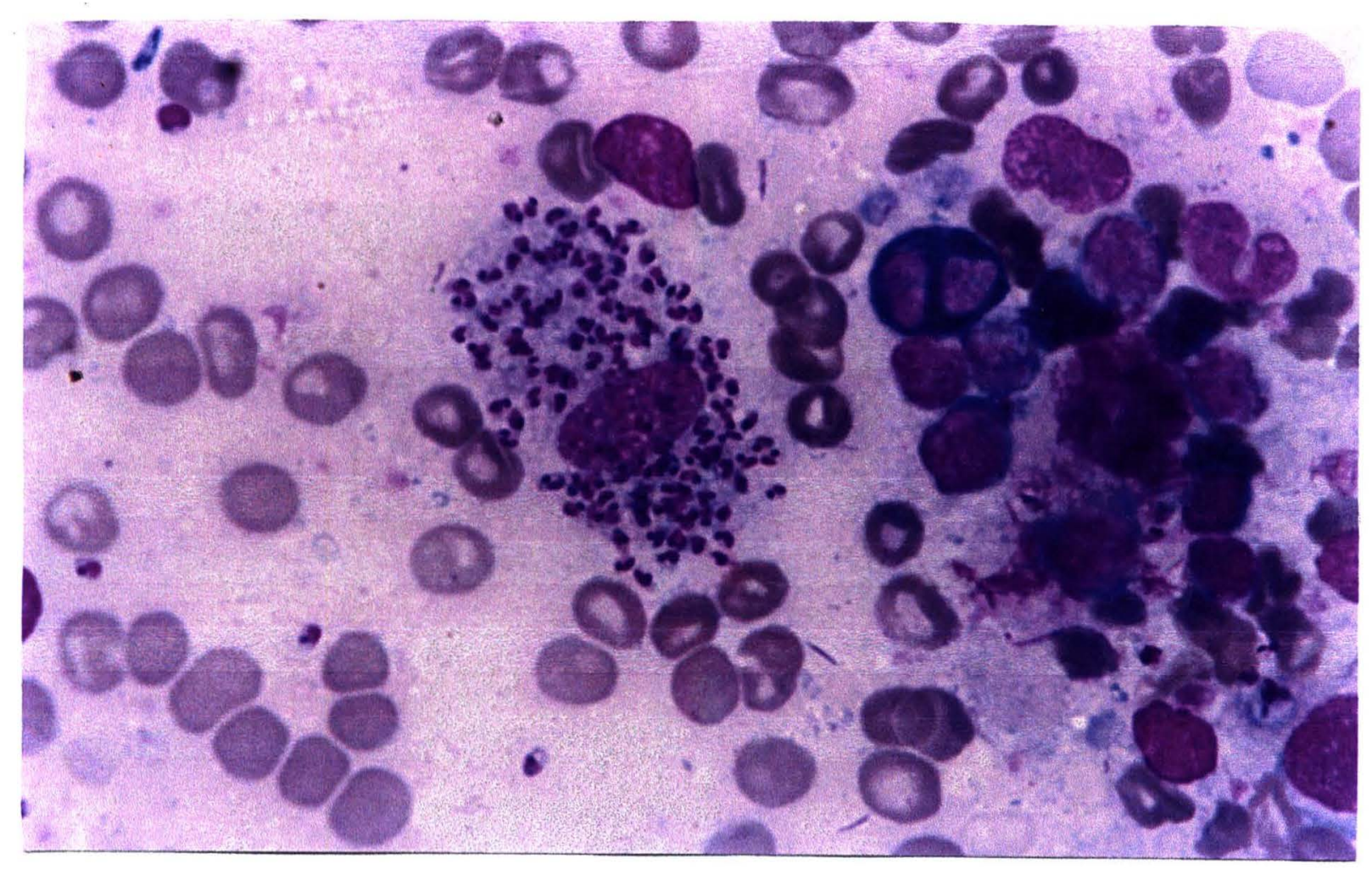

Figura 14 - Formas amastigotas de Leishmania observadas no interior de citoplasma de macrófago em decalque de baço de hamster. (Coloração diferencial aumento de 1000 vezes).

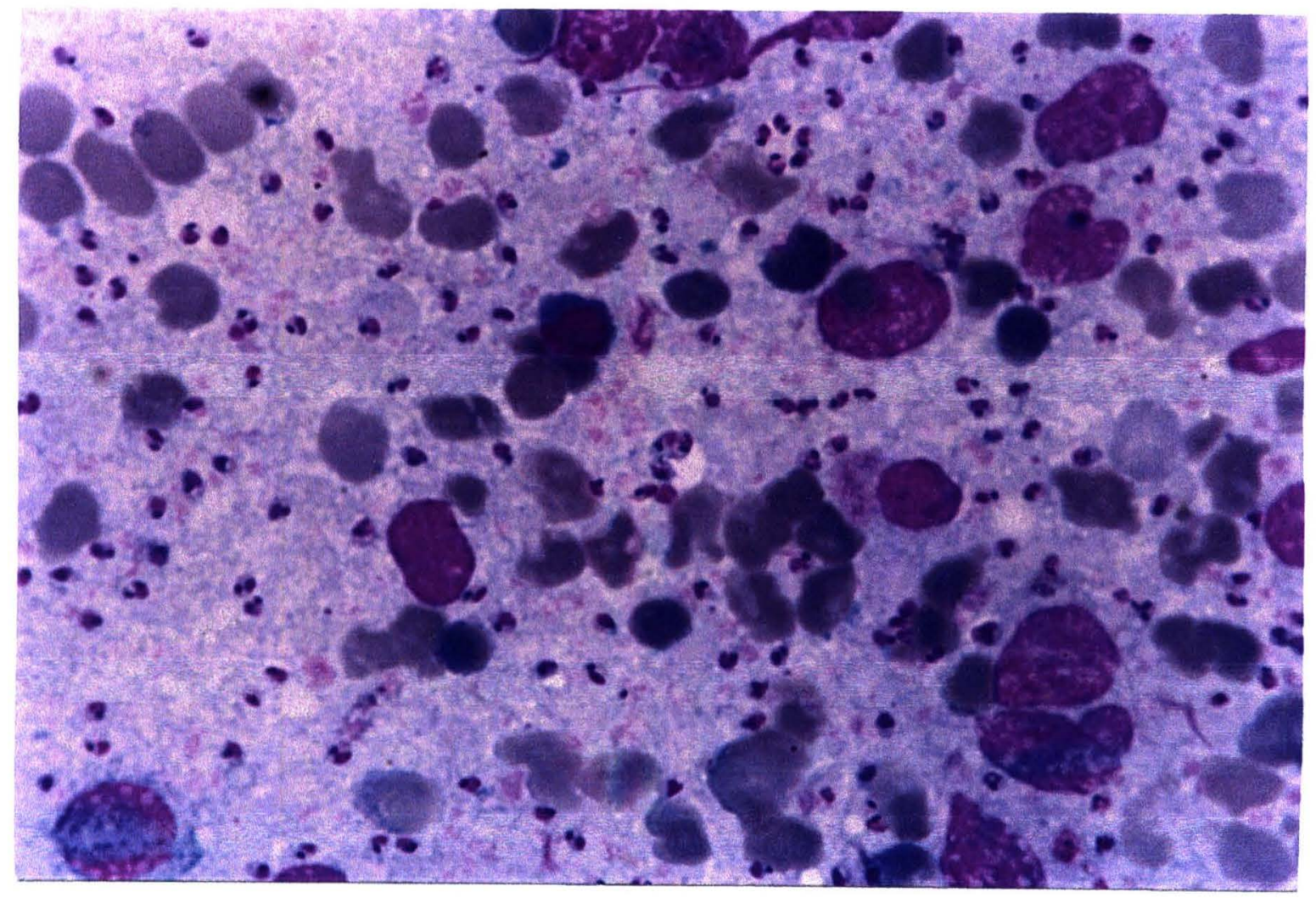

Figura 15 - Formas amastigotas de Leishmania dispersas no interstício de células esplênicas observadas em decalque de baço de hamster. (Coloração diferencial - aumento de 1000 vezes). 


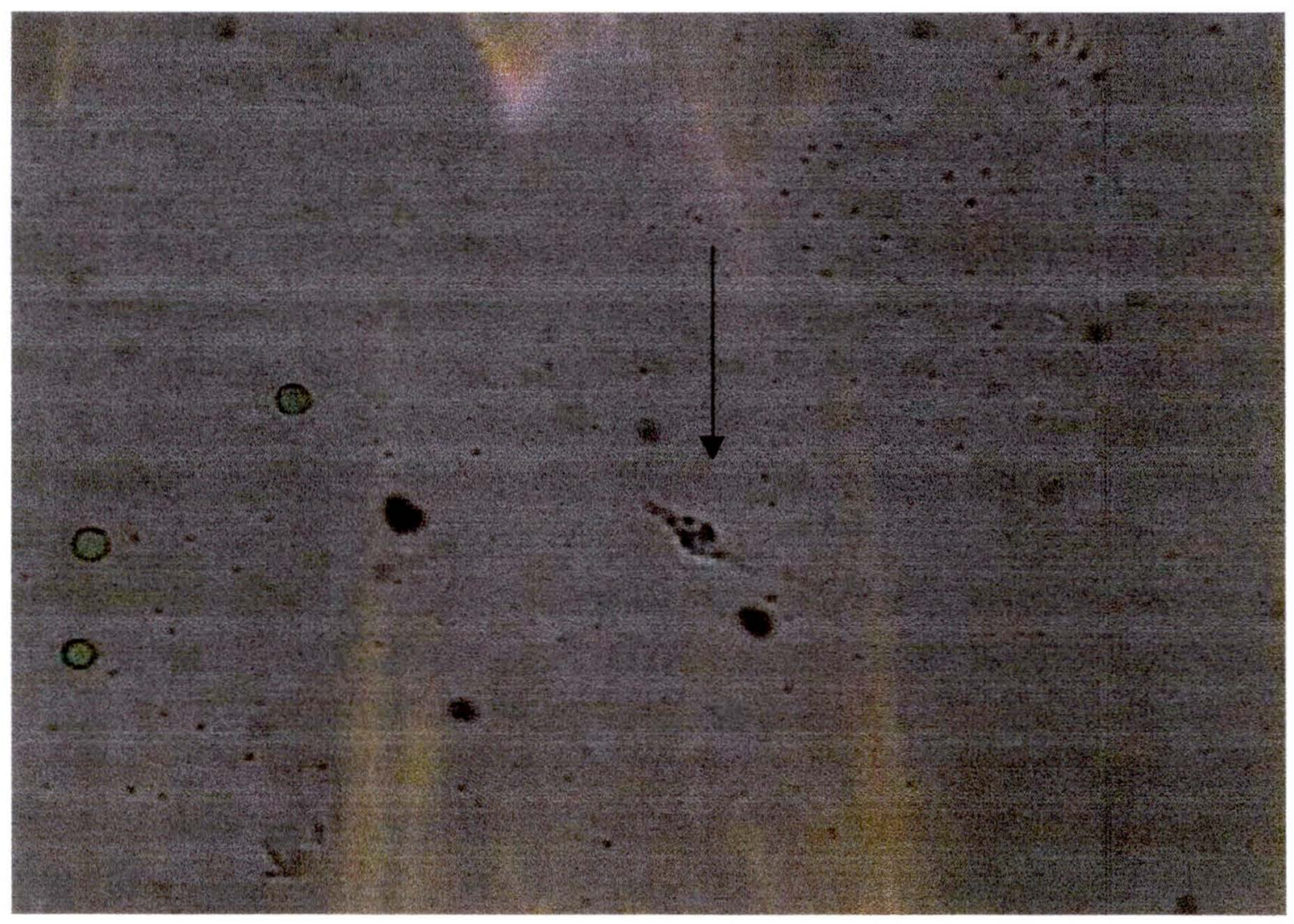

Figura 16 - Forma promastigota de Leishmania observada em preparado de meio de cultura em lâmina de microscopia. (Aumento de 400 vezes). 


\section{DISCUSSÃO}

Dentre as principais medidas preconizadas para o controle da leishmaniose visceral, encontram-se indicações aplicáveis ao tratamento das pessoas acometidas, à identificação e eliminação de cães soropositivos e o controle de vetores com uso de inseticidas, em áreas de transmissão (MONTEIRO et al. 1994). Essas medidas, quando aplicadas de maneira harmônica e contínua durante um longo período, podem manter a parasitose sob controle (MAGALHÃES et al. 1980), entretanto, o avanço da leishmaniose visceral para grande parte do território nacional e a eficiência dos programas de controle tem sido motivo de grande preocupação das autoridades sanitárias (COSTA e VIEIRA 2001).

Com relação aos vetores, estudos sobre a dinâmica das formas aladas dos flebotomíneos podem contribuir para a implementação de medidas dirigidas ao seu controle.

As armadilhas automáticas luminosas em miniatura têm sido empregadas em pesquisas entomológicas realizadas em áreas florestais (AGUIAR et al. 1985; ARIAS e FREITAS 1982; BARROS et al. 2000; CHANIOTIS et al. 1971) e em ambientes rurais antrópicos (DOURADO et al. 1989; RYAN e BRAZIL 1984), sendo seu uso mais restrito no meio urbano, em virtude da interferência luminosa ambiental que podem sofrer nesse ambiente (GALATI et al. 1997).

Embora o uso exclusivo das armadilhas em miniatura não possibilite um amplo conhecimento sobre o comportamento dos flebotomíneos, com o seu emprego por um período contínuo relativamente longo, e com capturas semanais, pôde se ter uma idéia aproximada desse comportamento na área estudada.

Durante todo o ano, nas armadilhas luminosas automáticas instaladas sistematicamente durante 528 oportunidades, apenas em duas ocasiões foram capturados exemplares de flebotomíneos de espécies diversas de L. longipalpis, constatando-se, dessa maneira, a ampla predominância dessa espécie entre os componentes da subfamília Phlebotominae na área estudada.

Aparentemente, os machos podem ser mais atraídos quando o método de captura com armadilhas luminosas é empregado, sobretudo em áreas domiciliares, peridomiciliares e em abrigos de animais domésticos. A razão macho/ fêmea de $-, 1: 1$ 
obtida pode ser considerada condizente com o encontrado por outros pesquisadores (XIMENES et al. 1999) quando também utilizaram armadilhas luminosas em abrigos de animais domésticos

Lutzomyia longipalpis foi capturada em todos os meses do período de estudo e, pelo teste de correlação, pôde-se observar que a temperatura se constituiu num fator influente na densidade do flebotomíneo $(r=0,4019)$ sendo os periodos mais quentes do ano mais favoráveis ao vetor.

No Brasil, desde há muito tempo se reconhece a tendência de L. longipalpis predominar no período chuvoso. Isto tem sido constatado em áreas endêmicas da Região Nordeste, como no Ceará (DEANE 1956), na Bahia (SHERLOCK e GUITON 1969) e no Maranhão (REBÊLO 2001). Também, no Mato Grosso do Sul (GALATI et al. 1997), no Rio de Janeiro (AGUIAR e SOUCASAUX 1984) e em São Paulo (BARRETTO 1943), os flebotomíneos tendem a se apresentar com densidade mais elevada nos períodos mais quentes e úmidos do ano. Na presente oportunidade, a correlação da densidade do diptero com a precipitação pluviométrica não foi estatisticamente significativa, entretanto, observaram-se dois picos, em março ( $12^{\mathrm{a}}$ semana) e abril ( $14^{\mathrm{a}}$ semana) que ocorreram após um período contínuo de chuvas, o que está de acordo com padrão brasileiro. Um terceiro pico, ocorrido no mês de junho ( $24^{a}$ semana) foge desse padrão e, provavelmente, sua ocorrência tenha sido determinada por outros fatores (Figuras 9 e 10). A esse respeito, vale lembrar que além da precipitação pluviométrica e da temperatura, fatores endógenos, suprimento alimentar das formas imaturas bem como ausência de inimigos naturais provavelmente exerçam influência na densidade dos flebotomíneos e, quando passam a atuar em sinergismo, podem resultar em uma explosão da população alada (GALATI et al. 1997). Esse fenômeno pôde ser observado por ocasião das coletas com aspiradores automáticos, quando após a realização de capturas realizadas em um mesmo local em dias seguidos, entre noites com rendimento nulo ou muito baixo, de no máximo, 2 exemplares, obteve-se em uma única oportunidade, um rendimento de 44 exemplares de flebotomíneos.

De acordo com NASCIMENTO et al. (1999) os fatores de risco associados à infecção humana estão muito nitidamente relacionados ao contato homem-vetor, levando à suposição de que o combate ao vetor seja, potencialmente, mais efica? que 
um programa de eliminação de reservatórios domésticos. Por outro lado, a medida para eliminação do cão pela prova sorológica positiva permanece sendo assunto controvertido, haja vista a coprevalência homem/cão não provir argumento convincente para existência da transmissão direta do cão para o homem (ASHFORD et al. 1998). O enfoque deve abranger também os flebotomíneos, e assim, a sazonalidade da população é enfatizada, a qual influencia a manutenção da transmissão, mesmo diante da eliminação parcial de cães soropositivos. Com base nessas observações e nos resultados ora obtidos, é recomendável que, na eventualidade de serem aplicadas medidas profiláticas para a leishmaniose visceral dirigidas ao controle químico do vetor no município, as aplicações de inseticidas de longo poder residual, para o combate das formas aladas, seriam mais eficazes se efetuadas entre os meses de abril e maio, logo após a ocorrência dos dois primeiros picos observados no primeiro semestre do ano. No segundo semestre, as densidades do flebotomíneo foram mais baixas.

A presença de L. longipalpis foi constatada durante todos os meses do ano tanto no meio rural como no urbano e as condições climáticas foram favoráveis praticamente durante todo o ano.

Esses achados revelam, portanto, que o vetor tem encontrado um ambiente favorável ao seu desenvolvimento, a ele se adaptando com facilidade, tanto no ambiente domiciliar como nas áreas peridomiciliares urbanas $(\mathrm{z}=0,3472)$ aumentando a possibilidade de transmissão de Leishmania em todo o município.

Uma maior preferência de L. longipalpis por aves do que pelo homem foi verificada através de metodologia que utiliza a aspiração direta sobre animal contido em gaiolas (AGUIAR et al. 1987). Mais recentemente, no Mato Grosso do Sul, NUNES et al. (2001) constataram uma maior atração exercida pelos suínos sobre $L$. longipalpis, seguidos pelos cavalos, sendo a espécie menos atraída pelo homem e pelo cão.

Na presente avaliação da atração exercida pelo homem e animais domésticos sobre L. longipalpis, não foram encontradas diferenças estatisticamente significativas para o homem, boi, cão, porco e galinha. Infere-se, portanto, que o ecletismo do seu hábito alimentar, indiretamente demonstrado, lhe assegura fartas e diferentes fontes 
de alimento em virtude dos vários criatórios de bovinos, suínos e aves existentes principalmente nas áreas periféricas da cidade.

Nos três pontos urbanos de captura do presente estudo, parte da área peridomiciliar era utilizada para a criação de galináceos, fato comum observado nas residências urbanas, não apenas de Mirandópolis, como em várias cidades do interior paulista. Embora as aves não sejam reconhecidas como reservatórios de Leishmania, elas fornecem alimento e seus locais de criação podem se constituir em criadouros e abrigos para flebotomíneos.

Em regiões endêmicas, o risco de ocorrência de leishmaniose visceral é quatro vezes ampliado, em residências onde a criação de galináceos é praticada (RODRIGUES 1999). Diante disso, julga-se válido incluir nas campanhas de educação sanitária de controle e prevenção da leishmaniose visceral municipal, medidas aplicáveis a essa situação, com o objetivo de desestimular a prática de criar galinhas, principalmente quando as condições determinam o acúmulo de fezes e de matéria orgânica que favorecem ainda mais o desenvolvimento de flebotomíneos.

Durante a execução de medidas de combate direto ao vetor, a recomendação de se estender a borrifação de casas com inseticidas também aos abrigos de animais em áreas endêmicas (RODRIGUES 1999) deve merecer uma avaliação quanto a sua eficácia e aplicabilidade também em áreas de ocorrência recente de leishmaniose visceral humana ou canina, como é o caso da região noroeste paulista. Cabe ressaltar que esta recomendação encontra respaldo nas preconizações recentemente emitidas pelo Comitê de Assessores do Ministério da Saúde e técnicos da Fundação Nacional da Saúde (COSTA e VIEIRA 2001).

Os rendimentos das capturas de flebotomíneos com o emprego de armadilha de Shannon tanto no meio rural como na área urbana foram praticamente nulos. A esse respeito, informações pessoais da Prof . Eunice Aparecida Bianchi Galati, dão conta de que o resultado ora obtido não chega a ser surpreendente, pois ao longo da Serra da Bodoquena, Estado do Mato Grosso do Sul, durante 2 anos em 156 horas de exposição foram capturados apenas 13 machos e 2 fêmeas. Entretanto, outros fatores podem ter influenciado como a duração e o número das capturas realizadas. Quanto à 
aspiração em animais, possivelmente as fêmeas, por estarem sugando, sejam menos vulneráveis à ação do fluxo de ar dos aspiradores.

O principal objetivo da utilização dessas modalidades de captura de flebotomíneos foi obter fêmeas vivas e íntegras para investigar a presença de flagelados, uma vez que o produto das capturas com armadilhas luminosas em miniatura, na maioria das vezes, resultou em exemplares mortos, desidratados e/ou danificados

Os melhores resultados foram obtidos com a utilização, em noites seguidas, de aspiradores elétricos sobre paredes e anteparos de áreas peridomiciliares urbanas, notadamente em residências onde havia sido identificada a presença de cão soropositivo e/ou a positividade para L. longipalpis já tivesse sido anteriormente confirmada através de capturas com armadilhas luminosas em miniatura.

Dessa maneira, o rendimento proporcionado pelo emprego de aspiradores elétricos manuais, isoladamente, permitiu a pesquisa de formas flageladas de Leishmania em 19 fềmeas de L. longipalpis obtendo-se um índice de infecção natural nulo, o que de certa forma é esperado, tendo-se em vista que em Corumbá e Ladário, área considerada como hiperendêmica para a leishmaniose visceral, observou-se um indice de infecção natural para a L. chagasi em Lutzomyia cruzi de 0,39\% (SANTOS et al. 1998), implicando na necessidade do exame de pelo menos 250 fềmeas do vetor. Todavia, os resultados das coletas permitem inferir que o método de captura direta com aspiradores em paredes e anteparos, realizada em noites sucessivas, e em locais com a presença de L. longipalpis confirmada deva ser o preferido, entre os métodos presentemente praticados, para a obtenção de fêmeas íntegras para investigações do índice de infecção natural por flagelados ou estudos semelhantes.

A real importância do homem e dos outros hospedeiros na cadeia de transmissão da leishmaniose visceral se constitui numa das mais importantes lacunas a serem preenchidas para o completo entendimento do complexo eco-epidemiológico característico dessa enfermidade no Brasil (SHERLOCK 1996). Além do homem, particularmente crianças desnutridas, canídeos silvestres e marsupiais têm sido demonstrados como fontes de infecção de $L$. chagasi, o que faz ressaltar a necessidade de se desenvolver pesquisas para se esclarecer quais são de fat $c$ as 
principais fontes de $L$. chagasi para a população humana (COSTA e VIEIRA 2001). A presença do cão no domicílio não se constitui em fator de risco associado à ocorrência de leishmaniose visceral em áreas endêmicas (NASCIMENTO et al. 1999) e a importância do cão doméstico como reservatório da leishmaniose no Brasil tem sido redimensionada (COSTA 1997; COSTA et al. 1999).

Na região estudada, o gambá é a espécie de mamífero silvestre mais freqüentemente observada nas proximidades das moradias tanto urbanas como rurais. No presente estudo, não foi possível investigar a eventual infecção natural desses animais por Leishmania, entretanto, considerando a importância que eles possam adquirir como reservatórios silvestres e fontes de infecção para os flebotomíneos, amostras de material obtido de cinco animais capturados puderam ser armazenadas. Somente após a realização de provas sorológicas e moleculares, poder-se-á confirmar ou não a presença da infecção por Leishmania nesses animais.

Com relação à infecção de cães por Leishmania, no presente estudo, não foi observada associação da leishmaniose com o sexo, o que está de acordo com NOLI (1999) e BANDEIRA et al. (1999), não havendo diferença estatisticamente significativa na positividade entre cães machos e fêmeas, positividade esta estabelecida tanto pelo teste de imunofluorescência como pelo teste de Elisa.

Uma maior predisposição racial de cães a algumas afecções são conhecidas como a displasia coxo-femural em animais de raças de grande porte como o Pastor Alemão, Fila brasileiro, Dogue Alemão e Rottweiler. Dálmatas tendem a ser mais atingidos por cálculos vesicais de urato do que animais de outras raças. Semelhantemente, cães das raças Boxer e Beagle são mais predispostos a neoplasias e cães Cocker Spaniel sofrem mais de seborréias oleosas do que animais de outras raças, segundo informações pessoais da Prof Luciane Biazzono do Curso de Medicina Veterinária de Araçatuba/ Universidade Estadual paulista - UNESP.

Entretanto, a maior susceptibilidade de cães de raça à infecção por Leishmania já sugerida (LIMA e BEZERRA 1999, BANDEIRA et al. 1999) não pôde ser verificada nesta oportunidade uma vez que a maior parte dos animais estudados era composta de cães sem raça definida. As informações sobre esse quesito fornecidas pelos proprietários, leigos em sua grande maioria, não foram consideradas confiáveis, julgando-se sensato não considerá-las. 
A taxa de positividade de 1,7\% (10 animais positivos em 603 examinados) estimada pelo inquérito canino com o emprego do teste de imunofluorescência indireta, pode ser considerada baixa quando comparada com a soroprevalência obtida por outros autores. NUNES et al. (1988) examinaram 481 cães em Corumbá, Estado do Mato Grosso do Sul obtendo um percentual de positividade de $8,7 \%$. Nesse mesmo Estado, SANTOS et al. (1998) obtiveram a taxa de 24,0\% em Corumbá e Ladário. Em Cuiabá, Mato Grosso, região de foco recente de leishmaniose canina, MOURA et al. (1999) examinaram 62 animais, verificando um índice de reagentes de $64,5 \%$. Mais recentemente, uma taxa de positividade de $64,6 \%$ para a leishmaniose canina foi verificada na região metropolitana de Belo Horizonte por SILVA et al. (2001) e NUNES et al. (2001) estabeleceram em 23,7\% a positividade da parasitose em cães na serra da Bodoquena no Mato Grosso do Sul, ambas as taxas nitidamente superiores à obtida nesta oportunidade.

A taxa de soros caninos reagentes em Mirandópolis, foi inferior também a de 26,3\% constatada em Araçatuba por GALLIMBERTI et al. (1999), situada na mesma região noroeste do Estado de São Paulo, onde se localiza o município estudado, porém, sendo superior a $1,0 \%$, permite a indicação de medidas dirigidas à eliminação de cães positivos, de acordo com MONTEIRO et al. (1994).

$\mathrm{Na}$ presente situação, acredita-se que a taxa obtida através do teste de imunofluorescência indireta, possa se aproximar da real situação, podendo ser utilizada como indicador da prevalência da leishmaniose visceral canina no município. A possibilidade de ocorrência de reações cruzadas com outras tripanosomíases, restrição mencionada por COSTA (1991), aqui não é inteiramente aplicável, uma vez que não existem casos conhecidos de doença de Chagas em cães no município, sendo improvável a ocorrência de superposição dessa enfermidade com a leishmaniose na região estudada, que poderia resultar numa superestimação da prevalência da leishmaniose visceral canina.

Por outro lado, existem cães na região citologicamente positivos para Leishmania que, quando examinados sorologicamente através do teste de Elisa, apresentam resultados negativos. Isso pode estar ocorrendo por fatores ligados a uma não resposta ou resposta insuficiente do sistema imunológico à infecção por $L$. chagasi ou a doença se encontra em um estágio tão inicial que a produção de 
anticorpos ainda é insuficiente para atingir o limiar de detecção do teste empregado. Essa possibilidade já foi confirmada, de acordo com informações pessoais da Prof ${ }^{a}$. Valéria Marçal Felix de Lima, do Curso de Medicina Veterinária de Araçatuba/ UNESP, entretanto, não se pode eliminar a possibilidade de ocorrência de outra espécie de Leishmania. $\mathrm{O}$ isolamento e a tipificação de cepas de Leishmania a partir de cães infectados, poderá contribuir para um melhor esclarecimento a esse respeito

Em ambos estudos sorológicos realizados, a positividade entre cães errantes não diferiu significativamente da verificada entre cães com dono, fato que permite inferir que animais de ambas categorias estejam igualmente expostos ao risco de infecção por Leishmania. Entretanto, cães sem dono e aqueles criados livremente com amplo acesso às ruas podem ser mais responsabilizados como disseminadores de leishmaniose visceral do que os residentes, que permanecem as maiores partes do tempo nas áreas domiciliares.

Essas considerações são cabíveis também para outras zoonoses de natureza infecciosa ou parasitária transmitidas ao homem pelos cães, o que leva a pensar na necessidade de se desenvolverem projetos educativos, com enfoque na posse responsável de animais de estimação, especialmente o cão, com especial abordagem dos riscos de transmissão de doenças de importância em saúde publica. Exames parasitológicos realizados em amostra de 54 cães nessas condições, revelaram uma positividade de $74,0 \%$ para ancilostomíase e $14,8 \%$ toxocariase, cujos agentes etiológicos em seus estágios larvários provocam no homem, especialmente em crianças, os quadros clínicos conhecidos por larva migrans cutânea e larva migrans visceral, respectivamente, corroboram essa afirmativa.

Nesse sentido, deve-se considerar que o serviço desenvolvido pelo Canil Municipal, principalmente o referente à retirada das ruas de cães que vivem soltos deva ser valorizado pelas autoridades, apesar da antipatia que provoca em parte da população.

A constatação da infecção por Leishmania em cão de zona rural e também a presença do vetor nesse ambiente, indicam que a parasitose não se limita à área urbana. Esses achados, portanto, se constituem num alerta para que as ações dos programas de controle e prevenção da doença atinjam também a área rural, onde 
geralmente o acesso aos serviços públicos é mais restrito e as condições socioeconômicas dos habitantes inferiores às dos moradores da área urbana.

A despeito da elevada especificidade do IFI $(100,0 \%)$ demonstrada no presente trabalho, o valor preditivo negativo do teste foi relativamente baixo. O IFI teve seus resultados concordantes com o Elisa em apenas 35,0\%, o que está em consonância com o obtido por BRAGA et al. (1999), que encontraram uma percentual de concordância de $31,8 \%$ entre O IFI e o Elisa. Ademais, das duas estirpes de $L$. chagasi isoladas de órgãos de cães, uma era proveniente de um cão soropositivo para o Elisa e não reagente pelo IFI.

Essas considerações, aliadas à elevada proporção de cães portadores de anticorpos contra Leishmania que não apresentam sintomas indicativos, de 63,2\% (MARZOCHI et al. 1985), 20,0\% a 40\% segundo NOLI (1999), de 68,0\% (SILVA et al. 2001) e de, no mínimo, 70,0\% no presente estudo, ressaltam a necessidade de utilização de técnicas ou de combinações de técnicas mais sensiveis e específicas para a identificação da leishmaniose visceral na população canina.

O comitê de assessores do Ministério da Saúde e técnicos da Fundação Nacional da Saúde, nas mudanças sugeridas para o programa de controle da leishmaniose visceral no Brasil, indica que as ações não devem ser centralizadas na eliminação de cães, por uma série de fatores (COSTA e VIEIRA 2001), entretanto, a identificação de cães infectados por $L$. chagasi através de exames sorológicos, continua sendo de relevante importância epidemiológica

No presente trabalho, o Elisa se revelou significativamente mais sensivel que o IFI e, diante dos resultados obtidos, a aplicação desse teste nos futuros inquéritos sorológicos de cães torna-se recomendável, para que uma avaliação da prevalência da leishmaniose canina, mais próxima da realidade seja obtida, permitindo, sobretudo, um melhor acompanhamento da evolução da parasitose na área.

O superior desempenho do teste de Elisa em relação ao IFI, verificado no presente trabalho, permitiu corrigir a taxa de positividade obtida no inquérito sorológico realizado com o emprego do IFI, elevando-a de 1,7\% para 4,8\%, de acordo com AHLBOM e NORELL (1990). Assim, essa taxa de positividade deve estar mais próxima da prevalência real. 
Portanto, a identificação da real prevalência da leishmaniose visceral canina no município, contribuirá, desde que satisfeitos outros quesitos, para com a tomada de decisão no desencadeamento de ações dirigidas ao controle do vetor, pois ultrapassa 2,0\%, valor estabelecido pelos serviços estaduais de saúde, como limite para tanto (SECRETARIA DE ESTADO DA SAÚDE 2000). Todavia, pesquisas contínuas sobre o comportamento do vetor são necessárias para o norteamento dessas ações. As armadilhas em miniatura têm sido um dos métodos eleitos para o estudo dos flebotomíneos. O rendimento médio (1,4 flebotomíneo/captura) proporcionado pela utilização das armadilhas em miniatura na área urbana foi superior ao das armadilhas instaladas no meio rural ( 0,5 flebotomíneo/captura), resultado que permite indicar a utilização dessas armadilhas para um monitoramento da população de vetores no município, tendo em vista que são de baixo custo e podem ser manipuladas pelo próprio morador. Instaladas em pontos estratégicos da cidade teriam a sua utilização supervisionada por um órgão de controle local.

Embora não tenham sido realizados estudos das formas imaturas dos flebotomíneos, supõe-se que os seus criadouros se localizem nos quintais, em locais de acúmulo de matéria orgânica decorrente da decomposição de flores, frutos, folhas e excrementos de animais. Com a presença do flebotomíneo assinalada em toda a área urbana do município, há a necessidade de se investigar os locais de criadouros e abrigos desses dípteros, com vistas às medidas de controle dessas populações, principalmente as ligadas ao manejo ambiental, tendo em vista que a aplicação de inseticida de eficácia comprovada (FALCÃO et al. 1988) não tem se mostrado eficaz quando aplicado no peridomicílio (FALCÃO et al. 1991). 


\title{
6 CONCLUSÕES
}

\author{
Considerando:
}

- a ocorrência constante e disseminada do vetor no ambiente domiciliar e peridomiciliar tanto da área urbana como da rural, favorecido pelas condições climáticas locais;

- a constatação da enfermidade em cães errantes e domiciliados da área urbana e da zona rural;

- a taxa de positividade estabelecida pelo inquérito sorológico canino de $1,7 \%$, que pode estar subestimada em virtude da baixa sensibilidade do teste de imunofluorescência, o qual apresentou um baixo valor preditivo negativo quando comparado ao teste de Elisa;

- a confirmação da presença do agente etiológico obtida através de isolamento a partir de órgãos de cães sorologicamente positivos;

Conclui-se que, com relação aos principais elos da cadeia de transmissão da leishmaniose visceral, as condições de possibilidade de transmissão para os habitantes do município de Mirandópolis encontram-se presentes com perigo de endemicidade para a população humana.

A investigação da evolução da prevalência da infecção canina da leishmaniose visceral deve ser apoiada pelo menos em dois testes sorológicos, que podem ser o IFI e Elisa.

As medidas de controle voltadas para as formas aladas dos vetores devem ser ancoradas em pesquisa contínua sobre a ocorrência dos mesmos em pontos estratégicos da cidade, com o uso de armadilhas automáticas luminosas que podem ser instaladas pelos próprios moradores e monitoradas pelos órgãos técnicos.

Há necessidade de se conhecer os criadouros e abrigos naturais dos vetores para que se possa desencadear medidas de controle dos flebotomíneos, sobretudo por meio de manejo ambiental. 


\section{REFERÊNCIAS BIBLIOGRÁFICAS}

Aguiar GM, Vilela ML, Schuback PA, Soucasaux T, Azevedo ACR. Aspectos da ecologia dos flebótomos do Parque Nacional da Serra dos Órgãos, Rio de Janeiro. IV. Freqüência mensal em armadilhas luminosas (Diptera, Psychodidae, Phlebotominae). Mem Inst Oswaldo Cruz 1985; 80 : 465-82.

Aguiar GM, Vilela ML, Lima RB. Ecology of the sandflies of Itaguaí, an area of cutaneous leishmaniasis in the state of Rio de Janeiro. Food preferences (Diptera, Psychodidae, Phlebotominae). Mem Inst Oswaldo Cruz 1987; 82 (4): $583-584$.

Aguiar G M, Souzacasaux T. Aspectos da ecologia dos flebótomos do Parque Nacional da Serra dos Órgãos, Estado do Rio de Janeiro. 1. Freqüência mensal em isca humana (Diptera, Psychodidae, Phlebotominae). Mem Inst Oswaldo Cruz 1984; 79: 197-200.

Aguilar CM, Rangel EF, Grimaldi Jr G, Momen H. Alta freqüência de leishmaniose tegumentar canina em foco endêmico no Estado do Rio de Janeiro, Brasil. Mem Inst Oswaldo Cruz 1987; 82 (Suppl I): 56.

Ahlbom A, Norell S. Introduction to modern epidemiology. $2^{\text {nd }}$ ed. Stockholm: Epidemiology Resources Inc.; 1990.

Alencar JE. Leishmaniose visceral no Brasil. Rev Med Univ Fed Ceará 1978; 17-18: 129-48.

Alencar JE. Profilaxia do Calazar no Ceará, Brasil. Rev Inst Med Trop $1961 ; 3: 175-80$. 
Arias JR, Freitas RA. On the vetors of cutaneous leishmaniais in the Central Amazon of Brazil. 3. Phlebotominae sand fly stratification in a terra firme forest. Acta Amazonica 1982; 12: 599-608.

Arias JR, Monteiro PS, Zicker F. The reemergence of visceral Leishmaniasis in Brazil. Emerging Infectious Diseases 1996; 2 (2): 145-6.

Arias JR, Naiff RD, Miles MA, Souza AA. The opossum Didelphis marsupialis (Marsupialia: Didelphidae) as a reservoir host of Leishmania braziliensis guyanensis in the Amazon Basin of Brazil. Trans R Soc Trop Med Hyg 1981; 75: 537-41.

Ashford DA, David JR, Freire M, David R, Sherlock I, Eulálio MC, Sampaio DP, Badaró R. Studies on control of visceral leishmaniasis: impact of dog control on canine and human visceral leishmaniais in Jacobina, Bahia, Brazil. Am Soc Trop Med Hyg 1998; 59: 53-7.

Badaró R, Jones TC, Carvalho EM, Sampaio D, Reed SG, Barral A, Teixeira R, Johnson Jr. WD. New perspectives on a subclinical form of visceral leishmaniasis. J Infect Dis 1986; 154: 1003-1011.

Bandeira GG, Tellez CCC, Nascimento EG, Carvalho LCP, Moreira Junior ED. Estudo de corte transversal de fatores de risco para leishmaniose visceral canina numa área endêmica em Jequié, Bahia, Brasil. Rev Soc Bras Med Trop 1999; 32:9.

Barreto MP. Observações sobre a biologia, em condições naturais, dos flebótomos no Estado de São Paulo (Diptera, Psychodidae); 1943. [Tese de Livre-Docência, São Paulo - Faculdade de Medicina, Universidade de São Paulo] 
Barreto AC, Vexenat JA, Cassia AC, Rosa AC, Cuba-Cuba AC, Lago E et al. Epidemiological study of cutaneous leishmaniasis in equines from na endemic area of the state of Bahia, Brazil. Mem Inst Oswaldo Cruz 1986; 81 (Suppl): 63.

Barros VLL, Rebelo JMM, Silva FS. Flebotomíneos (Diptera, Psychodidae) de capoeira do Município do Paço do Lumiar, Estado do Maranhão, Brasil. Área de transmissão de leishmaniose. Cad Saúde Pública 2000; 16 (1): 265 270.

Braga DMM, Bezerra CF, Braga AS, Pacheco HV, Pompeu LM, Gomes NAT. Estudo comparativo da pesquisa direta do parasito com testes sorológicos no diagnóstico do calazar no cão. Rev Soc Bras Med Trop 1999; $32: 215$

Cerf BJ, Jones TC, Badaró R, Sampaio D, Carvalho EM, Rocha H, Teixeira R, Johnson Jr. WD. Malnutrition as a risk factor for severe visceral leishmaniasis. J Infect Dis 1987; 156: 1030-2.

Chagas E, Cunha AM, Ferreira LC, Deane L, Deane G, Guimarães FN, Von Paumgartten MJ, Sá B. Leishmaniose Visceral Americana (Relatório dos trabalhos realizados pela Commissão encarregada do estudo da Leishmaniose Visceral Americana em 1937). Mem Inst Oswaldo Cruz 1938; 33: 89-229.

Chaniotis BN, Neely JM, Correa MA, Tesh RB, Johnson KM. Natural population dynamics of phlebotominae sandflies in Panama. J. Med Entomol $1971 ; 8: 339-52$.

Cipa Group. Disponível em $<\underline{\text { URL }}$ http $/ /$ cipa.snv.jussieu.fr. 
Christensen HA, Arias JR, de Vasques AM, Freitas RA. Hosts of sand flie vectors of Leishmania braziliensis guyanensis in the Central Amazon of Brazil. Am J Trop Med Hyg 1982; 31: 239-42.

Corredor A, Gallego JF, Tesh RB, Morales A, Ferro De Carrasquilla C, Young DG et.al. Epidemiology of visceral leishmaniasis in Colombia. Am J Trop Med Hyg 1989; 40 (5): 480-486.

Costa AIP, Casanova C, Rodas LAC, Galati EAB. Atualização da distribuição geográfica e primeiro encontro de Lutzomyia longipalpis em área urbana no Estado de São Paulo, Brasil. Rev Saúde Pública 1997; 31 (6) 632-3.

Costa CA, Genaro O, Lana M, Magalhães PA, Dias M, Michalick MSM, Melo MN, Costa RT, Magalhães RNM, Mayrink W. Leishmaniose visceral canina: avaliação da metodologia sorológica utilizada em inquéritos epidemiológicos. Rev Soc Bras Med Trop 1991; 24: 21-25.

Costa CHN. Are dogs important reservoirs of visceral leishmaniasis in Brazil? Rev Soc Bras Med Trop 1997; 30 (Supl I): 155-57.

Costa CHN, Vieira JBF. Mudanças no controle da leishmaniose visceral no Brasil. Rev Soc Med Trop 2001; 34(2): 223-228.

Costa CHN, Pereira HF, Pereira FCA, Tavares JP, Araújo MV, Gonçalves MJO. Is the household dog a risk factor for American visceral leishmaniasis in Brazil? Trans R Soc Trop Med Hyg 1999; 93:464.

Costa Lima A. Sobre os flebótomos americanos (Diptera: Psychodidae) Mem Inst Oswaldo Cruz 1932; 26:15-69. 
Deane LM Leishmaniose visceral no Brasil. Estudos sobre reservatórios e transmissores realizados no Estado do Ceará. Rio de Janeiro: Serviço Nacional de Educação Sanitária; 1956.

Deane LM, Deane MP. Observações preliminares sobre a importância comparativa do homem, do cão e da raposa (Lycalopex vetulus) como reservatórios de Leishmania donovani em área endêmica de calazar no Ceará. Hospital 1955; 48: 61-76.

Deane LM, Deane MP. Visceral leishmaniasis in Brazil: geographical distribution and transmission. Rev Inst Med Trop 1962; 4: 198-212.

Deane LM, Deane MP. Encontro de Leishmania nas vísceras e na pele de uma raposa em zona endêmica de calazar, nos arredores de Sobral. Hospital $1954 ; 45: 419-421$

Deane MP e Deane LM. Infeç̧ão experimental do Phlebotomus longipalpis em raposa (Lycalopex vetulus) naturalmente infectada pela L. donovani. Hospital 1954; 46:651-653.

Dedet JP. Leishmania et leishmanioses du continent américan. Ann Inst Pasteur/ actual 1993; 4 (1): 3-25.

Dourado MIC, Noronha CV, Alcântara N, Ichihara MY, Loureiro S. Epidemiologia da leishmaniose tegumentar americana e suas relações com a lavoura e o garimpo, em localidade do Estado da Bahia (Brasil). Rev Saúde Pública $1989 ; 23: 2-8$.

Falcão AR, Pinto CT, Gontijo CMF. Susceptibility of Lutzomyia longipalpis to deltamethrin. Mem Inst Oswaldo Cruz 1988; 83 (3): 395-396. 
Falcão AL, Falcão AR, Pinto CT, Gontijo CMF, Falqueto A. Effect of deltamethrin spraying on the sandfly populations in a focus of american cutaneous leishmaniasis. Mem Inst Oswaldo Cruz 1991; 86 (4): 399-404.

Falqueto A, Varejão JBM, Sessa PA. Cutaneous leishmaniasis in a horse (Equus caballus) from endemic area in the state of Espírito Santo, Brazil. Mem Inst Oswaldo Cruz 1987; 82: 443.

Falqueto A, Sessa PA, Varejão JBM, Barros GC, Momen H, Grimaldi Jr G. Leishmaniasis due to Leishmania braziliensis in Espirito Santo state, Brazil. Further evidence on the role of dogs as a reservoir of infection for humans. Mem Inst Oswaldo Cruz 1991; 86: 449-500.

Feitosa MM, Ikeda FA, Luvizotto MC, Perri SHV. Aspectos clínicos de cães com leishmaniose visceral no município de Araçatuba - São Paulo. Clin Vet $2000 ; 28: 36-44$.

Forattini OP. Entomologia médica. São Paulo: Edgard Blucher/ Editora da Universidade de São Paulo; 1973. v.4.

Forattini OP, Rabelo EX, Galati EAB. Novos encontros de flebotomíneos no Estado de São Paulo, Brasil, com especial referência a Lutzomyia longipalpis. Rev Saúde Pública 1976; 10:125-8.

Forattini OP, Rabelo EX, Pattoli, DBG. Sobre o encontro de Lutzomyia longipalpis (Lutz \& Neiva, 1912) no Estado de São Paulo. Rev Saúde Pública 1970; 4: 99-100.

Galati EAB. Phylogenetic systematics of Phlebotominae (Diptera, Psychodidae) with emphasis on American groups. Bol Dir Malariol y San Amb 1995; 35 (Suppl. 1): 133-142. 
Galati EAB, Nunes LV, Rego Jr FA, Oshiro ET, Rodrigues M. Estudo de flebotomíneos (Diptera, Psychodidae) em foco de leishmaniose visceral no Estado de Mato grosso do Sul, Brasil. Rev Saúde Publica 1997; 31 (4) 37890 .

Galati EAB, Nunes VLB, Dorval MEC, Cristaldo G, Rocha HC, Andrade RMG, Naufel G. Attractiveness of black Shannon trap for phlebotomines. Mem Int Oswaldo Cruz 2001; 96 (5): 641-647.

Galimbertti MZ, Camargo-Neves VLF, Rodas LAC, Casanova C, Costa, AI, Araujo MF et.al. Leishmaniose Visceral no Estado de São Paulo. Rev Soc Bras Med Trop 1999; 32:217.

Gomes AC. Perfil epidemiológico da leishmaniose tegumentar no Brasil. Anais Brasileiros de Dermatologia 1992; 67:55-60

Gomes AC. Controle, diagnóstico e tratamento da leishmaniose visceral (Calazar). Normas Técnicas. Brasília. Fundação Nacional da Saúde 1996

Grimaldi Jr G, Tesh RB. Leishmaniasis of New World: current concepts and implications for future research. Clin Microbiol Rev 1993; 6: 230-250.

Grimaldi Jr G, Tesh RB, Mcmahon-Pratt D. A review of the geographic distribuition and epidemiology of leishmaniasis in the new world. Am $\mathbf{J}$ trop Med Hyg 1989; 41:687-725.

Iversson LB, Camargo ME, Rocha e Silva EO, Cheffi PP, Barros JAC. Investigação epidemiológica de um caso de leishmaniose visceral autóctone da Grande São Paulo, Brasil. Rev Saúde Pública 1979; 15: 159-67. 
Iversson LB, Pires RBR, Ribeiro MA, Takeda AK, Escrivão A, Buralli GM Investigação epidemiológica de um novo caso de leishmaniose visceral ocorrido na Grande São Paulo, Brasil. Rev Saúde Pública 1982; 16: 205219.

Jacobs L, Melton ML. A procedure for testing meat samples for Toxoplasma with preliminary results of a survey of pork and beef sample. J Parasitol 1957; 42: 38-39.

Lainson R. Our present knowledge of the ecology and control of leishmaniasis in the Amazon region of Brazil. Rev Soc Bras Med Trop $1985 ; 18: 47-56$.

Lainson R, Shaw JJ, Lins ZC. Leishmaniasis in Brasil: IV. The fox Cerdocyon thous as a reservoir of Leishmania donovani in Pará State, Brazil Trans R Soc Trop Med Hyg 1969; 63:741-745.

Lainson R, Shaw JJ. Epidemiological considerations of the leishmaniasis with particular reference to the New World. In A.M. Fallis Ed. Ecology and Physiology of parasites. University of Toronto Press, 1971; 21-57.

Lainson R, Shaw JJ. Evolution, classification and geographical distribution. In: Peter W. Killick-Kendrick R.Ed. The leishmaniasis in biology and medicine. London, Academic Press; 1987. v. 1.

Lainson R, Shaw JJ. Leishmanis (Viammia) naiffi $s p$. a parasite of the armadillo, Dasypus novemcincuts (L.) in Amazonian Brazil. Ann Parsitol Hum Comp 1989; 64: 3-9.

Lainson R, Shaw JJ, Silveira FT, Souza AAA, Braga RR, Ishikawa EAY. The dermal leishmaiasis of Brazil, with special reference to the eco-epidemiology of the disease in Amazonia. Mem Inst Oswaldo Cruz 1994; 89: 435-43. 
Lima JWO, Bezerra AA. Susceptibilidade de cães de raça à infecção pela Leishmania chagasi. Rev Soc Bras Med Trop 1999; 32:33

Lutz A, Neiva A. Contribuição para o conhecimento das espécies do gênero Phlebotomus existentes no Brasil. Mem Int Oswaldo Cruz 1912; 4: 82-95.

Magalhães PA, Mayrink W, Costa CA, Melo MN, Dias M, Batista SM, Michalick MSM, Williams P. Calazar na Zona do Rio Doce - Minas Gerais. Resultados de medidas profiláticas. Rev Inst Med Trop 1980; 22 (4): 197 202.

Manson-Bahr PEC, Southgate BA, Harvey AEC. Development of kala-azar in man after inoculation with a Leishmania from a Kenya sandfly. Br Med J 1963; I: 1208-10.

Marzochi MCA, Coutinho SG, Souza W, Toledo LM, Grimaldi Jr G, Momen H, Pacheco RS, Sabroza PC, Souza MAS, Rangel Jr FB, Tramontano NC. Canine visceral leishmaniasis in Rio de Janeiro, Brazil. Clinical, parasitological, therapeutical and epidemiological findings. Mem Inst Oswaldo Cruz 1985; 80: 349-357.

Marzochi MCA, Marzochi KBF, Carvalho RW. Visceral leishmaniasis in Rio de Janeiro. Parasitol Today 1994; 10: 37-40.

Mello DA, Rego Jr. FA, Oshiro E, Nunes VLB. Cerdocyon thous (L.) (Carnivora, Canidae) naturally infected with Leishmania donovani chagasi (Cunha \& Chagas, 1937) in Corumbá (Mato Grosso do Sul State, Brazil). Mem Inst Oswaldo Cruz 1988; 83(2): 259.

Monteiro OS, Lacerda MM, Arias, JR. Controle da leishmaniose visceral no Brasil. Rev Soc Bras Med Trop 1994; 27 : 67-72. 
Monteiro Filho ELA. Biologia reprodutiva e Espaço Domiciliar de Didelphis albiventris em uma Área Perturbada na Região de Campinas, Estado de São Paulo (Mammalia-Marsurpialia). Campinas; 1987. [Dissertação de Mestrado - Instituto de Biologia da UNICAMP].

Morrison AC, Ferro C, Morales A, Tesh RB, Wilson ML. Dispersal of the sand fly Lutzomyia longipalpis (Diptera: Psychodidae) at an endemic focus of visceral leishmaniasis in Colombia. J Med Ent 1993; 30 (2): 427-435.

Moura ST, Fernandes CGN, Pandolpho VC, Rodrigues e Silva R. Diagnóstico de leishmaniose canina na área urbana do município de Cuiabá, Estado de Mato Grosso do Sul, Brasil. Braz J Vet Res Anim Sci [periódico on line] 1999; 36 (2). Disponível em URL: http.//www. scielo.br $>$ [2001 fev 4]

Nascimento MDSB, Viana GMC, Souza EC, Pereira ACS, Pereira VM, Oliveira MRB, Almeida PEA, Silva MH, Filho CSS et al. Fatores de risco da leishmaniose visceral em área urbana da Ilha de São Luís, Maranhão- Brasil. Rev Soc Bras Med Trop 1999; 32 (Suppl I) 229-230.

Natal D, Marucci D, Reis IM, Galati EAB. Modificação da armadilha CDC com testes para coletas de flebotomíneos (DIPTERA). Rev Bras Ent 1991; 35 (4): $697-700$.

Noli C. Leishmaniossis canina. Waltham Focus; 1999, 9 (2): 16-24.

Nunes VLB, Yamamoto YY, Rego Júnior FA, Dorval MEC, Galati EAB, Oshiro ET, Rodríguez, M. Aspectos epidemiológicos da leishmaniose visceral em cães de Corumbá, Mato Grosso do Sul. Pesq Vet Bras 1988, 8: $17-21$. 
Nunes VLB.Condicionantes para a transmissão de leishmanioses em assentamento agrícola do INCRA e adjacências, Planalto da Bodoquena, Estado de Mato Grosso do Sul, Brasil, 1998-1999. São Paulo, 2001. [Tese de Doutorado - Faculdade de Saúde Pública da USP].

Nunes VLB, Galati EAB, Nunes DB, Zinezzi RO, Savani ESMM, Ishikawa E, Camargo MCGO, D'Áuria SRN, Cristaldo G, Rocha HC. Ocorrência de leishmaniose visceral canina em assentamento agrícola no Estado de Mato Grosso do Sul, Brasil. Rev Soc Bras Med Trop 2001; 34 (3); 299-300.

Pirmez C, Coutinho SG, Marzochi MCA, Nunes MP, Grimaldi Jr G. Canine american cutaneous leishmaniasis: a clinical and immunological study in dogs naturally infected with Leishmania braziliensis braziliensis in na endemic area of Rio de Janeiro, Brazil. Am J Trop Med Hyg 1988; 38: 5258 .

Rangel EF, Souza NA, Wermelinger ED, Barbosa AF, Andrade CA. Biologia de Lutzomyia intermedia Lutz \& Neiva, 1912 e Lutzomyia longipalpis Lutz \& Neiva, 1912 (DIPTERA, PSYCHODIDAE), em condições experimentais. I. Aspectos da alimentação de larvas e adultos. Mem Inst Oswaldo Cruz 1986; $81(4): 431-8$.

Rebêlo JMM. Freqüência horária e sazonalidade de Lutzomyia longipalpis (Diptera: Psychodidae: Phlebotominae) na Ilha de São Luís, Maranhão, Brasil. Cad Saúde Pública 2001; 1: 221-227.

Riera C, Valladares JE, Gallego M, Aisa MJ, Castillejo S, Fisa R, Ribas N, Carrió $\mathrm{J}$ et al. Serological and parasitological follow-up in dogs experimentally infected with Leishmania infantum and treated with meglumine antimoniate. Veterinary Parasitoloy $1999 ; 84$ : 33-47. 
Rodrigues, AC, Santos AB, Feitosa LF, Santana CS, Nascimento EG, Moreira Jr ED. Criação peridomiciliar de galináceos aumenta o risco de leishmaniose visceral humana. Rev Soc Med Trop 1999; 32: 12.

Rosa AC, Cuba CC, Vexenat A, Barreto AC, Arsden PD. Predominance of Leishmania braziliensis braziliensis in the region of Tres Braços and Corte da Pedra, Bahia, Brazil. Trans R Soc Trop Med Hyg 1988; 82: 409-410.

Ryan L, Brazil RP. Leishmania infections in Lutzomyia longipalpis (Diptera: Psychodidae) on the Island of São Luis, Maranhão State, Brazil. Mem Inst Oswaldo Cruz 1984; 79: 383-4.

San Martin-Savani EM. Inquérito sorológico sobre leishmaniose tegumentar Americana em cães errantes do município de São Paulo, 1995 - 1996. São Paulo, 1998. [Dissertação (Mestrado) - Faculdade de Saúde Pública da Universidade de São Paulo].

Santos SO, Arias J, Ribeiro AL, Hoffmann MP, Freitas RA, Mallaco MAF. Incrimination of Lutzomyia cruzi as a vector of American visceral leishmaniasis. Med Vet Entomol 1998; 12:315-7.

SAS INSTITUTE. SAS/ stat software: changes and enhancements through release 6.12. Cary: Statistical Analysis Sistem Institute 1997.

Secretaria de Estado da Saúde de São Paulo/ Coordenação dos Institutos de Pesquisa. Leishmaniose visceral americana (Informe técnico); 2000.

Sherlock I. Ecological interactions of visceral leishmaniasis in the state of Bahia, Brazil. Mem Inst Oswaldo Cruz 1996; 97(6): 671-683. 
Sherlock IA. Interação ecológica da Lutzomyia longipalpis com a Leishmania chagasi na epidemiologia da leishmaniose visceral americana. Rev Soc Bras Med Trop 1994; 27 (Suppl 4): 579-82.

Sherlock IA, Guitton N. Observações sobre calazar em Jacobina, Bahia. IV. Variação horária e estacional de Phlebotomuns longipalpis. Rev Bras Malariol 1969, 21: 715-727.

Sherlock IA, Miranda JC, Sadigursky M, Grimaldi Jr G. Natural infection of the opossum Didelphis albiventris (Marsupialia, Didelphydae) with Leishmania donovani in Brazil. Mem Inst Oswaldo Cruz 1984; 79 (4): 511.

Silva ES, Gontijo CM, Pacheco RS, Brazil RP. Visceral leishmaniasis in Metropolitan Region of Belo Horizonte, MG, Brazil. Molecular characterization of canine and human isolates. Mem Inst Oswaldo Cruz 1997; 92 (Suppl I): 202.

Silva ES, Pirmez C, Gontijo CMF, Fernandes O, Brazil RP. Visceral leishmaniasis in the crab-eating for (Cerdocyon thous) in south-east Brazil. Veterinary Record 2000: 147: 421-422.

Silva ES, Gontijo CMF, Pacheco RS, Fiuza VOP, Brazil RP. Visceral leishmaniasis in the Metropolitan Region of Belo Horizonte, State of Minas Gerais, Brazil. Mem Inst Oswaldo Cruz 2001; 96 (3): 285-291.

Silveira FT, Lainson R, Shaw JJ, Povoa MM. Leishmaniasis in Brazil: XVII. Further evidence incriminating the fox Cerdocyon thous $(\mathrm{L})$ as a reservoir of Amazonian visceral leishmaniasis. Trans R Soc Trop Med Hyg 1982; 76 (6): 830-832. 
Travi BL, Jaramillo C, Montoya J, Segura I, Zea A, Goncalves A, Velez ID. Didelphis marsupialis an important reservoir of Trypanosoma (Schyzotrypanum) cruzi and Leishmania (Leishmania) chagasi in Colombia. Am J Trop Med Hyg 1994; 50 (5): 557-65.

Tolezano JE. Ecoepidemiological aspects of american cutaneous leishmaniasis in the state of São Paulo, Brazil. Mem Inst Oswaldo Cruz 1994; 89: 427-434.

Tolezano JE, Luvizotto MC, Ulisses SRB, Araujo MFL, Taniguchi HH, Barbosa JAR et al. Leishmaniose Visceral Americana (LVA) em Araçatuba, região oeste do estado de São Paulo. Investigações laboratoriais e diagnóstico etiológico de uma doença emergente em terras paulistas. Rev Soc Bras Med Trop 1999; 32 (Suppl I): 218.

Vexenat JA, Olliaro PL, Fonseca de Castro, JA, Cavalcante R, Furtado Campos JH, Tavares JP, Miles MA. Clinical recovery and limited cure in canine visceral leishmaniasis treated with aminosidine (paromomycin). Am J Trop Med Hyg 1998; 58 (4): 448-53.

Vieira JBF, Coelho GE. Leishmaniose visceral ou calazar: aspectos epidemiológicos e de controle. Rev Brás Soc Med Trop 1998, 31 : 85-92.

World Health Organization. Control of leishmaniases: report of a WHO expert committee. Geneva; 1990.

World Health Organization. Report of the Second WHO Meeting on Emerging Infectious Diseases. Geneva; 1995. 
Ximenes MFFM, Souza MF, Castellón EG. Density of Sand Flies (Diptera: Psycodidae) in domestic and wild animal shelters in an area of visceral leishmaniasis in the state of Rio Grande do Norte, Brazil. Mem Inst Oswaldo Cruz 1999; 94 (4): 427-432.

Yoshida ELA, Correa FMA, Marques AS, Solf HLO, Dillon NL, Momen H et al. Human, canine and equine (Equus caballus) leishmaniasis due to Leishmania braziliensis ( $=$ L. braziliensis braziliensis) in the south-east region of São Paulo state, Brazil. Mem Inst Oswaldo Cruz 1990; 85: 133 134.

Young DG, Duncan MA. Guide to the identification and geographical distribuition of Lutzomyia and sand flies in Mexico, The West Indies, Central and SouthAmerica (Diptera, Psycodidae). Mem Amer Entomol Inst 1994; 54: 1-881.

Zar JH. Bioestatistical analysis. $2^{\text {nd }}$ ed. New Jersey: Prentice-Hall; 1984. 
Anexo 1 - Localização do munichio de Mirand 1 Paulo e planta da cidade.

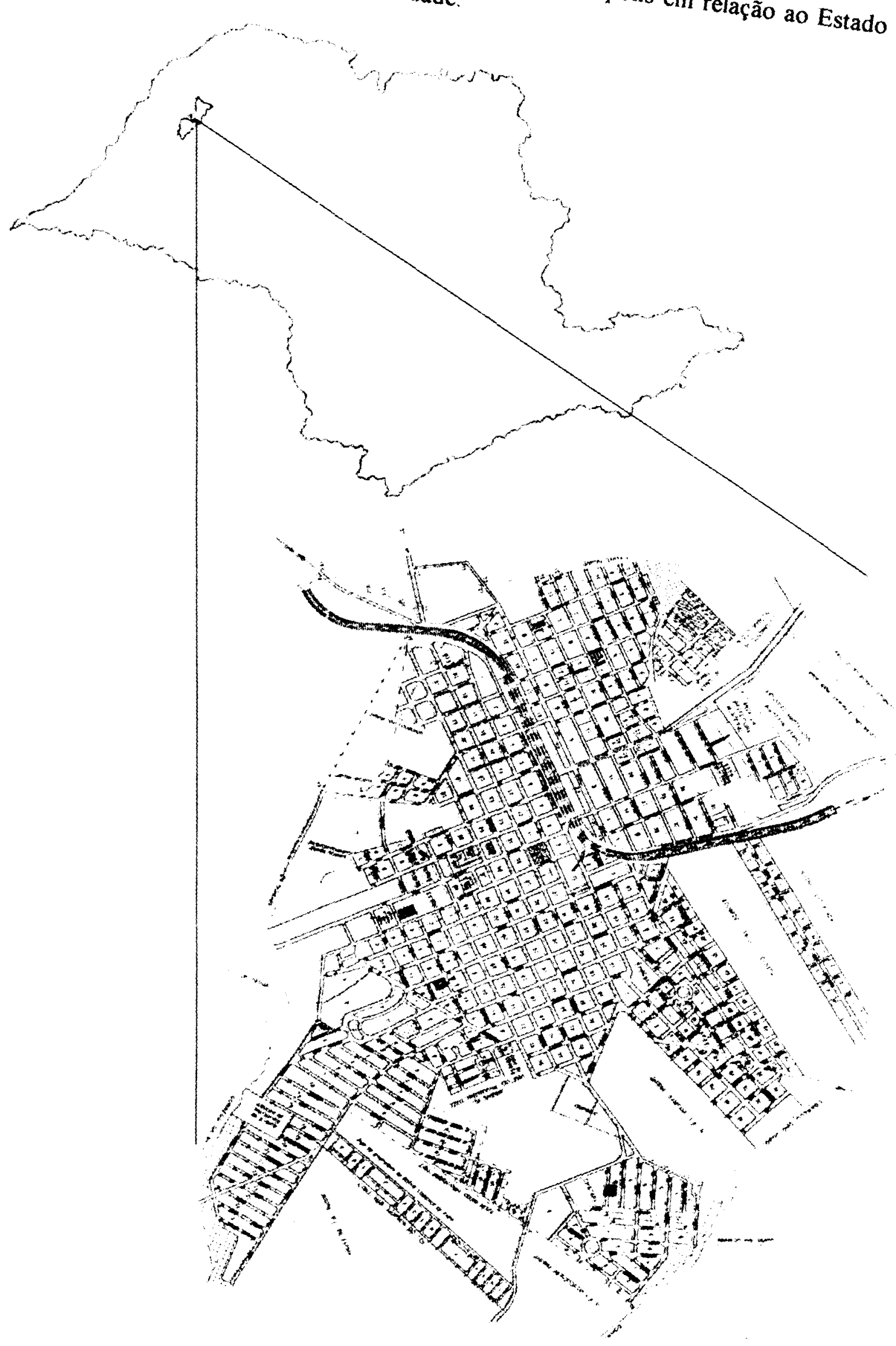


Anexo 2 - Localização dos pontos fixos de captura de flebotomíneos na área urbana do município de Mirandópolis.

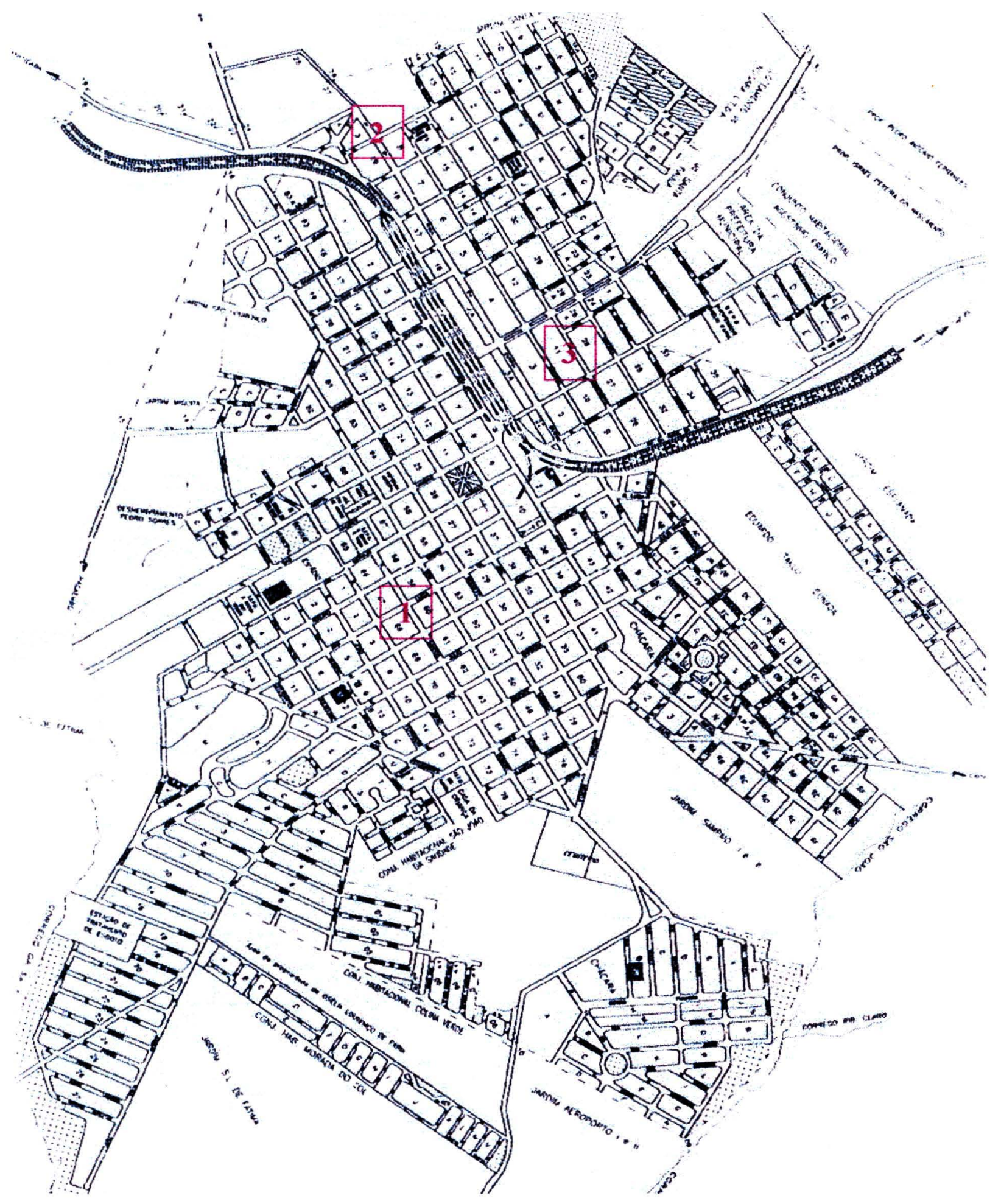


Anexo 3 - Localização dos postos de vacinação anti-rábica e de colheita de amostras de sangue de cães no município de Mirandópolis.

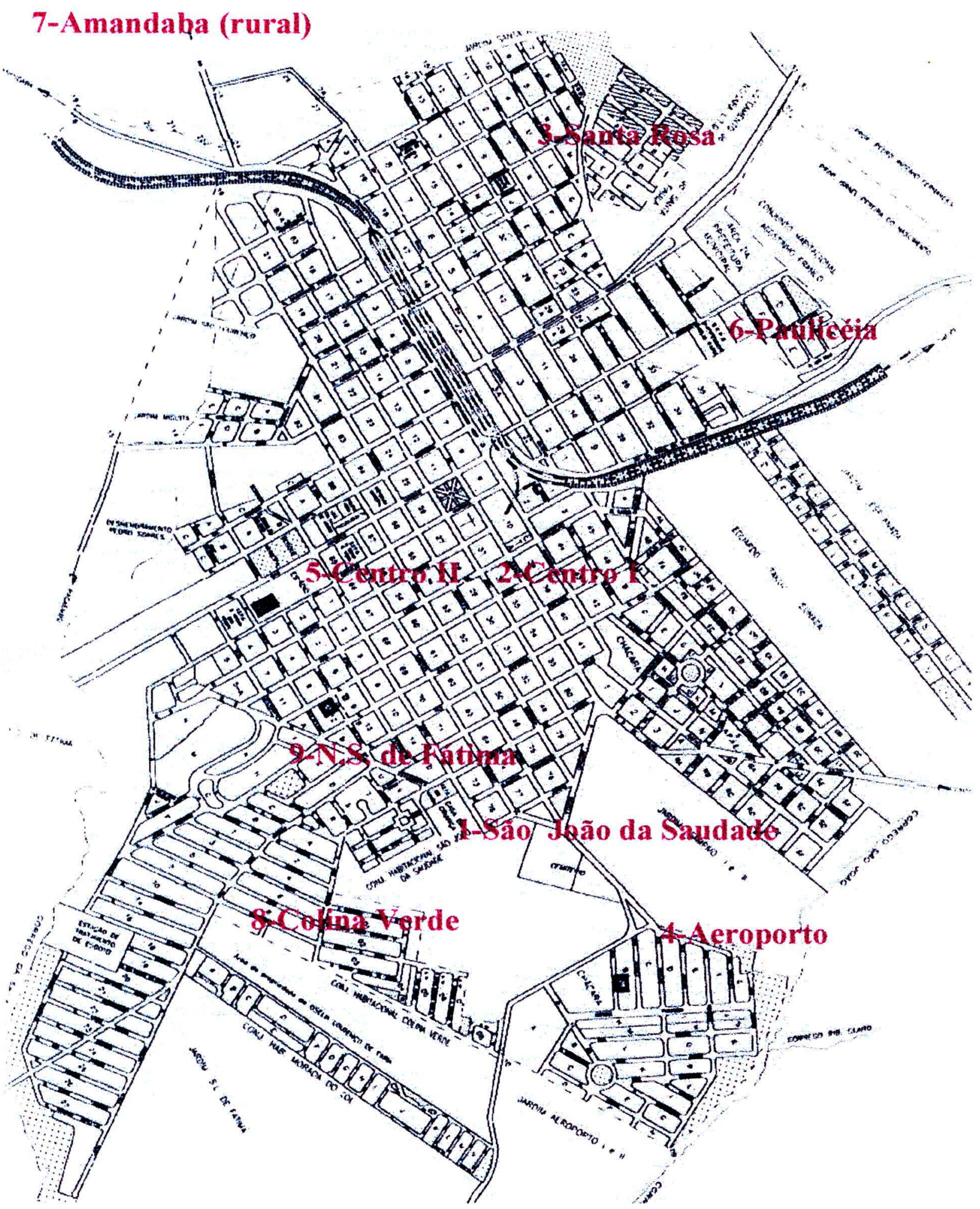


Anexo 4 - Etiquetas de identificação das amostras de sangue dos cães.

PREFEITURA MUNICIPAL DE MIRANDÓPOLIS

POSTO DE VACINAÇÃO:

AMOSTRA:

PROPRIETÁRIO:

ENDEREÇO

Nome do animal:

Sexo.

Raça.

Sintomas:

PREFEITURA MUNICIPAL DE MIRANDÓPOLIS

POSTO DE VACINAÇÃO:

AMOSTRA:

PROPRIETÁRIO:

ENDERECYO:

Nome do animal:

Sexo.

Raça.

Sintomas:

PREFEITURA MUNICIPAL DE MIRANDÓPOLIS

POSTO DE VACINAÇÃO:

AMOSTRA:

PROPRIETÁRIO:

ENDEREÇO:

Nome do animal:

Sexo.

Raça

Sintomas: 
Anexo 5 - Esquema representativo do sistema de marcação utilizado nas orelhas de gambás capturados, com a finalidade de individualização. $\mathrm{Na}$ orelha direita, vista pela frente (D) numeram-se as unidades e nas esquerdas (E) as dezenas.

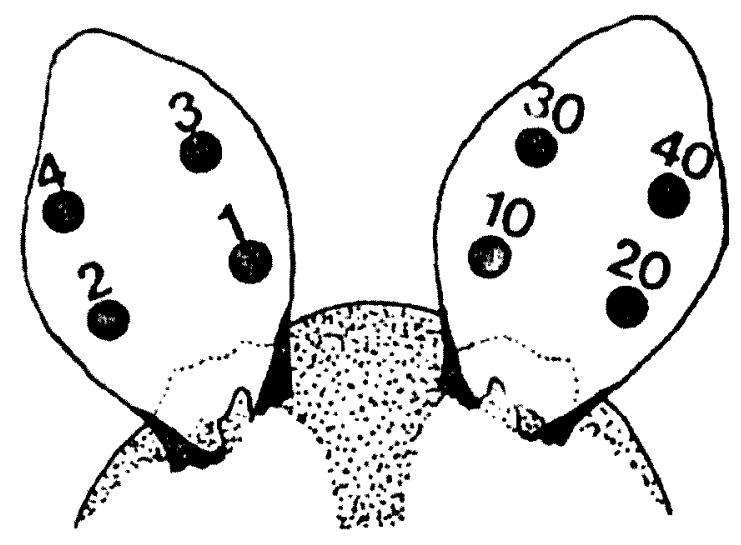

$\mathbf{E}$

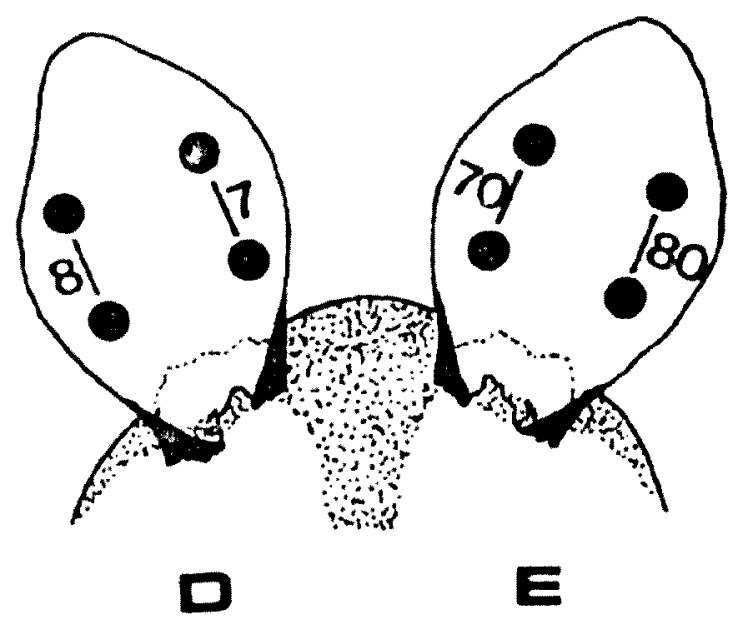

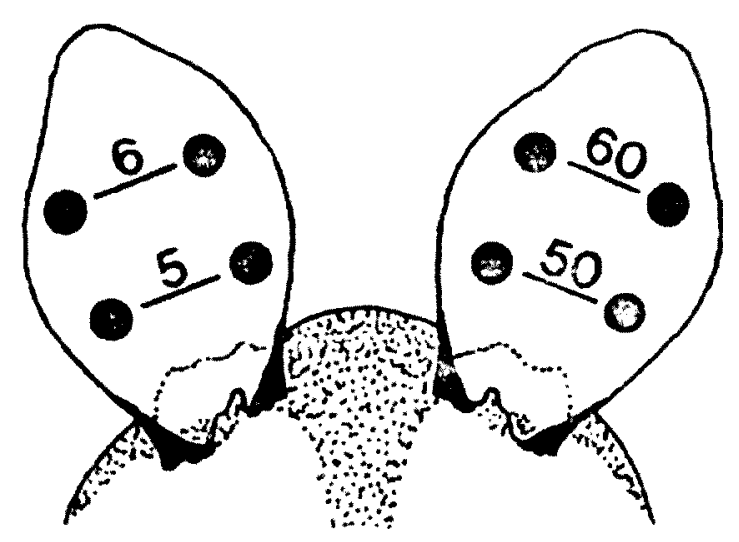

E

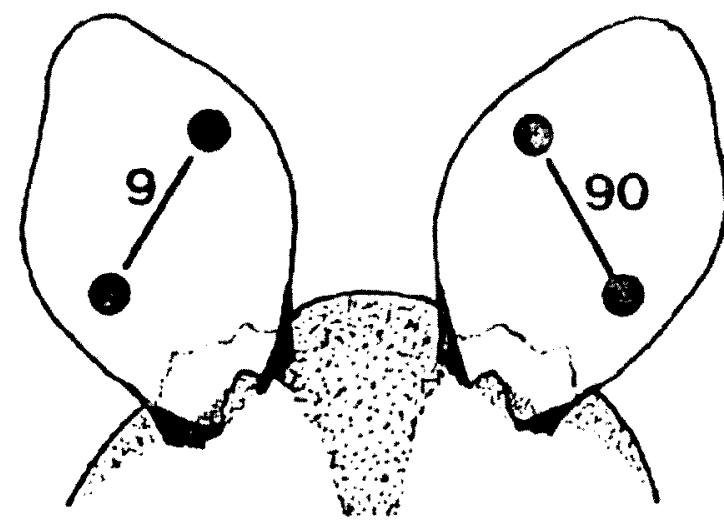

$\mathbf{E}$

Fonte: Monteiro Filho. Biologia Reprodutiva e Espaço Domiciliar de Didelphis albiventris em uma Área Perturbada na Região de Campinas, Estado de São Paulo. (Mammalia-Marsupialia). Campinas; 1987. [Dissertação de Mestrado Instituto de Biologia da UNICAMP]. 
A -6

Anexo 6 - Nematódeo observado no interior de uma fềmea de L. longipalpis.

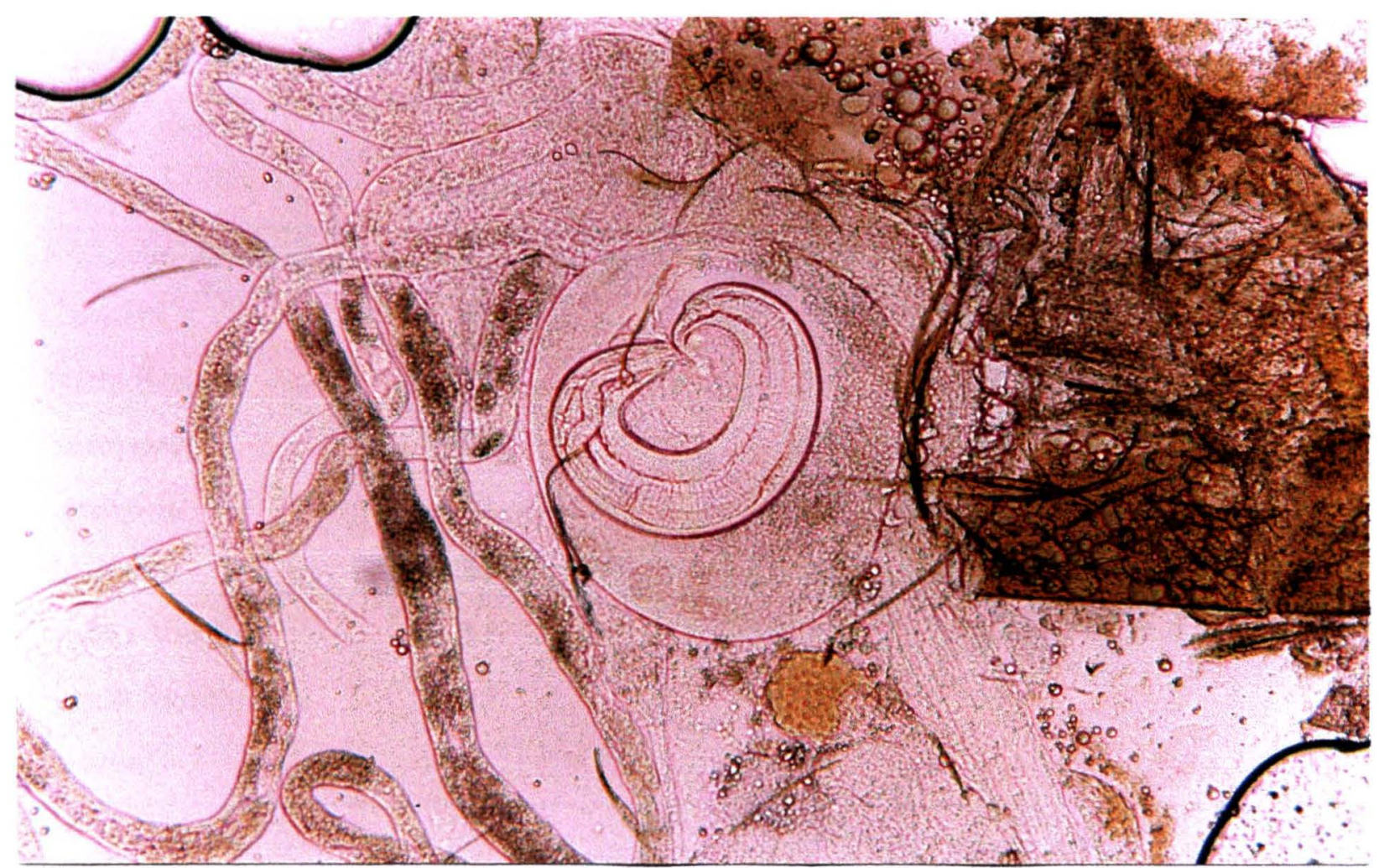


Anexo 7 - Número de cães com dono, da área urbana, examinados pelo teste de imunofluorescência indireta para o diagnóstico da leishmaniose visceral segundo sexo e residência na cidade de Mirandópolis. Agosto de 2000.

\begin{tabular}{lcccccc}
\hline \multicolumn{1}{c}{ Bairro } & \multicolumn{2}{c}{ Macho } & & \multicolumn{3}{c}{ Fêmea } \\
& Negativo & Positivo & Total & Negativo & Positivo & Total \\
\hline São João da Saudade & 37 & 0 & 37 & 27 & 0 & 27 \\
Centro I & 50 & 0 & 50 & 48 & 0 & 48 \\
Santa Rosa & 20 & 0 & 20 & 9 & 0 & 9 \\
Aeroporto & 29 & 0 & 29 & 14 & 0 & 14 \\
Centro II & 62 & 2 & 64 & 37 & 3 & 40 \\
Paulicéia & 21 & 0 & 21 & 15 & 1 & 16 \\
Colina Verde & 31 & 1 & 32 & 37 & 1 & 38 \\
Nossa Senhora de & 25 & 0 & 25 & 11 & 0 & 11 \\
Fátima & & & & & & \\
\hline Total & 275 & 3 & 278 & 198 & 5 & 203 \\
\hline
\end{tabular}


Anexo 8 - Número de cães com dono, da zona rural, examinados pelo teste de imunofluorescência indireta para o diagnóstico da leishmaniose visceral segundo sexo, no município de Mirandópolis. Agosto de 2000.

\begin{tabular}{lcccccc}
\hline \multirow{2}{*}{ Local } & \multicolumn{2}{c}{ Macho } & \multicolumn{3}{c}{ Fêmea } \\
& Negativo & Positivo & Total & Negativo & Positivo & Total \\
\hline Amandaba & 58 & 1 & 59 & 47 & 0 & 47 \\
\hline Total & 58 & 1 & 59 & 47 & 0 & 47 \\
\hline
\end{tabular}


Anexo 9 - Número de cães errantes, examinados pelo teste de imunofluorescência indireta para o diagnóstico da leishmaniose visceral, segundo sexo e local de captura, no município de Mirandópolis. Agosto de 2000.

\begin{tabular}{lcccccc}
\hline \multicolumn{1}{c}{ Bairro } & \multicolumn{2}{c}{ Macho } & & Fêmea \\
& Negativo & Positivo & Total & Negativo & Positivo & Total \\
\hline Área urbana & 6 & 1 & 7 & 8 & 0 & 8 \\
Área rural & 1 & 0 & 1 & 0 & 0 & 0 \\
\hline Total & 7 & 1 & $\mathbf{8}$ & 8 & 0 & 8 \\
\hline
\end{tabular}


Anexo 10 - Temperatura $\left({ }^{\circ} \mathrm{C}\right)$ máxima (max.) e mínima (min.) do ar no município de Mirandópolis (SP). Dados diários. Janeiro a junho de 2000.

\begin{tabular}{|c|c|c|c|c|c|c|c|c|c|c|c|c|}
\hline DIA & JAN-max. & JAN-min. & EV-max. & FEV-min. $n$ & MAR-max. & MAR-min. & ABR-max. & ABR-min. 1 & MAI-max. & MAI-min. J & $J \cup N-\max . J$ & IUN-min. \\
\hline 1 & 36.0 & 22.0 & 35.0 & 21.5 & 31.5 & 22.0 & 29.0 & 20.0 & 33.0 & 20.0 & 25.5 & 13.0 \\
\hline 2 & 33.0 & 21.0 & 30.5 & 22.0 & 32.0 & 21.5 & 33.0 & 20.5 & 33.5 & 20.5 & 23.0 & 13.0 \\
\hline 3 & 32.0 & 20.0 & 35.5 & 23.0 & 31.0 & 22.5 & 32.5 & 18.0 & 34.0 & 19.5 & 25.0 & 15.0 \\
\hline 4 & 33.0 & 20.0 & 29.5 & 22.0 & 32.0 & 22.0 & 30.0 & 18.0 & 33.0 & 20.0 & 30.0 & 17.0 \\
\hline 5 & 33.0 & 21.5 & 32.5 & 22.5 & 29.0 & 21.5 & 30.5 & 18.5 & 32.0 & 19.0 & 30.0 & 18.0 \\
\hline 6 & 33.0 & 21.0 & 34.5 & 22.0 & 32.0 & 22.0 & 31.0 & 19.5 & 33.5 & 18.0 & 30.5 & 17.0 \\
\hline 7 & 35.0 & 21.0 & 35.5 & 22.5 & 34.0 & 23.0 & 32.0 & 20.0 & 22.5 & 12.0 & 30.5 & 15.5 \\
\hline 8 & 31.0 & 20.0 & 34.5 & 21.5 & 32.0 & 20.0 & 33.0 & 20.0 & 26.0 & 12.5 & 30.5 & 15.0 \\
\hline 9 & 33.5 & 20.0 & 35.0 & 21.5 & 28.5 & 17.0 & 33.0 & 22.0 & 29.0 & 17.0 & 31.5 & 16.5 \\
\hline 10 & 34.5 & 21.0 & 29.5 & 22.0 & 30.0 & 17.5 & 33.5 & 21.5 & 29.0 & 17.0 & 31.5 & 16.5 \\
\hline 11 & 37.0 & 22.0 & 27.5 & 21.0 & 29.0 & 20.0 & 34.0 & 21.5 & 29.0 & 15.0 & 32.0 & 16.0 \\
\hline 12 & 35.5 & 22.5 & 31.0 & 21.0 & 29.0 & 21.0 & 35.0 & 23.0 & 26.5 & 13.0 & 32.0 & 15.5 \\
\hline 13 & 31.5 & 22.0 & 25.0 & 21.0 & 28.5 & 19.0 & 35.0 & 23.0 & 28.0 & 14.0 & 31.5 & 15.5 \\
\hline 14 & 36.5 & 22.5 & 29.0 & 21.0 & 31.5 & 20.0 & 34.5 & 21.5 & 32.0 & 17.0 & 32.0 & 16.5 \\
\hline 15 & 38.0 & 23.0 & 33.0 & 21.0 & 26.0 & 20.0 & 34.5 & 22.5 & 31.5 & 17.5 & 32.5 & 18.0 \\
\hline 16 & 38.5 & 23.0 & 34.5 & 21.5 & 28.5 & 21.0 & 34.0 & 21.5 & 31.0 & 17.0 & 32.0 & 17.0 \\
\hline 17 & 39.0 & 25.0 & 35.5 & 19.0 & 32.0 & 22.0 & 34.0 & 19.0 & 32.0 & 16.5 & 32.0 & 17.0 \\
\hline 18 & 35.5 & 22.0 & 27.0 & 17.5 & 32.0 & 21.0 & 32.0 & 20.0 & 25.0 & 10.5 & 33.0 & 17.5 \\
\hline 19 & 33.0 & 22.5 & 30.5 & 21.0 & 28.0 & 21.0 & 23.0 & 20.0 & 19.0 & 11.0 & 29.5 & 16.0 \\
\hline 20 & 38.5 & 22.5 & 34.5 & 20.0 & 28.5 & 20.0 & 24.0 & 13.5 & 17.0 & 11.5 & 22.5 & 13.0 \\
\hline 21 & 36.0 & 22.0 & 33.0 & 21.0 & 31.5 & 20.5 & 24.0 & 12.0 & 23.0 & 12.0 & 21.0 & 11.0 \\
\hline 22 & 37.5 & 21.5 & 33.5 & 20.0 & 30.0 & 21.5 & 25.0 & 19.0 & 25.0 & 12.5 & 19.0 & 9.0 \\
\hline 23 & 38.5 & 23.0 & 33.0 & 20.0 & 31.5 & 22.5 & 26.0 & 15.0 & 27.0 & 13.0 & 24.5 & 9.0 \\
\hline 24 & 39.5 & 22.5 & 33.5 & 21.0 & 33.0 & 22.0 & 29.0 & 21.5 & 28.5 & 16.5 & 28.5 & 11.5 \\
\hline 25 & 39.0 & 22.0 & 35.5 & 21.0 & 34.5 & 21.5 & 30.0 & 18.0 & 31.5 & 16.0 & 31.5 & 18.0 \\
\hline 26 & 37.0 & 22.5 & 37.5 & 23.5 & 35.0 & 22.0 & 32.0 & 19.0 & 30.5 & 15.5 & 32.0 & 18.0 \\
\hline 27 & 32.0 & 21.0 & 36.5 & 23.0 & 34.5 & 20.0 & 32.0 & 19.5 & 33.0 & 15.5 & 34.0 & 18.5 \\
\hline 28 & 30.0 & 20.5 & 36.0 & 21.5 & 27.5 & 19.5 & 31.0 & 20.0 & 29.0 & 16.5 & 31.0 & 18.0 \\
\hline 29 & 33.5 & 18.5 & 32.0 & 22.0 & 29.0 & 19.5 & 32.0 & 18.5 & 27.0 & 11.5 & 31.5 & 15.0 \\
\hline 30 & 33.5 & 18.0 & 32.8 & 21.3 & 28.5 & 18.0 & 32.0 & 20.0 & 28.5 & 11.0 & 31.5 & 15.5 \\
\hline \multirow[t]{2}{*}{31} & 32.0 & 21.5 & & & 30.0 & 18.5 & 31.0 & 19.5 & 25.0 & 11.5 & 29.4 & 15.4 \\
\hline & 35.0 & 21.5 & & & 30.6 & 20.6 & & & 28.5 & 15.2 & & \\
\hline
\end{tabular}

Fonte: Prefeitura Municipal de Mirandópolis 
Anexo 11 - Temperatura $\left({ }^{\circ} \mathrm{C}\right)$ máxima (max.) e mínima (min.) do ar no município de Mirandópolis (SP). Dados diários. Julho a dezembro de 2000.

\begin{tabular}{|c|c|c|c|c|c|c|c|c|c|c|c|c|}
\hline DIAJ & $U L-\max . J$ & UL-min. & GO-max. $A C$ & Go-min. $s$ & ET-max. $S$ & ET-min. & UT-max. & $U T-\min$ & $10 \mathrm{~V}-\max$. & Nov-mi & $E Z-m$ & DEZ \\
\hline 1 & 26.0 & 15.5 & 29.0 & 15.5 & 29.5 & 17.5 & 30.0 & 19.0 & 36.5 & 21.0 & 32.0 & 21.0 \\
\hline 2 & 29.0 & 17.0 & 27.0 & 16.0 & 31.5 & 18.0 & 35.0 & 19.0 & 37.0 & 22.0 & 34.0 & 18.0 \\
\hline 3 & 31.5 & 18.0 & 31.5 & 15.5 & 21.5 & 16.0 & 37.0 & 20.0 & 36.0 & 21.0 & 32.0 & 190 \\
\hline 4 & 29.0 & 16.0 & 23.0 & 13.0 & 20.0 & 12.5 & 38.0 & 22.5 & 35.0 & 21.5 & 30.0 & 21.0 \\
\hline 5 & 28.0 & 15.0 & 26.5 & 10.0 & 25.5 & 13.0 & 33.0 & 20.0 & 36.5 & 21.0 & 31.0 & 19.5 \\
\hline 6 & 28.0 & 15.0 & 29.0 & 10.0 & 29.5 & 14.5 & 31.0 & 18.0 & 35.0 & 21.0 & 33.5 & 18.0 \\
\hline 7 & 29.0 & 16.0 & 33.0 & 15.5 & 29.0 & 15.5 & 33.0 & 18.0 & 34.5 & 21.5 & 36.5 & 20.5 \\
\hline 8 & 29.5 & 17.0 & 34.0 & 17.0 & 31.0 & 15.5 & 36.0 & 18.5 & 34.0 & 20.0 & 37.5 & 20.5 \\
\hline 9 & 30.0 & 18.0 & 35.0 & 18.5 & 31.5 & 15.5 & 37.0 & 20.5 & 35.0 & 22.0 & 38.0 & 25.0 \\
\hline 10 & 32.0 & 18.0 & 34.0 & 18.0 & 31.0 & 17.0 & 38.0 & 21.0 & 36.5 & 22.0 & 35.5 & 22.5 \\
\hline 11 & 32.0 & 17.0 & 34.0 & 14.0 & 32.0 & 19.5 & 34.0 & 20.5 & 37.0 & 22.5 & 35.5 & 21.5 \\
\hline 12 & 18.5 & 9.0 & 26.5 & 11.5 & 31.0 & 20.5 & 27.0 & 20.5 & 39.5 & 20.5 & 38.5 & 22.5 \\
\hline 13 & 15.5 & 2.0 & 24.0 & 10.0 & 33.0 & 19.0 & 38.0 & 22.0 & 34.0 & 20.0 & 38.5 & 24.5 \\
\hline 14 & 19.0 & 2.5 & 28.0 & 10.0 & 27.0 & 19.0 & 38.5 & 22.5 & 28.5 & 20.5 & 30.0 & 21.5 \\
\hline 15 & 26.0 & 3.0 & 34.0 & 15.5 & 29.5 & 18.5 & 38.0 & 20.5 & 31.0 & 20.5 & 32.0 & 22.0 \\
\hline 16 & 24.5 & 8.5 & 33.5 & 17.5 & 29.0 & 16.5 & 39.0 & 21.0 & 35.0 & 18.5 & 27.5 & 21.5 \\
\hline 17 & 17.5 & 2.0 & 30.5 & 16.5 & 31.0 & 17.0 & 39.5 & 21.0 & 35.0 & 19.0 & 30.0 & 18.5 \\
\hline 18 & 18.5 & 2.5 & 30.0 & 15.0 & 29.5 & 19.5 & 39.5 & 22.5 & 36.0 & 20.0 & 24.5 & 17.5 \\
\hline 19 & 22.5 & 6.5 & 28.0 & 14.0 & 33.0 & 20.0 & 39.5 & 23.5 & 26.5 & 20.0 & 24.5 & 17.5 \\
\hline 20 & 20.0 & 6.5 & 30.0 & 15.5 & 38.0 & 22.0 & 40.5 & 23.5 & 32.0 & 20.0 & 31.5 & 20.0 \\
\hline 21 & 21.0 & 5.5 & 33.5 & 17.5 & 35.5 & 20.5 & 40.5 & 24.0 & 35.0 & 20.0 & 34.0 & 21.5 \\
\hline 22 & 28.0 & 7.0 & 34.0 & 17.0 & 37.0 & 20.5 & 41.0 & 22.5 & 35.5 & 20.5 & 37.0 & 21.0 \\
\hline 23 & 30.0 & 11.5 & 34.5 & 17.5 & 36.0 & 18.5 & 41.0 & 23.5 & 36.0 & 22.0 & 38.0 & 21.5 \\
\hline 24 & 13.5 & 4.5 & 35.5 & 19.5 & 36.5 & 20.5 & 35.0 & 21.5 & 37.5 & 21.5 & 38.0 & 22.0 \\
\hline 25 & 20.4 & 4.5 & 36.0 & 20.0 & 34.0 & 14.5 & 35.0 & 22.0 & 37.0 & 21.5 & 33.0 & 21.0 \\
\hline 26 & 23.0 & 9.5 & 37.0 & 20.0 & 27.5 & 11.5 & 34.0 & 21.0 & 32.5 & 19.0 & 36.0 & 23.0 \\
\hline 27 & 28.0 & 10.5 & 36.5 & 20.5 & 28.5 & 12.5 & 37.5 & 22.5 & 34.0 & 21.0 & 35.5 & 21.0 \\
\hline 28 & 28.5 & 10.5 & 31.5 & 15.5 & 25.0 & 15.0 & 25.5 & 19.0 & 37.5 & 22.0 & 36.0 & 21.5 \\
\hline 29 & 30.0 & 12.0 & 17.0 & 14.0 & 28.0 & 17.5 & 33.0 & 18.0 & 37.5 & 22.5 & 34.5 & 21.5 \\
\hline 30 & 32.0 & 14.0 & 19.5 & 14.0 & 31.0 & 18.5 & 33.5 & 17.0 & 37.5 & 21.0 & 36.5 & 22.0 \\
\hline \multirow[t]{2}{*}{31} & 33.0 & 14.5 & 19.0 & 16.0 & 30.3 & 17.2 & 36.0 & 17.0 & 36.0 & 20.9 & 33.5 & 21.0 \\
\hline & 26.6 & 10.6 & 30.1 & 15.5 & & & 35.9 & 20.7 & & & 33.7 & 21.0 \\
\hline
\end{tabular}

Fonte: Prefeitura Municipal de Mirandópolis 
Ánexo 12 - Pluviosidade ( $\mathrm{mm}$ ) no município de Mirandópolis em 2000. Dados diários.

\begin{tabular}{|c|c|c|c|c|c|c|c|c|c|c|c|c|}
\hline DIA & JAN. & FEV. & MAR. & ABR. & MAI. & JUN. & JUL. & AGO. & SET. & OUT. & NOV. & DEZ. \\
\hline 1 & 1.1 & 11.5 & 0.2 & & & & 5.5 & & 16.5 & 0.2 & 0.3 & 10.8 \\
\hline 2 & 21.0 & 24.0 & 3.0 & & & & & & 34.7 & & & \\
\hline 3 & 3.0 & 6.2 & 0.3 & & & & & & 15.7 & & 0.2 & \\
\hline 4 & & 19.2 & 43.9 & & & & & & & 0.5 & & 0.4 \\
\hline 5 & 1.5 & 5.5 & 1.6 & & & & & & & 2.5 & & 5.8 \\
\hline 6 & 26.0 & & & & 2.3 & & & & 0.7 & & & \\
\hline 7 & & & & & & & & 5.0 & & & 0.3 & \\
\hline 8 & 21.0 & & 15.1 & & & & & & & & & \\
\hline 9 & 15.0 & 1.0 & & & & & & & 67.4 & & & \\
\hline 10 & 1.1 & 27.0 & & & & & & & & 5.2 & & \\
\hline 11 & 0.4 & 6.1 & 1.4 & & & & & & & 6.7 & 0.3 & \\
\hline 12 & & 9.6 & 1.3 & & 1.0 & & & & & & 21.6 & \\
\hline 13 & 0.5 & 32.1 & 10.6 & & & & & & 16.6 & & 25.4 & \\
\hline 14 & & 18.7 & & & & & & & 7.3 & & 3.0 & 52.3 \\
\hline 15 & & & 2.6 & & & & & & 1.9 & & 13.0 & 9.3 \\
\hline 16 & & & 4.7 & & & & 9.6 & 19.5 & & & & 22.3 \\
\hline 17 & & 14.1 & 15.5 & & & & & & & & & 10.0 \\
\hline 18 & 21.0 & & 48.7 & 2.6 & & & & 13.0 & & & 39.2 & 5.1 \\
\hline 19 & & & & 5.0 & & & & & & & 1.3 & \\
\hline 20 & 2.4 & 3.2 & & 1.1 & & & & & & & & \\
\hline 21 & 0.4 & 3.1 & & & & 1.7 & & & & & 0.1 & \\
\hline 22 & & 37.2 & 0.7 & & & & & & & & 3.7 & 36.6 \\
\hline 23 & & 20.7 & 5.9 & & & & 15.8 & & & & & 15.6 \\
\hline 24 & & 6.8 & & & & & & & & & & \\
\hline 25 & & & & & & & & & 3.5 & 4.0 & 2.3 & \\
\hline 26 & 22.4 & & & & & & & & & 0.9 & 4.5 & \\
\hline 27 & 57.0 & & 8.6 & & 4.9 & & & & & & & \\
\hline 28 & & 7.8 & 4.5 & & 4.8 & & & 22.3 & 0.1 & 3.1 & & 14.7 \\
\hline 29 & & & 1.4 & & & & & 11.3 & & & & \\
\hline 30 & & & & & & 4.7 & & & 0.1 & & 48.5 & \\
\hline 31 & 0.3 & & & & 1.9 & & & & & & & 7.4 \\
\hline Total & 194.1 & 253.8 & 170.0 & 8.7 & 14.9 & 6.4 & 30.9 & 71.1 & 164.5 & 23.1 & 163.7 & 190.3 \\
\hline
\end{tabular}

Fonte: Escritório de Desenvolvimento Rural de Andradina 